\title{
Interventions for preventing falls in people with multiple sclerosis.
}

HAYES, S., GALVIN, R., KENNEDY, C., FINLAYSON, M., MCGUIGAN, C., WALSH, C.D. and COOTE, S. 


\section{Cochrane}

Library

Cochrane Database of Systematic Reviews

\section{Interventions for preventing falls in people with multiple sclerosis} (Review)

Hayes S, Galvin R, Kennedy C, Finlayson M, McGuigan C, Walsh CD, Coote S

Hayes S, Galvin R, Kennedy C, Finlayson M, McGuigan C, Walsh CD, Coote S. Interventions for preventing falls in people with multiple sclerosis.

Cochrane Database of Systematic Reviews 2019, Issue 11. Art. No.: CD012475. DOI: 10.1002/14651858.CD012475.pub2.

www.cochranelibrary.com 
TABLE OF CONTENTS

HEADER

ABSTRACT

PLAIN LANGUAGE SUMMARY

SUMMARY OF FINDINGS

2

BACKGROUND

OBJECTIVES

METHODS

RESULTS

Figure 1.

Figure 2.

Figure 3.

DISCUSSION

AUTHORS' CONCLUSIONS

ACKNOWLEDGEMENTS

REFERENCES

CHARACTERISTICS OF STUDIES

DATA AND ANALYSES

Analysis 1.1. Comparison 1 Exercise versus control, Outcome 1 Falls rate.

Analysis 1.2. Comparison 1 Exercise versus control, Outcome 2 Number of fallers.

Analysis 1.3. Comparison 1 Exercise versus control, Outcome 3 Adverse events.

Analysis 2.1. Comparison 2 Education versus control, Outcome 1 Number of fallers.

Analysis 2.2. Comparison 2 Education versus control, Outcome 2 Adverse events.

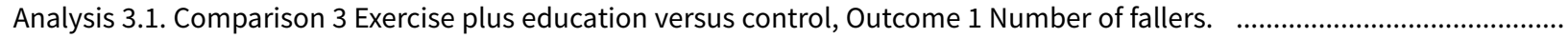

Analysis 3.2. Comparison 3 Exercise plus education versus control, Outcome 2 Adverse events.

Analysis 4.1. Comparison 4 Individual exercise versus control, Outcome 1 Falls rate.

Analysis 4.2. Comparison 4 Individual exercise versus control, Outcome 2 Number of fallers.

Analysis 5.1. Comparison 5 Yoga versus control, Outcome 1 Falls rate.

Analysis 6.1. Comparison 6 Functional Electrical Stimulation versus Exercise, Outcome 1 Falls rate.

Analysis 6.2. Comparison 6 Functional Electrical Stimulation versus Exercise, Outcome 2 Adverse events.

Analysis 7.1. Comparison 7 Exercise versus education, Outcome 1 Falls rate.

Analysis 7.2. Comparison 7 Exercise versus education, Outcome 2 Number of fallers.

Analysis 7.3. Comparison 7 Exercise versus education, Outcome 3 Adverse events.

Analysis 8.1. Comparison 8 Exercise versus Exercise plus Education (post-intervention), Outcome 1 Number of fallers. ............

Analysis 8.2. Comparison 8 Exercise versus Exercise plus Education (post-intervention), Outcome 2 Adverse events. ...............

Analysis 9.1. Comparison 9 Education versus Exercise plus Education (post-intervention), Outcome 1 Number of fallers. ........

Analysis 9.2. Comparison 9 Education versus Exercise plus Education (post-intervention), Outcome 2 Adverse events. ...........

Analysis 10.1. Comparison 10 Sensory integration balance training versus conventional rehabilitation, Outcome 1 Falls rate. ..

Analysis 11.1. Comparison 11 Motor and sensory balance rehabilitation versus motor balance rehabilitation, Outcome 1 Falls rate.

Analysis 11.2. Comparison 11 Motor and sensory balance rehabilitation versus motor balance rehabilitation, Outcome 2 Number of fallers.

Analysis 12.1. Comparison 12 Motor and sensory balance rehabilitation versus conventional rehabilitation, Outcome 1 Falls rate.

Analysis 12.2. Comparison 12 Motor and sensory balance rehabilitation versus conventional rehabilitation, Outcome 2 Number of fallers.

Analysis 13.1. Comparison 13 Motor balance rehabilitation vs conventional non balance rehabilitation, Outcome 1 Falls rate. .. Analysis 13.2. Comparison 13 Motor balance rehabilitation vs conventional non balance rehabilitation, Outcome 2 Number of fallers.

Analysis 14.1. Comparison 14 Group exercise versus Yoga, Outcome 1 Falls rate.

Analysis 14.2. Comparison 14 Group exercise versus Yoga, Outcome 2 Number of fallers.

Analysis 15.1. Comparison 15 Group exercise versus individual exercise, Outcome 1 Falls rate. 
Analysis 16.1. Comparison 16 Individual exercise versus yoga, Outcome 1 Falls rate.

Analysis 16.2. Comparison 16 Individual exercise versus yoga, Outcome 2 Number of fallers.

Analysis 17.1. Comparison 17 Exercise versus control (3-month follow-up), Outcome 1 Number of fallers.

Analysis 18.1. Comparison 18 Exercise versus control (6 month follow up), Outcome 1 Number of fallers.

Analysis 19.1. Comparison 19 Balance and mobility rehabilitation versus conventional rehabilitation (2 month follow-up), Outcome 1 Number of fallers.

APPENDICES 
[Intervention Review]

\title{
Interventions for preventing falls in people with multiple sclerosis
}

\author{
Sara Hayes ${ }^{1}$, Rose Galvin², Catriona Kennedy ${ }^{3}$, Marcia Finlayson ${ }^{4}$, Christopher McGuigan ${ }^{5}$, Cathal D Walsh ${ }^{6}$, Susan Coote ${ }^{2}$
}

1School of Allied Health, Ageing Research Centre, Health Research Institute, University of Limerick, Limerick, Ireland. 2Department of Clinical Therapies, Faculty of Education and Health Sciences, University of Limerick, Limerick, Ireland. ${ }^{3}$ School of Nursing and Midwifery, Robert Gordon University, Aberdeen, UK. ${ }^{4}$ School of Rehabilitation Therapy, Queen's University, Kingston, Canada. ${ }^{5}$ Department of Neurology, St. Vincent's University Hospital \& University College Dublin, Dublin, Ireland. ${ }^{6}$ Health Research Institute (HRI) and MACSI, Department of Mathematics and Statistics, University of Limerick, Ireland

Contact address: Sara Hayes, School of Allied Health, Ageing Research Centre, Health Research Institute, University of Limerick, Limerick, Ireland.Sara.Hayes@ul.ie.

Editorial group: Cochrane Multiple Sclerosis and Rare Diseases of the CNS Group

Publication status and date: New, published in Issue 11, 2019.

Citation: Hayes S, Galvin R, Kennedy C, Finlayson M, McGuigan C, Walsh CD, Coote S. Interventions for preventing falls in people with multiple sclerosis. Cochrane Database of Systematic Reviews 2019, Issue 11. Art. No.: CD012475. DOI: 10.1002/14651858.CD012475.pub2.

Copyright (c) 2019 The Cochrane Collaboration. Published by John Wiley \& Sons, Ltd.

\section{A B S T R A C T}

\section{Background}

Multiple sclerosis (MS) is one of the most prevalent diseases of the central nervous system with recent prevalence estimates indicating that MS directly affects 2.3 million people worldwide. Fall rates of $56 \%$ have been reported among people with MS in a recent meta-analysis. Clinical guidelines do not outline an evidence-based approach to falls interventions in MS. There is a need for synthesised information regarding the effectiveness of falls prevention interventions in MS.

\section{Objectives}

The aim of this review was to evaluate the effectiveness of interventions designed to reduce falls in people with MS. Specific objectives included comparing: (1) falls prevention interventions to controls and; (2) different types of falls prevention interventions.

\section{Search methods}

We searched the Trials Register of the Cochrane Multiple Sclerosis and Rare Diseases of the CNS Group, Cochrane Central Register of Controlled Trials (2018 Issue 9); MEDLINE (PubMed) (1966 to 12 September 2018); Embase (EMBASE.com) (1974 to 12 September 2018); Cumulative Index to Nursing and Allied Health Literature (EBSCOhost) (1981 to 12 September 2018); Latin American and Caribbean Health Science Information Database (Bireme) (1982 to 12 September 2018); ClinicalTrials.gov; and World Health Organization International Clinical Trials Registry Platform; PsycINFO (1806 to 12 September 2018; and Physiotherapy Evidence Database (1999 to 12 September 2018).

\section{Selection criteria}

We selected randomised controlled trials or quasi-randomised trials of interventions to reduce falls in people with MS. We included trials that examined falls prevention interventions compared to controls or different types of falls prevention interventions. Primary outcomes included: falls rate, risk of falling, number of falls per person and adverse events.

\section{Data collection and analysis}

Two review authors screened studies for selection, assessed risk of bias and extracted data. We used a rate ratio (RaR) and $95 \%$ confidence interval to compare falls rate between groups. For risk of falling, we used a risk ratio (RR) and $95 \% \mathrm{Cl}$ based on the number of fallers in each group. 


\section{Main results}

A total of 839 people with MS (12 to 177 individuals) were randomised in the 13 included trials. The mean age of the participants was 52 years (36 to 62 years). The percentage of women participants ranged from 59\% to 85\%. Studies included people with all types of MS. Most trials compared an exercise intervention with no intervention or different types of falls prevention interventions. We included two comparisons: (1) Falls prevention intervention versus control and (2) Falls prevention intervention versus another falls prevention intervention. The most common interventions tested were exercise as a single intervention, education as a single intervention, functional electrical stimulation and exercise plus education. The risk of bias of the included studies mixed, with nine studies demonstrating high risk of bias related to one or more aspects of their methodology.

The evidence was uncertain regarding the effects of exercise versus control on falls rate (RaR of $0.68 ; 95 \%$ Cl 0.43 to 1.06 ; very low-quality evidence), number of fallers (RR of $0.85 ; 95 \% \mathrm{Cl} 0.51$ to 1.43 ; low-quality evidence) and adverse events (RR of $1.25 ; 95 \% \mathrm{Cl} 0.26$ to 6.03 ; low-quality evidence).

Data were not available on quality of life outcomes comparing exercise to control. The majority of other comparisons between falls interventions and controls demonstrated no evidence of effect in favour of either group for all primary outcomes.

For the comparison of different falls prevention interventions, the heterogeneity of intervention types across studies prohibited the pooling of data.

In relation to secondary outcomes, there was evidence of an effect in favour of exercise interventions compared to controls for balance function with a SMD of 0.50 ( $95 \% \mathrm{Cl} 0.09$ to 0.92 ), self-reported mobility with a SMD of 16.30 ( $95 \% \mathrm{Cl} 9.34$ to 23.26$)$ and objective mobility with a SMD of $0.28(95 \% \mathrm{Cl} 0.07$ to 0.50$)$. Secondary outcomes were not assessed under the GRADE criteria and results must be interpreted with caution.

\section{Authors' conclusions}

The evidence regarding the effects of interventions for preventing falls in MS is sparse and uncertain. The evidence base demonstrates mixed risk of bias, with very low to low certainty of the evidence. There is some evidence in favour of exercise interventions for the improvement of balance function and mobility. However, this must be interpreted with caution as these secondary outcomes were not assessed under the GRADE criteria and as the results represent data from a small number of studies. Robust RCTs examining the effectiveness of multifactorial falls interventions on falls outcomes are needed.

\section{PLAIN LANGUAGE SUMMARY}

\section{Falls interventions in multiple sclerosis}

\section{Review question}

Do people with multiple sclerosis (MS) who received interventions to reduce falls show better falls outcomes than those who received no treatment? In addition, do different types of falls interventions result in different outcomes for people with MS?

\section{Background}

Due to damage to the central nervous system among people with MS, difficulties in thinking, muscle strength, muscle tone, sensation, coordination and mobility can lead to an increased risk of falling, compared to people without MS. Interventions to prevent falls are offered to people with MS and often include: exercises, medication, surgery, management of urinary incontinence, fluid or nutrition therapy, psychological intervention, environment/assistive technology, environment (social environment), knowledge interventions and other interventions. The risk of falling in people with MS is three times higher than that in older people, yet it is unclear whether falls interventions are effective in reducing falls in MS. Currently there are a few good-quality studies that have investigated the effectiveness of falls interventions in people with MS.

\section{Study characteristics}

This review included 13 studies with 839 participants involving various types of falls interventions, most comparing an exercise intervention with no intervention or two or more falls prevention interventions.

\section{Key results and quality of the evidence}

There is uncertainty on the effect of exercises on prevention of falls due to the low to very low quality of the evidence for some of the primary outcomes. Our confidence in these results is low for the prevention of falls because this has been evaluated in only a few small trials that we judged as having some risk of bias and methodological shortcomings. There are still relatively few large, good-quality studies to base our findings on, so more are needed. 
S U M MARY OF FINDINGS

Summary of findings for the main comparison. Exercise compared to control (post-intervention) for preventing falls in people with multiple sclerosis

Exercise compared to control (post-intervention) for preventing falls in people with multiple sclerosis

Patient or population: people with multiple sclerosis (including people with relapsing-remitting, secondary progressive or primary progressive types of MS), mean age: 53 years

Setting: community or home

Intervention: exercise (community-based or home-based exercise interventions), ranging from 6 to 24 weeks in duration, ranging from once to 5 times weekly frequency

Comparison: usual care treatment or wait-list control

\begin{tabular}{|c|c|c|c|c|c|c|}
\hline \multirow[t]{2}{*}{ Outcomes } & \multicolumn{2}{|c|}{$\begin{array}{l}\text { Anticipated absolute effects }{ }^{*} \\
(95 \% \mathrm{Cl})\end{array}$} & \multirow{2}{*}{$\begin{array}{l}\text { Relative ef- } \\
\text { fect } \\
(95 \% \mathrm{CI})\end{array}$} & \multirow{2}{*}{$\begin{array}{l}\text { № of partici- } \\
\text { pants } \\
\text { (studies) }\end{array}$} & \multirow{2}{*}{$\begin{array}{l}\text { Certainty of } \\
\text { the evidence } \\
\text { (GRADE) }\end{array}$} & \multirow[t]{2}{*}{ Comments } \\
\hline & $\begin{array}{l}\text { Risk with } \\
\text { control (post- } \\
\text { intervention) }\end{array}$ & $\begin{array}{l}\text { Risk with Exer- } \\
\text { cise }\end{array}$ & & & & \\
\hline $\begin{array}{l}\text { Falls rate } \\
\text { Falls were measured using prospective daily diaries, prospective } \\
\text { monthly calendars or retrospectively. Falls rate calculation= num- } \\
\text { ber of falls/number in group * (number of days/365) } \\
\text { The timing of measurement was post-intervention for all studies }\end{array}$ & $\begin{array}{l}\text { Not applica- } \\
\text { ble }\end{array}$ & Not applicable & $\begin{array}{l}\text { Rate ratio } 0.68 \\
(0.43 \text { to } 1.06)\end{array}$ & $\begin{array}{l}399 \\
\text { (5 RCTs) }\end{array}$ & $\begin{array}{l}\oplus \oplus \oplus \ominus \\
\text { VERY LOW }\end{array}$ & \\
\hline $\begin{array}{l}\text { Number of fallers } \\
\text { Falls were measured using prospective daily diaries, prospective } \\
\text { monthly calendars or retrospectively } \\
\text { The timing of measurement was post-intervention for all studies }\end{array}$ & 305 per 1,000 & $\begin{array}{l}259 \text { per } 1,000 \\
\text { (156 to } 436)\end{array}$ & $\begin{array}{l}\text { RR } 0.85 \\
\text { (0.51 to } 1.43 \text { ) }\end{array}$ & $\begin{array}{l}355 \\
\text { (5 RCTs) }\end{array}$ & $\begin{array}{l}\oplus \oplus \oplus \ominus \\
\text { LOW }\end{array}$ & \\
\hline $\begin{array}{l}\text { Adverse events } \\
\text { The timing of measurement was post-intervention for all studies }\end{array}$ & 44 per 1,000 & $\begin{array}{l}56 \text { per } 1,000 \\
(12 \text { to } 268)\end{array}$ & $\begin{array}{l}\text { RR } 1.25 \\
\text { (0.26 to } 6.03)\end{array}$ & $\begin{array}{l}97 \\
\text { (3 RCTs) }\end{array}$ & $\begin{array}{l}\oplus \oplus \oplus \ominus \\
\text { LOW }\end{array}$ & \\
\hline Quality of life & $\begin{array}{l}\text { see com- } \\
\text { ments }\end{array}$ & see comments & not estimable & & & $\begin{array}{l}\text { Studies in- } \\
\text { cluded in this } \\
\text { analysis did } \\
\text { not report da- } \\
\text { ta on quality } \\
\text { of life }\end{array}$ \\
\hline
\end{tabular}


*The risk in the intervention group (and its $95 \%$ confidence interval) is based on the assumed risk in the comparison group and the relative effect of the intervention (and its $95 \% \mathrm{Cl})$.

Cl: Confidence interval; RR: Risk ratio.

\section{GRADE Working Group grades of evidence}

High certainty: We are very confident that the true effect lies close to that of the estimate of the effect

Moderate certainty: We are moderately confident in the effect estimate: The true effect is likely to be close to the estimate of the effect, but there is a possibility that it is substantially different

Low certainty: Our confidence in the effect estimate is limited: The true effect may be substantially different from the estimate of the effect

Very low certainty: We have very little confidence in the effect estimate: The true effect is likely to be substantially different from the estimate of effect

Falls rate: GRADE assessment- Downgraded one level due to risk of bias and one level due to imprecision and one level due to inconsistency. Four studies at high risk of bias in allocation concealment domain; five studies at unclear risk of bias in blinding of participants domain; two studies at high risk of bias and one study at unclear risk of bias in selective reporting domain; wide $\mathrm{Cl} ; 12=59 \%$

Number of fallers: GRADE assessment- Downgraded one level due to risk of bias and one level due to imprecision, One study at high risk of bias in attrition domain; two study at unclear risk of bias in allocation concealment domain; five studies at unclear risk of bias in blinding of participants domain; and four studies at high risk of bias in selective reporting domain; wide $\mathrm{Cl}$

Adverse events: GRADE assessment- Downgraded one level due to risk of bias and one level due to imprecision, One study at unclear risk of bias in allocation concealment domain; three studies at unclear risk of bias in blinding of participants domain; and three studies at high risk of bias in selective reporting domain; wide $\mathrm{C}$ 


\section{B A C K G R O U N D}

Multiple sclerosis (MS) is one of the most prevalent diseases of the central nervous system (CNS) with recent prevalence estimates indicating that MS directly affects 2.3 million people worldwide (Browne 2014). Global annual incidence estimates range from 0.07 to 13.75 per 100,000 people (Browne 2014). Wide variations occur in relation to the prevalence and incidence of MS, according to geographic location, with parts of Northern Europe and Canada being the most commonly affected (Browne 2014). It is the most common disabling neurological disorder among young people.

Traditionally MS has been categorised according to clinical phenotype as primary-progressive, relapsing-remitting, secondary-progressive and progressive-relapsing (Lublin 1996). However, it has been suggested that a classification based on clinical and radiological activity be instigated (Lublin 2014). MS is an immune-mediated disease characterised by inflammatory demyelination and neurodegeneration within the CNS. This damage to the CNS structures in turn leads to impairments in cognition, muscle strength, muscle tone, sensation, coordination and gait, all of which are associated with an increased risk for falls. Despite the recent increased availability of disease-modifying medical treatments and their potential to delay the clinical progression of MS, falls continue to present as a common and serious health concern in people with this disease.

\section{Description of the condition}

Fall rates of $56 \%$ have been reported among people with MS (measured using prospective measures) in a recent meta-analysis of 537 individuals, with $37 \%$ of the study population falling recurrently (Nilsagard 2015). This study demonstrated that most falls occurred indoors (65\%) between 6 a.m. and 6 p.m. (75\%). In addition, primary progressive MS and Expanded Disability Severity Scale (EDSS) (Kurtzke 1983) levels of 4.0 and 6.0 were associated with significantly increased odds of falls $(P<0.05)$. The falls rate was also lower in women than men (relative risk (RR) 0.80 ; $95 \%$ confidence interval (CI) 0.67 to 0.94 ) and decreased with increasing age (RR 0.97 for each year, $\mathrm{Cl} 0.95$ to 0.98$)$. In a study by Matsuda 2011, $28 \%$ of people with MS who had reported to have fallen (265 of a total of 455 respondents) suffered a fracture. A population-based European study reported that the incidence rate of fracture was significantly higher among people with MS than age- and gender-matched peers without MS (Bazelier 2011). People with MS with a history of falls report significantly poorer physical and psychological health status compared with non-fallers with MS (Coote 2013b). Falls can further have an adverse impact on fear of falling and falls self-efficacy, and can contribute to activity curtailment, physiological deconditioning, loss of independence, and institutionalisation (Finlayson 2010; Matsuda 2012). A systematic review with meta-analysis identified four factors significantly associated with falls in people with MS: balance dysfunction, the use of a mobility aid, cognitive dysfunction, and progressive MS subtype (Gunn 2013). Given the high prevalence of falls among people with MS and the associated serious and wide-ranging consequences, an increased number of randomised controlled trials have evaluated the effect of falls prevention interventions among people with MS.

\section{Description of the intervention}

To our knowledge there currently is no classification of falls prevention interventions in the MS literature. The effectiveness of several categories of falls prevention interventions has been reviewed systematically among older adults (Gillespie 2003; Gillespie 2012) and people post-stroke (Verheyden 2013) by Cochrane. These categories are also used by the few researchers that have examined fall prevention or management in MS. However the Prevention of Falls Network Europe (ProFaNE) (Lamb 2005; Lamb 2011) proposes the following categories for older adults: exercises, medication, surgery, management of urinary incontinence, fluid or nutrition therapy, psychological intervention, environment/assistive technology, environment (social environment), knowledge interventions and other interventions. In the ProFaNE taxonomy, interventions are also classified as single interventions, multiple interventions or multifactorial interventions. A single intervention consists of only one intervention component which is delivered to all participants in the intervention group, (e.g. exercise). Multiple interventions consist of a combination of two or more intervention components, delivered to all of the participants in the intervention group, (e.g. exercise plus psychological interventions). Multifactorial interventions consist of more than one intervention component, but participants receive different combinations of interventions based on an individual assessment to identify potential risk factors for falls.

\section{How the intervention might work}

Falls prevention interventions are designed to minimise known modifiable personal, task and environmental risk factors for falling, and thereby reduce risk in order to prevent falls and associated injuries. Interventions are designed to reduce the falls rate by targeting improvement in personal risk factors, e.g. reduced balance function, and incorporate exercises to improve joint flexibility, muscle strength, reaction times and coordination. Other interventions are aimed at improving non-physical personal risk factors and include strategies to promote risk awareness, planning and attention. Interventions are also designed to reduce falls by promoting improved task performance, e.g. safe mobility aid use, and include participant education regarding task analysis and planning. Interventions are additionally designed to ameliorate the falls rate by addressing environmental risk factors, e.g. home environmental modifications, and include the provision of aids for personal care.

Single component interventions are designed to address and ameliorate specific risk factors for falling. For example, in Cochrane Reviews focusing on falls prevention interventions among older adults, vitamin $\mathrm{D}$ prescription interventions have been shown to be effective in reducing falls rates among older adults in care facilities (Cameron 2012) and exercise interventions have been shown to be effective in reducing falls rates among older adults living in the community (Gillespie 2012). There is potential for this improvement to be mediated indirectly through the effect of exercise on balance function and mobility functions. To date in the MS literature, of the few falls interventions that have been evaluated, most have predominantly used combinations of education and exercise, targeting mobility, balance, and falls self-efficacy outcomes. The association between balance, mobility impairments, and falls in MS is complex. Programmes focused on balance and stability in older adult populations have been shown to decrease falls in other populations (Gillespie 2012) whereas those that target mobility alone have tended to be either ineffective or to increase falls in older adult populations (Gillespie 2012).

Multiple component interventions aim to reduce several components of falls risk rather than dealing with single risk factors. Commonly, multiple component interventions focus on two or more 
common risk factors and provide these to all participants, regardless of their exact risk status. However, there is no assessment and individual tailoring of the intervention to risk factors. There is some evidence that multiple component interventions may reduce the rate of falls and the risk of falling in older people living in the community (Gillespie 2012).

The rationale underlying multifactorial interventions is that participants undergo an assessment for risk of falling, and a tailored intervention is provided based on their modifiable risk factors. Gillespie 2012 found some evidence that multifactorial interventions may reduce the rate of falls (i.e. the total number of falls per unit of person time that falls were monitored), but not the risk of falling (i.e. the number of people who fell once or more among older people living in the community).

\section{Why it is important to do this review}

The incidence of falls in people with MS is three times higher than that in older people, yet recently published clinical guidelines (NGC 2014) do not outline an evidence-based approach to falls interventions among people with MS. This topic has been examined and reviewed systematically among older adults (Gillespie 2003; Cameron 2012; Gillespie 2012) and people post-stroke (Verheyden 2013) by Cochrane. Therefore there is a clear clinical need for synthesised information regarding the effectiveness of falls prevention interventions among people with MS. This clinical need is relevant across multiple disciplines and multiple settings (home, community, clinical setting). A Cochrane systematic review of this topic has the potential to guide clinical decisions regarding care pathways for people with MS who are at risk of falling, and ultimately to improve quality of life of people with MS.

\section{O B J E C T IVES}

The aim of this review was to evaluate the effectiveness of interventions designed to reduce falls in people with multiple sclerosis (MS). Specific objectives included comparing: (1) falls prevention interventions to controls and; (2) different types of falls prevention interventions.

\section{METHODS}

\section{Criteria for considering studies for this review}

\section{Types of studies}

We included randomised controlled trials (RCTs) and quasi-randomised trials, including randomised and quasi-randomised cluster and cross-over trials. We included all trials regardless of methodological quality.

\section{Types of participants}

We included adults 18 years of age or older, male and female, with clinically definite MS. People with the clinical diagnosis of MS according to the ICD-8 (code 340) (ICD-8 1965), and the McDonald criteria (Schumacher 1965; Poser 1983; McDonald 2001; Polman 2005; Polman 2011) were included. All subgroups of MS such as relapsing remitting, primary progressive and secondary progressive MS, and people at any time since diagnosis were included. People with neurological and non-neurological co-morbidities that may affect falls, e.g. dementia, Parkinson's disease, and recent orthopaedic surgery, were excluded, wherein separate MS data could not be extracted from the trial results.

\section{Types of interventions}

Falls prevention interventions were considered to be any programme in which the primary or secondary aim is to reduce fallswhether stated explicitly by the authors or not. Most fall prevention interventions can be classified according to the taxonomy developed by the Prevention of Falls Network Europe (ProFANE) (Lamb 2007; Lamb 2011). We decided to include studies wherein the authors tested interventions which may have an effect on falls (as defined by ProFANE), e.g. exercise programmes, even if the authors did not explicitly state that the intervention being tested was a falls prevention intervention. This inclusion of such interventions relates to our aim to capture all relevant evidence in this area. Some anticipated falls prevention interventions included: exercise (e.g. aerobic, strengthening, balance), medical intervention (e.g. supplementation with vitamin D), psychological (e.g. cognitive behavioural interventions), environment modifications (e.g. the provision of hip protectors, adaptations to homes), assistive technology interventions (e.g. provision of aids for personal care and protection and personal mobility, eyeglasses, hearing aids, personal alarm systems), surgical interventions (e.g. surgery to address a comorbidity such as hip or knee replacement for osteoarthritis) or other interventions (e.g. educational interventions designed to increase knowledge relating to falls prevention). This review included all interventions tested in trials that measured one or more of the primary falls outcomes (rate of falls, risk of falling).

Acceptable control interventions included: wait-list control, usual care control, another type of intervention.

\section{Types of outcome measures}

Outcome measures were examined at the end of the intervention period in all included studies (post-intervention) at the end of follow-up (e.g. 3-, 6- or 12-month follow-up periods).

\section{Primary outcomes}

- The rate of falls (the number of falls per person year), baseline measure using retrospective (e.g. retrospective falls diary) and prospective measures, recommended by the International MS Falls Prevention Research Network (IMSFPRN) was the primary outcome for falls prevention trials (Sosnoff 2014b).

- The risk of falling, i.e. the number of fallers: number of participants who fell at least once during the study.

- The number of adverse events resulting from the intervention.

\section{Secondary outcomes}

- Physiological falls risk, measured using measures including, but not restricted to, the Physiological Profile Assessment (PPA). The PPA measures five aspects of physiological components including contrast sensitivity, position sense, muscles strength, reaction time and postural sway (Lord 2003).

- Quality of life, measured using measures including, but not restricted to, the Multiple Sclerosis Impact Scale-29 (Hobart 2001).

- Balance function, measured using measures including, but not restricted to, the Berg Balance Scale (Berg 1989), Mini-BEST test (Franchignoni 2010).

- Cognition, measured using measures including, but not restricted to, the Symbols Digit Modalities Test (SDMT) (Smith 1982). 
- Measures of MS disease progression, including but not restricted to the Expanded Disease Severity Scale (EDSS) (Kurtzke 1983), and Patient Determined Disease Steps (PDDS) (Hohol 1995).

- Measures of mobility including, but not restricted to the Six Minute Walk Test (Fry 2006), and MS Walking Scale-12 (Hobart 2003).

- Measures of functional outcome, including but not restricted to the Functional Independence Measure (FIM) (Keith 1987).

- Self-reported fatigue, measured using measures including, but not restricted to, the Modified Fatigue Impact Scale (MFIS) (Fischer 1999).

- Measures of participation, including but not restricted to the Community Integration Measure (CIM) (McColl 2001).

- Outcomes that reflect cost, service utilisation and care burden.

\section{Search methods for identification of studies}

A systematic search without language or date restrictions was conducted using the optimally-sensitive strategy developed for Cochrane to identify all relevant published and unpublished RCTs (Lefebvre 2011). We employed the services of a professional translator for the translation of one full text, for study screening.

\section{Electronic searches}

The Information Specialist searched the Trials Register of the Cochrane Multiple Sclerosis and Rare Diseases of the CNS Group, which, among other sources, contains trials from:

- Cochrane Central Register of Controlled Trials (CENTRAL) (2018 Issue 12);

- MEDLINE (PubMed) (1966 to 12 December 2018);

- Embase (EMBASE.com) (1974 to 12 December 2018);

- Cumulative Index to Nursing and Allied Health Literature (ClNAHL) (EBSCOhost) (1981 to 12 December 2018);

- Latin American and Caribbean Health Science Information Database (LILACS) (Bireme) (1982 to 12 December 2018);

- ClinicalTrials.gov (www.clinicaltrials.gov);

- World Health Organization (WHO) International Clinical Trials Registry Platform (apps.who.int/trialsearch);

- PsycINFO (1806 to 12 December 2018); and

- Physiotherapy Evidence Database (PEDro) (1999 to 12 December 2018).

Information on the Trials Register of the Review Group and details of the search strategies used to identify trials can be found in the 'Specialised Register' section within the Cochrane Multiple Sclerosis and Rare Diseases of the CNS Group (https://msrdcns.cochrane.org/).

The keywords that were used to search for trials for this review are listed in Appendix 1.

In addition, we performed separate searches to ensure we retrieved the most up-to-date results. The search strategies run are in Appen$\operatorname{dix} 2$

\section{Searching other resources}

We also:
- handsearched the reference lists of all retrieved articles, texts and other reviews on the topic;

- contacted researchers active in this field for additional data, for example we sent the list of included studies to the researchers within the International Falls Research Network (IFRN) in order to acquire further potentially suitable studies that our search did not highlight;

- contacted principal authors of unpublished manuscripts to ask if they are willing to disclose their unpublished data, for example Prof Sheila Lennon (Lennon 2013a) for the data from an unpublished trial (Lennon 2013).

\section{Data collection and analysis}

\section{Selection of studies}

Titles and abstracts of the citations retrieved by the literature search were screened independently by two review authors (SH, $\mathrm{SC}$ ) for inclusion or exclusion, based on predetermined inclusion criteria. The full text of potentially relevant studies were selected for further assessment and two authors (SH, SC) ascertained and agreed on eligibility based on the full article. The eligibility (on the basis of the information available in the published data) of these studies was evaluated independently. Papers assessed in full text that did not meet the inclusion criteria are listed in the 'Characteristics of excluded studies' table with the reasons for exclusion. Any disagreement regarding inclusion was resolved by discussion.

\section{Data extraction and management}

For each included study, two of the following four review authors ( $\mathrm{SH}, \mathrm{SC}, \mathrm{LH}$ or RG) independently extracted data from the selected trials using standardised forms and $\mathrm{SH}$ entered the data into the RevMan software (Review Manager 2014). We extracted data on the following:

- study design;

- characteristics of participants (number, age, type of MS, EDSS score);

- inclusion and exclusion criteria;

- brief description of experimental intervention;

- brief description of control intervention;

- methodological quality of studies;

- description of setting;

- description of outcomes.

Disagreements were discussed and resolved by consensus among the review authors.

\section{Assessment of risk of bias in included studies}

The risk of bias for all included studies was independently assessed by two review authors (SH, SC) using the 'Risk of bias' tool outlined in the Cochrane Handbook for Systematic Reviews of Interventions (Higgins 2011) . The domains are: sequence generation, allocation concealment, blinding, incomplete outcome data, selective outcome and other biases. Disagreements among the review authors on the methodological quality of the identified studies was resolved by discussion, or by referral to a third assessor (RG) if necessary.

We used the summary quality assessment at the analysis stage as a means of interpreting the results. For each dimension and for the 
summary assessment we assigned the 'Risk of bias' categories (Hig gins 2011) as:

- low risk of bias, plausible bias unlikely to seriously alter the results;

- unclear risk of bias, plausible bias that raises some doubt about the results; and

- high risk of bias, plausible bias that seriously weakens confidence in the results.

We also rated the overall risk of bias (low, unclear, high) specific for each outcome included in the Summary of Findings table.

\section{Assessing the quality of the body of evidence using the GRADE approach}

We assessed the quality of the evidence using the GRADE approach as outlined in the GRADE handbook in order to assess the quality of the body of evidence relating to the following outcomes for the main comparisons:

- rate of falls;

- number of fallers: number of participants who fell at least once during the study;

- adverse events;

- quality of life.

\section{Summary of findings table}

We used the GRADEpro to import data from Review Manager 5.3 (Review Manager 2014) in order to create a 'Summary of findings' (SOF) table. As per the Cochrane Handbook for Systematic Reviews of Interventions guidelines, the SOF tables include the following information (Higgins 2011): a list of all important outcomes; absolute and relative magnitude of intervention effect; numbers of participants and studies addressing these outcomes; a rating of the overall quality of evidence for each outcome and a space for comments.

Due to the heterogeneity of the included trials, in terms of intervention types, this review comprised 21 comparisons, within the main comparison headings of: 1) Falls interventions versus control and 2) Falls intervention versus another falls intervention. As exercise is a very commonly-prescribed falls prevention intervention in clinical practice, wherein the alternative is often usual care treatment, we present the data from the exercise versus control comparison in the SoF table only (Summary of findings for the main comparison). The findings from the other comparisons are presented within the text of this review.

We created the 'Summary of findings' table for the following outcomes:

\section{- rate of falls}

- number of fallers

- adverse events

- quality of life

A summary of the intervention effect and a measure of quality for each outcomes was produced using the GRADE approach. The GRADE approach uses five domains (study limitations, consistency of effect, imprecision, indirectness and publication bias) to assess the quality of the body of evidence for each outcome. The evidence can be downgraded from 'high quality' by one level for serious (or by two levels for very serious) limitations, depending on assessments for risk of bias, indirectness of evidence, serious inconsistency, imprecision of effect estimates or potential publication bias. We graded the quality of evidence as high, moderate, low, or very low upon considering within-study risk of bias, directness of evidence, heterogeneity, precision of effect estimates, and risk of publication bias. Assumed baseline risks used in calculating absolute risks were based on the range of outcomes measured in comparison groups in the included studies.

\section{Measures of treatment effect}

According to the study characteristics, we determined the treatment effect of:

- falls prevention interventions versus no treatment control, e.g. exercise versus control;

- falls prevention intervention versus another falls prevention intervention, e.g. exercise versus functional electrical stimulation plus exercise.

According to the type of outcomes reported we used the following effect measures:

- dichotomous data: risk ratio (RR). For the number of fallers and recurrent fallers (risk of falling) and number of adverse events we used a risk ratio (RR) and $95 \% \mathrm{Cl}$ based on the number of people falling and the number of people reporting adverse events in each group.

- continuous data: mean difference (MD) or standardised mean difference (SMD) in the studies that assessed the same outcome but measured it in a variety of ways (for example, $10 \mathrm{~m}$ walk speed and $25 \mathrm{ft}$ walk speed). For the pooling of continuous data, wherein studies used different measures of the same outcomes, e.g. the Berg Balance Scale and Four Step Square Test to measure balance, to ensure the accurate pooling of data and representation of the different outcome measures on the same standardised scale, we applied the rule that lower scores indicated poorer performance and higher scores indicated better performance. For the individual scales wherein the opposite was the case, we multiplied the mean estimate by minus 1 ;

- A rate ratio (RaR) and $95 \%$ confidence interval $(\mathrm{Cl})$ was used to compare the rate of falls between intervention and control groups. Falls rate was reported by one study only (Taylor 2014). Therefore, where possible, by receiving additional data from study authors, we calculated the falls rate for individual studies. If a rate ratio was not reported, but appropriate raw data (number of falls in each group, number of participants in each group, length of assessment period) were available, the author $\mathrm{SH}$ used excel to calculate the falls rate (total number of falls, number of participants in each group and duration of falls data collection period (number of falls per person per year) for both groups in the included studies. The Generic Inverse Variance option in Revman requires entering the natural log of the rate ratio and its standard error for each study. The author CW calculated these in Stata.

\section{Unit of analysis issues}

Data analysis took into account the level at which randomisation occurred (e.g. cross-over trials). Two cross-over randomised trials were included in the review (Prosperini 2013; Taylor 2014). We 
consulted a statistician (CW), in addition to the guidance from the Cochrane Handbook Chapter 16.4.3 (Higgins 2011) to determine the most appropriate methods to meta-analyse these data. Both trials included an exercise intervention component and given the nature of exercise, and potential for more sustained exercise behaviour change after crossing over to another intervention component, we decided to extract and analyse data from both groups, only for the first period of the two crossover studies. Therefore these data have been analysed in the same manner as a parallel group standard trial design (Cochrane Handbook Chapter 16.4.3) (Higgins 2011). With regard to dealing with studies with multiple arms: Cattaneo 2007 included three arms and the two other studies included four arms (Coote 2013; Sosnoff 2015); we did not include multiple arms in any of the included meta-analyses in our review. Therefore, we did not need to take measures to account for double counting of participants.

\section{Dealing with missing data}

If trial data were insufficient or missing, we attempted to obtain additional information from the authors of included studies by personal communication. We analysed only the available data (ignoring the missing data).

\section{Assessment of heterogeneity}

Prior to the assessment of statistical heterogeneity, as an interdisciplinary reviewer team, we determined the clinical heterogeneity of included studies. Specifically, we considered the types of participants, interventions and outcomes before making a decision to pool data in meta-analyses. After the pooling of appropriate data we calculated the $\mathrm{I}^{2}$ statistic for each pooled estimate to assess the impact on statistical heterogeneity. When the $\mathrm{I}^{2}$ was $>30 \%$ we used random-effects models to take account of the between-study variation in our findings (Higgins 2011). Where there was substantial clinical heterogeneity (e.g. in the nature of interventions) then these were analysed in homogenous subgroups.

\section{Assessment of reporting biases}

Due to the lack of unpublished suitable studies identified for inclusion in this review, it was not possible to examine the influence of unpublished papers on the overall effects.

\section{Data synthesis}

We performed separate analyses for trials comparing: (1) falls prevention interventions with control interventions and; (2) trials comparing two different types of falls prevention interventions. This outlines the two main comparisons we aimed to make across primary and secondary outcomes in this review and meta-analysis. Data extraction from the included studies however, demonstrated that there were a wide variety of falls interventions, with less potential for pooling of data than anticipated. For example, due to the clinical heterogeneity evident in the included studies wherein the effectiveness of different types of falls prevention interventions were compared, we were not able to pool data from more than one study.

We analysed the data using Review Manager 5.3. We decided whether or not to perform meta-analyses based on the similarity of the included trials. Where we could not carry out meta-analysis because of substantial differences between studies and when only one study was identified, we presented results in a forest plot (with the pooled summary of outcomes suppressed) and provided a narrative review. The data of individual trials was pooled for each outcome using a fixed-effect model (if heterogeneity was not present $\left(I^{2}<30\right)$ and using a random-effects model if heterogeneity was present $(12 \geq 30)$.

\section{Subgroup analysis and investigation of heterogeneity}

We had planned on undertaking subgroup analyses to establish if the following subgroups affected the overall effects:

- participant-related characteristics (e.g. type of impairment at baseline: participants with muscle weakness, participants with ataxia, etc.; age; time since diagnosis of MS; type of MS, level of impairment at baseline; adherence to intervention);

- intervention-related characteristics (e.g. type of falls prevention intervention, duration of intervention; frequency of intervention; intensity of intervention);

- study design characteristics (e.g. type of comparison, type of falls outcome measurement, retrospective falls rate versus prospective falls rate). Retrospective data may have been reported by trials wherein retrospective falls diaries were used as an outcome measure.

However, due to insufficient number of studies, we were not able to perform these analyses. Given the clinical heterogeneity of many of the included studies within the comparison "Falls prevention intervention versus another falls prevention intervention", we conducted separate analyses across various intervention-related characteristics.

\section{Sensitivity analysis}

We considered risk of bias of included studies when interpreting evidence using the GRADE approach. Sensistivity analysis was not performed.

\section{RES U LTS}

\section{Description of studies}

\section{Results of the search}

We screened a total of 728 citations; this includes duplicates. The results of our searching activities are summarised in Figure 1 Thirteen studies were identified for inclusion in this review based on previously-outlined search strategy. 
Figure 1. Study flow diagram.

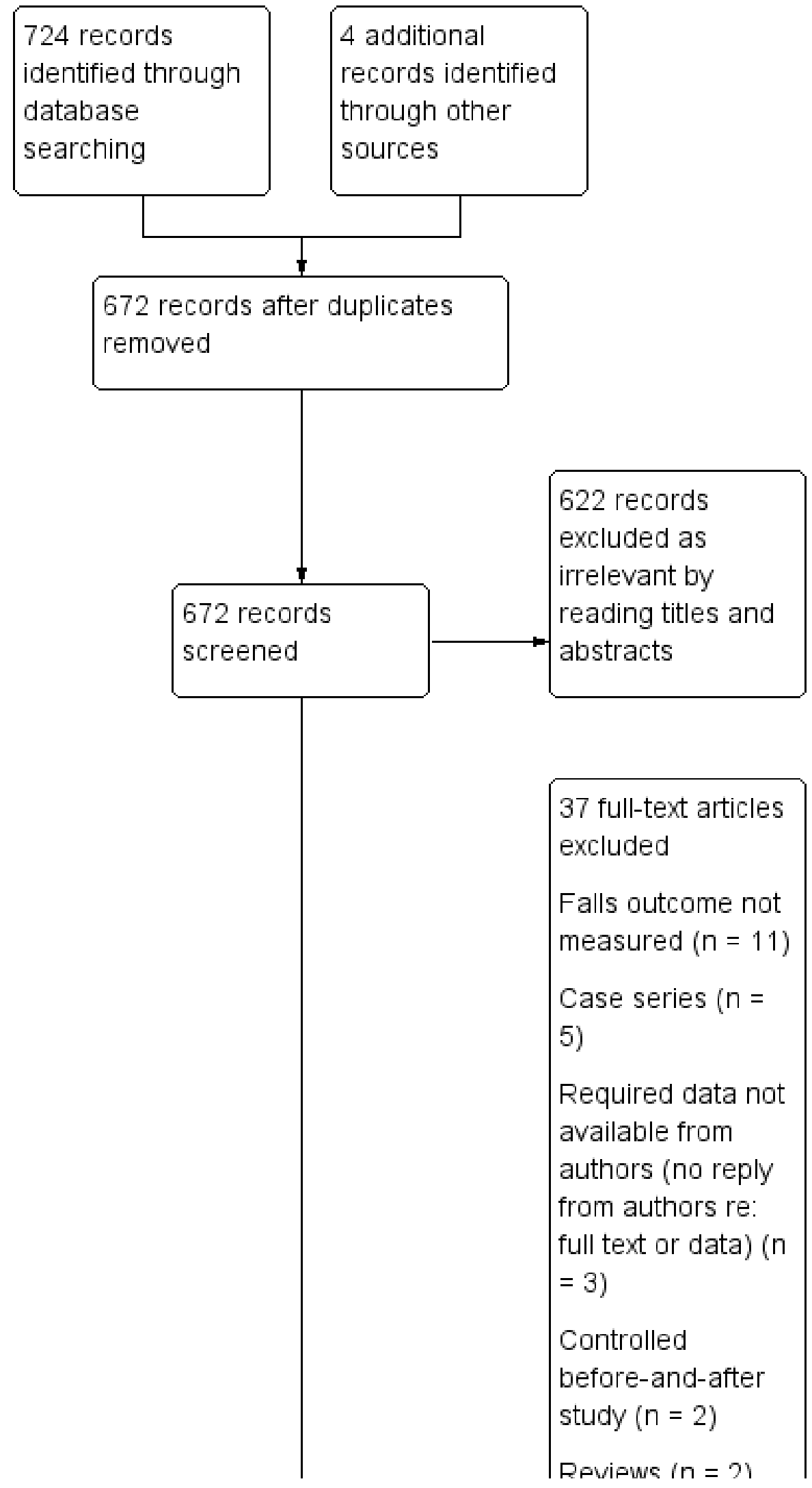


Figure 1. (Continued)

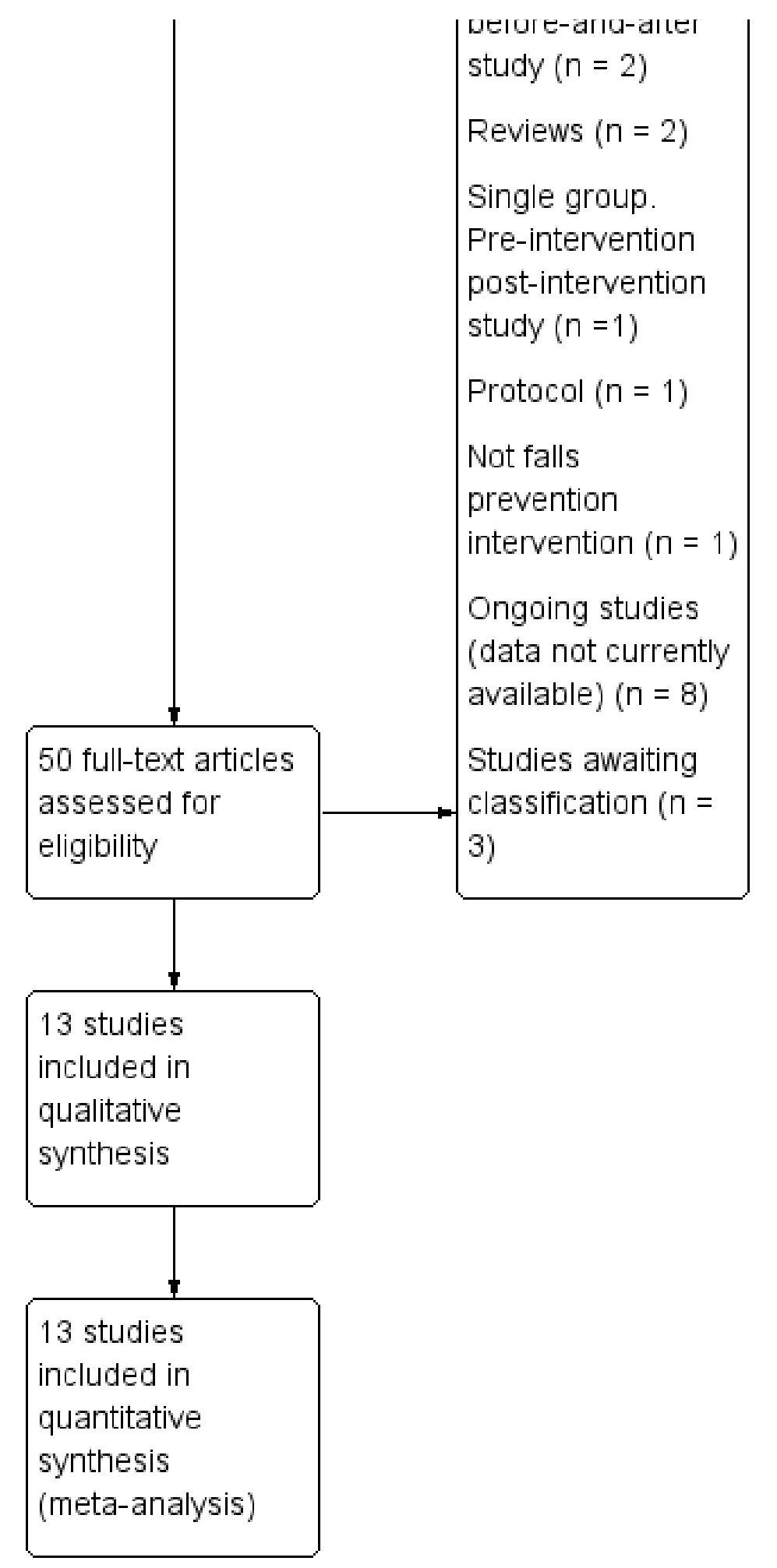


- We identified eight ongoing trials

- We identified three trials that are awaiting classification.

\section{Included studies}

Thirteen studies met the inclusion criteria for this review (Stephens 2001; Cattaneo 2007; Esnouf 2010; Coote 2013; Lennon 2013; Prosperini 2013; Sosnoff 2014; Taylor 2014; Gandolfi 2015; Sosnoff 2015; Cattaneo 2016; Hoang 2016; Carling 2017). We contacted authors on 11 of the included studies for additional participant data (Stephens 2001a; Esnouf 2010a; Coote 2013a; Lennon 2013a; Prosperini 2013a; Sosnoff 2014a; Taylor 2014a; Sosnoff 2015a; Cattaneo 2016a; Hoang 2016a; Carling 2017a). We received additional requested data relating to falls outcomes from the authors of the following studies (Esnouf 2010; Coote 2013; Lennon 2013; Prosperini 2013; Taylor 2014; Carling 2017).

\section{Participants}

A total of 839 people with MS (range 12 to 177 individuals) were randomised to falls interventions or control interventions in the 13 included trials. The mean age of the participants was 52 years, ranging from 36 years (Prosperini 2013) to 62 years (Sosnoff 2015). Participants were diagnosed with MS using the McDonald criteria in three studies (Prosperini 2013; Hoang 2016; Carling 2017), eight studies did not report the criteria used to diagnose MS, but reported that participants were diagnosed with clinically-definite MS (Stephens 2001; Cattaneo 2007; Esnouf 2010; Coote 2013; Lennon 2013; Sosnoff 2014; Sosnoff 2015; Gandolfi 2015) and two studies did not outline the criteria used to confirm MS diagnosis (Taylor 2014; Cattaneo 2016). Nine studies included participants with mixed types of MS (Stephens 2001; Cattaneo 2007; Coote 2013; Lennon 2013; Prosperini 2013; Sosnoff 2014; Sosnoff 2015; Hoang 2016; Carling 2017), two studies included participants with secondary progressive MS only (Esnouf 2010; Taylor 2014), Gandolfi 2015 included people with relapsing-remitting MS only and one study did not outline the type of MS included (Cattaneo 2016). The percentage of women participants ranged from $59 \%$ (Sosnoff 2015) to $85 \%$ (Sosnoff 2014). All trials delivered interventions in the community setting.

\section{Interventions}

Ten studies used two-group comparisons including those that compared a falls intervention and control (Lennon 2013; Prosperini 2013; Sosnoff 2014; Hoang 2016; Carling 2017) or studies that compared two active falls interventions (Stephens 2001; Esnouf 2010; Taylor 2014; Gandolfi 2015; Cattaneo 2016). One study employed three-group comparisons (Cattaneo 2007) and two studies used four-group comparisons (Coote 2013; Sosnoff 2015). Cattaneo 2007 examined the effectiveness of motor and sensory, motor and conventional rehabilitation interventions; Coote 2013 compared the effectiveness of group exercise, individual physiotherapy exercise, yoga and control interventions and; Sosnoff 2015 examined the effect of home-based exercise, exercise plus education, education and control interventions. Carling 2017 compared an exercise intervention with a wait list control group, wherein participants in the control group were delivered the exercise intervention at week seven of a 12-week intervention. Therefore to make a comparison between an exercise falls intervention and control, we extracted data from Carling 2017 at seven weeks. Taylor 2014 and Prosperini 2013 used cross-over trial designs. However, we included the pre-crossover phase of these trials only. We did not combine the first and second phases of these trials because of uncertainty about the carryover effects in such trials, given that they are exercise and education interventions, wherein the wash-out period is difficult to determine

Interventions to reduce falls varied across studies. Exercise interventions included interventions to promote improvements in: strength and balance function (Coote 2013; Sosnoff 2014; Sosnoff 2015; Carling 2017); balance function (Cattaneo 2007; Prosperini 2013; Gandolfi 2015; Cattaneo 2016; Hoang 2016); mobility and balance function (Stephens 2001; Lennon 2013); strength (Esnouf 2010; Taylor 2014). The majority of exercise interventions lasted from 6 to 12 weeks in duration (Stephens 2001; Esnouf 2010; Coote 2013; Lennon 2013; Prosperini 2013; Sosnoff 2014; Taylor 2014; Sosnoff 2015; Cattaneo 2016; Hoang 2016; Carling 2017), while Gandolfi 2015 and Cattaneo 2007 delivered 5- and 3-week exercise interventions, respectively. Frequency of exercise interventions ranged from once weekly (Coote 2013) to five times weekly (Prosperini 2013). Stephens 2001; Esnouf 2010; Coote 2013; Lennon 2013; Gandolfi 2015; Cattaneo 2016 and Carling 2017 evaluated group-based exercise interventions, while home-based exercise interventions were used in many of the included studies (Prosperini 2013; Taylor 2014; Sosnoff 2014; Sosnoff 2015 and Hoang 2016). Cattaneo 2007 and Coote 2013 also tested the effectiveness of individual exercise programmes delivered by Physiotherapists. Two studies compared the effectiveness of exercise interventions using home-based step training systems with exercise games to group and home-based exercise (Prosperini 2013 and Hoang 2016, respectively). Two studies compared the effectiveness of functional electrical stimulation (common peroneal nerve stimulation) to exercise interventions ( Esnouf 2010 and Taylor 2014).

\section{Comparisons}

The comparisons included wait list controls (Lennon 2013; Prosperini 2013; Sosnoff 2014; Sosnoff 2015; Carling 2017), treatment as usual controls (Coote 2013, Hoang 2016), other interventions that may reduce falls (Stephens 2001; Cattaneo 2007; Esnouf 2010; Coote 2013; Taylor 2014; Sosnoff 2015; Gandolfi 2015, Cattaneo 2016).

\section{Outcomes}

The 13 studies included a range of primary and secondary outcome measures. Outcomes were measured at the end of intervention for all included studies and at the end of 1-month (Gandolfi 2015), 2-month (Cattaneo 2016), 3-month (Lennon 2013) and 6month (Lennon 2013) follow-up periods. With regard to the primary outcomes; falls rate was reported by one study only (Taylor 2014). We therefore calculated the falls rate for each individual trial (number of falls per person per year) for the other included trials, wherein the required data were available. While it was not outlined in the protocol we have included the number of fallers (one or more fall) as an outcome in the review and was reported by six studies (Cattaneo 2007; Lennon 2013; Sosnoff 2014; Sosnoff 2015; Cattaneo 2016; Carling 2017). There were a range of definitions used for a fall and a variety of ways of collecting and reporting falls data in the included studies. Eight studies used prospective falls diaries to collect falls data (Stephens 2001; Esnouf 2010; Prosperini 2013; Taylor 2014; Gandolfi 2015; Sosnoff 2015; Hoang 2016; Carling 2017), three studies used retrospective methods of collecting self-report falls data (Coote 2013; Sosnoff 2014; Sosnoff 2015 and two studies did not outline how falls data were collected (Cattaneo 2007; Cat- 
taneo 2016). A variety of secondary outcome measures were used in the included studies; but only some trials shared the same outcomes and measures suitable for pooling.

\section{Excluded studies}

The most common reasons for exclusion were: a controlled trial in which the intervention did not meet the criteria for falls intervention or did not include a suitable comparison, or no falls outcomes were included. See Characteristics of excluded studies wherein we have outlined reasons for exclusion of each study.

\section{Risk of bias in included studies}

The risk of bias in the 13 included studies was generally mixed (Figure 2, Figure 3), with a high risk of selection bias associated with allocation concealment in one study (Lennon 2013), detection bias associated with lack of blinding of outcome assessment in two studies (Cattaneo 2007, Cattaneo 2016), attrition bias due to incomplete outcome data in two studies (Lennon 2013; Taylor 2014) and reporting bias due to selective reporting in seven studies (Coote 2013; Lennon 2013; Sosnoff 2014; Gandolfi 2015; Sosnoff 2015; Hoang 2016; Cattaneo 2016). We judged the risk of bias to be unclear in some instances mainly due to insufficient reporting of the methods used for random sequence generation (Stephens 2001; Coote 2013; Cattaneo 2016), allocation concealment (Stephens 2001; Cattaneo 2007; Esnouf 2010; Coote 2013; Lennon 2013; Prosperini 2013; Taylor 2014; Hoang 2016; Cattaneo 2016), blinding of participants and personnel (Stephens 2001; Esnouf 2010; Coote 2013; Sosnoff 2014; Taylor 2014; Gandolfi 2015; Sosnoff 2015; Cattaneo 2016; Hoang 2016; Carling 2017), blinding of outcome assessment (Stephens 2001; Coote 2013; Taylor 2014), handling of incomplete outcome data (Stephens 2001; Coote 2013), and selective reporting (Stephens 2001; Cattaneo 2007; Esnouf 2010; Prosperini 2013; Taylor 2014; Gandolfi 2015; Cattaneo 2016). We judged that nine studies to have an unclear risk of other bias related to the fact that inferential statistics were computed without completing a formal sample size calculation, potentially exposing the study to a Type II statistical error (Stephens 2001; Cattaneo 2007; Esnouf 2010; Coote 2013; Lennon 2013; Prosperini 2013; Sosnoff 2014; Taylor 2014; Sosnoff 2015).

Figure 2. Risk of bias graph: review authors' judgements about each risk of bias item presented as percentages across all included studies.

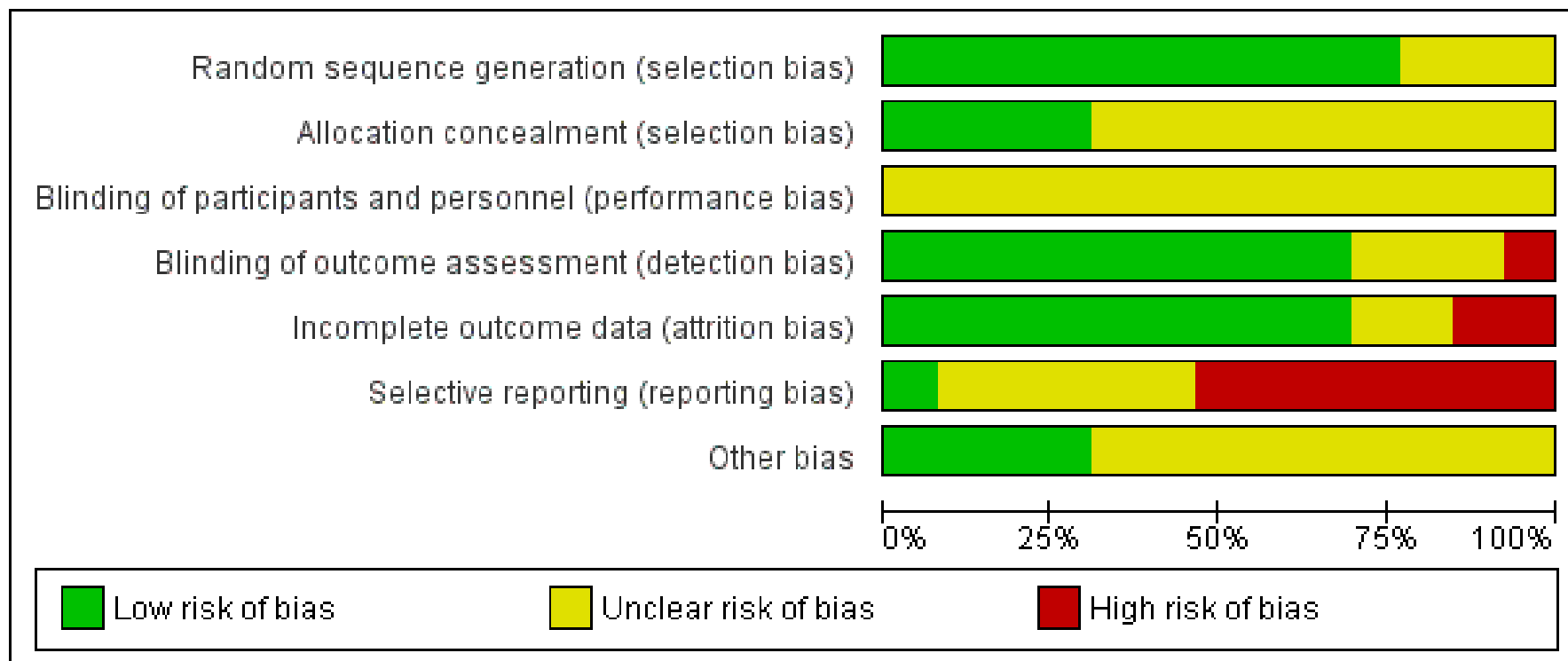


Figure 3. Risk of bias summary: review authors' judgements about each risk of bias item for each included study.

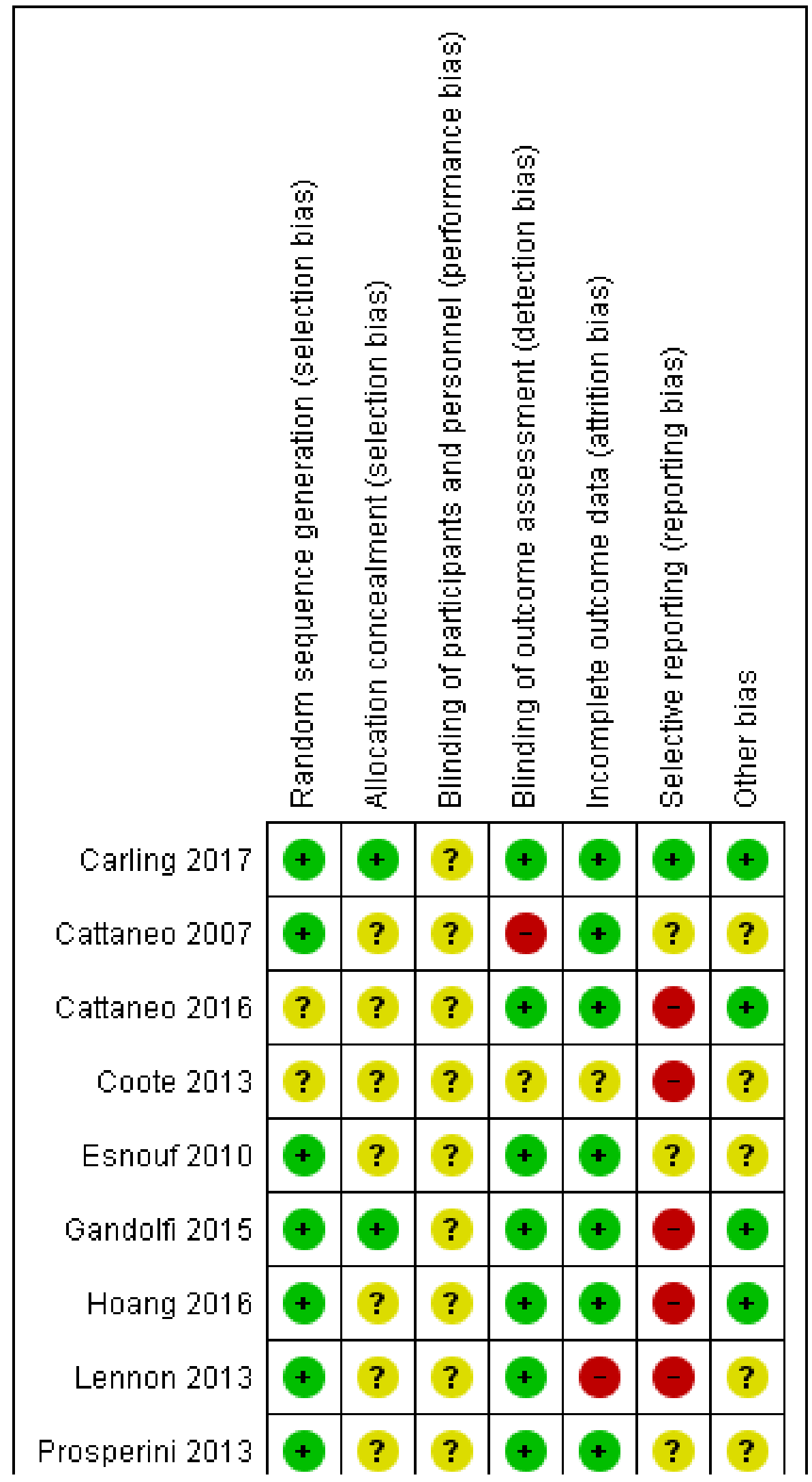


Figure 3. (Continued)

\begin{tabular}{|c|c|c|c|c|c|c|c|}
\hline Lennon $\angle \mathrm{U} 1 \mathrm{~S}$ & + & $?$ & $?$ & + & & & $?$ \\
\hline Prosperini 2013 & & $?$ & $?$ & + & & $?$ & $?$ \\
\hline Sosnoff 2014 & & & $?$ & & & & $?$ \\
\hline Sosnoff 2015 & & 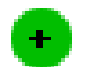 & $?$ & + & & & $?$ \\
\hline Stephens 2001 & $?$ & $?$ & $?$ & $?$ & $?$ & $?$ & $?$ \\
\hline Taylor 2014 & + & $?$ & $?$ & $?$ & & $?$ & $?$ \\
\hline
\end{tabular}




\section{Allocation}

Ten studies were judged to have a low risk of selection bias due to having adequate random sequence generation, having used a computerised random number generator by an independent unit (Cattaneo 2007; Esnouf 2010; Lennon 2013; Prosperini 2013; Sosnoff 2014; Taylor 2014; Gandolfi 2015; Sosnoff 2015; Hoang 2016; Carling 2017). The method used for random sequence generation and the risk of bias in three other studies was unclear (Stephens 2001; Coote 2013; Cattaneo 2016).

We judged four studies to have a low risk of selection bias due to effectively concealing allocation into groups using a concealed envelope system (Sosnoff 2014; Sosnoff 2015; Carling 2017) or having a separate staff member who was not otherwise involved in the study complete allocation (Gandolfi 2015). The remaining nine studies provided insufficient information in the paper to permit a judgement of high or low risk of bias and were deemed to have an unclear risk of bias relating to allocation concealment.

\section{Blinding}

Twelve studies were judged as having an unclear risk risk of performance bias due to lack of information provided on blinding procedures among participants or personnel blinding (Stephens 2001; Esnouf 2010; Coote 2013; Lennon 2013; Prosperini 2013; Sosnoff 2014; Taylor 2014; Gandolfi 2015; Sosnoff 2015; Cattaneo 2016; Hoang 2016; Carling 2017).

\section{Incomplete outcome data}

We judged two studies to have a high risk of attrition bias due to incomplete outcome data (Lennon 2013; Taylor 2014). Nine studies were deemed to have a low risk of attrition bias as reasons for attrition were adequately explained in the paper (Cattaneo 2007; Esnouf 2010; Prosperini 2013; Sosnoff 2014; Sosnoff 2015; Gandolfi 2015; Cattaneo 2016; Hoang 2016; Carling 2017). Two studies did not provide sufficient information to permit a judgement of low or high risk of bias relating to incomplete outcome data ( Stephens 2001; Coote 2013).

\section{Selective reporting}

Eight studies provided a trial registration number that enabled the examination of the domain of selective reporting of outcomes. In five studies where no reference to a trial registration number or published protocol were provided, these studies were deemed to have an unclear risk of bias under this domain (Stephens 2001; Cattaneo 2007; Esnouf 2010; Prosperini 2013; Taylor 2014).

Of the eight studies that provided a trial registration number, one study was deemed to have a low risk of bias (Carling 2017) as all outcomes reported in the trial mapped to those presented in the protocol. The remaining seven studies were deemed to have a high risk of selective reporting of outcomes (Stephens 2001; Cattaneo 2007; Esnouf 2010; Prosperini 2013; Taylor 2014; Gandolfi 2015; Cattaneo 2016). In three studies, additional outcomes are presented in the paper that are not documented in the protocol (Lennon 2013; Cattaneo 2016; Hoang 2016) and in four studies, not all outcomes presented in the protocol are reported in the paper (Coote 2013; Sosnoff 2014; Gandolfi 2015; Sosnoff 2015).

\section{Other potential sources of bias}

In terms of other potential sources of bias, we focused on whether studies had reported the completion of a formal sample size calculation a priori. Nine studies had an unclear risk of bias related to the fact that inferential statistics were computed without completing a formal sample size calculation, potentially exposing the study to a Type II statistical error (Stephens 2001; Cattaneo 2007; Esnouf 2010; Coote 2013; Lennon 2013; Prosperini 2013; Sosnoff 2014; Taylor 2014; Sosnoff 2015). The remaining studies were deemed to have a low risk of bias as a formal sample size was calculated a priori and the required number of participants were recruited.

\section{Effects of interventions}

See: Summary of findings for the main comparison Exercise compared to control (post-intervention) for preventing falls in people with multiple sclerosis

\section{Effect of falls interventions on primary outcome measures}

We present the results below according to the comparison being tested. Not all studies included all outcomes and therefore we report the results for primary and secondary outcomes, where available from the included studies. Therefore we have presented outcomes under two main comparison types:

- Falls prevention intervention versus control

- Falls prevention intervention versus another falls prevention intervention

\section{Effect of interventions on primary outcomes}

\section{Comparison 1: Falls prevention interventions versus control}

\section{- Exercise versus control}

See Summary of findings for the main comparison for comparison of main outcomes.

\section{The rate of falls}

Of the seven trials that compared the effect of exercise interventions and controls, none included a measure of falls rate post-intervention. The post-intervention findings we reported relate to the assessment time points immediately after the interventions were delivered in the individual included studies. We used data (where available in trial publications and through contacting trial authors) from five studies (Coote 2013; Lennon 2013; Prosperini 2013; Hoang 2016; Carling 2017) in order to calculate falls rate. There was no significant effect of exercise compared to control on falls rate (Rate Ratio [RaR] $0.68,95 \% \mathrm{Cl} 0.43$ to $1.06, \mathrm{l} 2=59 \%, \mathrm{n}=399$, very low GRADE evidence) (Analysis 1.1).

\section{The number of fallers}

Five studies reported the number of fallers per group post-intervention (Coote 2013; Lennon 2013; Sosnoff 2014; Sosnoff 2015; Carling 2017). There was no significant effect of treatment on the number of fallers post-intervention (Risk Ratio [RR] $0.85,95 \% \mathrm{Cl} 0.51$ to 1.43 , $12=45 \%, n=355$, low GRADE evidence) (Analysis 1.2). Only one study (Lennon 2013) examined this outcome at 3-month and 6-month follow-up, respectively. Results demonstrated no evidence of an effect in favour of exercise (RR $1.16,95 \% \mathrm{Cl} 0.78$ to 1.73 and RR 1.02 , $95 \% \mathrm{Cl} 0.69$ to 1.52 ) (Analysis 17.1 and Analysis 18.1 respectively). 


\section{Adverse events}

Three studies reported the number of participants with adverse events per group (Sosnoff 2014; Sosnoff 2015; Hoang 2016). There was no evidence of an effect of the intervention (RR 1.25, 95\% Cl 0.26 to $6.03,12=0 \%, n=97$, low GRADE evidence) (Analysis 1.3).

\section{- Education versus control}

\section{The number of fallers}

One study examined the effect of an education intervention versus a wait list control on number of fallers (Sosnoff 2015). There was no evidence of an effect in favour of either group (RR $0.83,95 \% \mathrm{Cl} 0.40$ to 1.76) (Analysis 2.1).

\section{Adverse events}

One study reported the number of participants with adverse events per group (Sosnoff 2015). There was no significant effect of education on the number of people reporting adverse events during the intervention (RR 2.00, 95\% Cl 0.22 to 18.33) (Analysis 2.2).

\section{- Exercise plus education versus control}

\section{The number of fallers}

One study examined the effect of an exercise plus education intervention versus a wait list control on the number of fallers (Sosnoff 2015). There was no evidence of an effect in favour of either group (RR 0.30, 95\% Cl 0.04 to 2.20) (Analysis 3.1).

\section{Adverse events}

One study reported the number of participants with adverse events per group (Sosnoff 2015). There was no significant effect of exercise plus education on the number of people reporting adverse events during the intervention (RR 3.38, $95 \% \mathrm{Cl} 0.43$ to 26.30 ) (Analysis 3.2).

\section{- Individual exercise versus control}

\section{Falls rate}

One study examined the effect of individual exercise versus control on the rate of falls (Coote 2013). There was evidence of an effect in favour of control group (RaR 4.50, 95\% Cl 1.04 to 19.48) (Analysis 4.1).

\section{The number of fallers}

One study examined the effect of individual exercise versus control on the number of fallers (Coote 2013). There was no evidence of an effect in favour of either group (RR 2.11, 95\% Cl 0.51 to 8.74) (Analysis 4.2).

\section{- Yoga versus control}

\section{Falls rate}

One study examined the effect of yoga versus control on the rate of falls (Coote 2013). There was no evidence of an effect in favour of either group ( $R a R 4.67,95 \% \mathrm{Cl} 0.99$ to 21.99 ) (Analysis 5.1).

\section{Comparison 2: Falls intervention versus another falls intervention}

- Functional Electrical Stimulation (FES) versus exercise

Falls rate
Two studies examined the effect of FES versus exercise on the rate of falls post-intervention (Esnouf 2010; Taylor 2014). There was no evidence of an effect in favour of either group (RaR 0.91, 95\% Cl 0.78 to $1.06,\left.\right|^{2} 54 \%$ ) (Analysis 6.1).

\section{Adverse events}

One study reported the number of participants with adverse events per group (Esnouf 2010). There was no significant effect of FES or exercise on the number of people reporting adverse events during the intervention (RR $2.00,95 \% \mathrm{Cl} 0.39$ to 10.16 ) (Analysis 6.2).

\section{- Exercise versus education}

\section{Falls rate}

One study examined the effect of exercise versus education on the rate of falls (Stephens 2001). There was no evidence of an effect in favour of either group ( $\mathrm{RaR} 0.71,95 \% \mathrm{Cl} 0.39$ to 1.28 ) (Analysis 7.1).

\section{The number of fallers}

One study examined the effect of an exercise versus education on the number of fallers per group (Sosnoff 2015). There was no evidence of an effect in favour of the intervention (RR $0.49,95 \% \mathrm{Cl} 0.16$ to 1.52) (Analysis 7.2).

\section{Adverse events}

One study reported the number of participants with adverse events per group (Sosnoff 2015). There was no significant effect of either intervention on the number of people reporting adverse events during the intervention (RR $0.41,95 \% \mathrm{Cl} 0.04$ to 3.82) (Analysis 7.3).

\section{Cost effectiveness}

None of the studies reported data on cost-effectiveness.

\section{- Exercise versus exercise plus education}

\section{The number of fallers}

One study examined the effect of an exercise plus education intervention versus exercise on the number of fallers (Sosnoff 2015). There was no evidence of an effect in favour of the intervention (RR $0.73,95 \% \mathrm{Cl} 0.20$ to 2.71 ) (Analysis 8.1 ).

\section{Adverse events}

One study reported the number of participants with adverse events per group (Sosnoff 2015). There was no significant effect of either intervention on the number of people reporting adverse events during the intervention ( $R R 0.24,95 \% \mathrm{Cl} 0.03$ to 1.92 ) (Analysis 8.2).

\section{- Education versus exercise plus education}

\section{The number of fallers}

One study examined the effect of an exercise plus education intervention versus education on the number of fallers per group (Sosnoff 2015). There was no evidence of an effect in favour of the intervention ( $\mathrm{RR} 2.08,95 \% \mathrm{Cl} 0.30$ to 14.55 ) (Analysis 9.1).

\section{Adverse events}

One study reported the number of participants with adverse events per group (Sosnoff 2015). There was no significant effect of either 
intervention on the number of people reporting adverse events during the intervention (RR $0.67,95 \% \mathrm{Cl} 0.15$ to 2.98 ) (Analysis 9.2).

\author{
- Sensory integration balance training versus conventional \\ rehabilitation
}

\section{Falls rate}

One study examined the effect of sensory integration balance training (SIBT) versus conventional rehabilitation on the rate of falls (Gandolfi 2015). There was evidence of an effect in favour of the SIMT group (RaR 0.10, 95\% Cl 0.01 to 0.67) (Analysis 10.1).

\section{- Motor and sensory balance rehabilitation versus motor balance} rehabilitation

\section{Falls rate}

One study examined the effect of motor and sensory balance rehabilitation versus motor balance rehabilitation on the rate of falls (Cattaneo 2007). There was no evidence of an effect in favour of either group ( $\mathrm{RaR} 6.00,95 \% \mathrm{Cl} 0.38$ to 95.93) (Analysis 11.1).

\section{The number of fallers}

One study examined the effect of motor and sensory balance rehabilitation versus motor balance rehabilitation on the number of fallers (Cattaneo 2007). There was no evidence of an effect in favour of either group (RR $0.48,95 \% \mathrm{Cl} 0.03$ to 6.96) (Analysis 11.2).

\section{- Motor and sensory balance rehabilitation versus conventional rehabilitation}

\section{Falls rate}

One study examined the effect of motor and sensory balance rehabilitation versus conventional rehabilitation on the rate of falls (Cattaneo 2007). There was no evidence of an effect in favour of either group ( $\mathrm{RaR} 3.00,95 \% \mathrm{Cl} 0.31$ to 28.84) (Analysis 12.1).

\section{The number of fallers}

One study examined the effect of a motor and sensory balance rehabilitation intervention versus conventional rehabilitation on the number of fallers (Cattaneo 2016). There was no evidence of an effect in favour of the intervention (RR $1.05,95 \% \mathrm{Cl} 0.49$ to 2.25 postintervention) (Analysis 12.2). However, there was evidence of an effect in favour of the conventional rehabilitation at 2-month follow-up with a RR of 9.46, 95\% Cl 1.31 to 68.38 (Analysis 19.1).

- Motor balance rehabilitation vs conventional non balance rehabilitation

\section{Falls rate}

One study examined the effect of motor balance rehabilitation versus conventional non-balance rehabilitation on the rate of falls (Cattaneo 2007). There was no evidence of an effect in favour of either group ( $\operatorname{RaR} 0.50,95 \% \mathrm{Cl} 0.05$ to 4.81 ) (Analysis 13.1).

\section{The number of fallers}

One study examined the effect of a motor balance intervention vs conventional non balance rehabilitation on the number of fallers (Cattaneo 2007). There was no evidence of an effect in favour of the intervention (RR $1.20,95 \% \mathrm{Cl} 0.07$ to 21.72 post-intervention) (Analysis 13.2).

\section{- Group exercise versus Yoga}

\section{Falls rate}

One study examined the effect of group exercise versus yoga on the rate of falls (Coote 2013). There was no evidence of an effect in favour of either group (RaR 0.75, 95\% Cl 0.34 to 1.66) (Analysis 14.1).

\section{The number of fallers}

One study examined the effect of group exercise versus yoga on the number of fallers (Coote 2013). There was no evidence of an effect in favour of either group (RR $0.87,95 \% \mathrm{Cl} 0.21$ to 3.56 ) (Analysis 14.2).

\section{- Group exercise versus individual exercise}

\section{Falls rate}

One study examined the effect of group exercise versus individual exercise on the rate of falls (Coote 2013). There was no evidence of an effect in favour of either group ( $R a R 1.00,95 \% \mathrm{Cl} 0.54$ to 1.85 ) (Analysis 15.1).

\section{The number of fallers}

One examined the effect of group exercise versus individual exercise on the number of fallers (Coote 2013). There was no evidence of an effect in favour of either group (RR $0.70,95 \% \mathrm{Cl} 0.27$ to 1.82 ) (Analysis 15.2).

\section{- Individual exercise versus yoga}

\section{The rate of falls}

One study examined the effect of individual exercise versus yoga on the rate of falls (Coote 2013). There was no evidence of an effect in favour of either group (RaR 0.75, 95\% Cl 0.32 to 1.74) (Analysis 16.1).

\section{The number of fallers}

One examined the effect of individual exercise versus yoga on the number of fallers (Coote 2013). There was no evidence of an effect in favour of either group (RR 1.19, 95\% Cl 0.37 to 3.77) (Analysis 16.2).

\section{Effect of interventions on secondary outcome measures}

\section{Comparison 1: Falls intervention versus control}

\section{- Exercise versus control}

\section{Physiological falls risk}

Two studies (Sosnoff 2014; Sosnoff 2015),examined the effect of exercise versus control on physiological falls risk post-intervention measured using the Physiological Profile Assessment (PFA). There was no evidence of an effect in favour of either group with a mean difference of $0.68\left(95 \% \mathrm{Cl}-0.27\right.$ to $\left.1.63, \mathrm{I}^{2}=42 \%\right)$.

\section{Balance function}

One study examined the effect of exercise versus control on postural sway in standing post-intervention using a swaymeter (eyes open) (Carling 2017). There was no evidence of an effect in favour of the intervention with a mean difference of $-512.12(95 \% \mathrm{Cl}-6357.16$ to 5332.92). One study (Sosnoff 2014) examined the effect of exercise versus control on balance confidence post-intervention, using the Activities-Specific Balance Confidence (ABC) scale. There was no evidence of an effect in favour of the intervention with a stan- 
dardised mean difference of $5.70(95 \% \mathrm{Cl}-11.07$ to 22.47$)$. Five studies (Coote 2013; Lennon 2013; Prosperini 2013; Sosnoff 2014; Carling 2017) examined the effect of exercise versus control on balance function post-intervention, measured using the Berg Balance Scale (BBS) (Coote 2013; Lennon 2013; Sosnoff 2014; Carling 2017) and the Four Step Square Test (FSST) (Prosperini 2013). There was evidence of an effect in favour of exercise with a standardised mean difference of $0.50(95 \% \mathrm{Cl} 0.09$ to $0.92,12=66 \%)$. One study examined the effect of exercise versus control on postural sway in standing post-intervention using a swaymeter (eyes closed) (Carling 2017). There was no evidence of an effect in favour of the intervention with a mean difference of $-615.43(95 \% \mathrm{Cl}-7458.57$ to 6227.71$)$. Two studies examined the effect of exercise versus control on dynamic balance post-intervention (Four Step Square Test [4SST] and choice step reaction test) (Prosperini 2013; Hoang 2016). There was no evidence of an effect in favour of the intervention with a mean difference of $0.65\left(95 \% \mathrm{Cl}-0.04\right.$ to $\left.1.34, \mathrm{l}^{2}=59 \%\right)$.

\section{Psychological measures}

Two studies (Coote 2013; Lennon 2013) examined the effect of exercise versus control on the psychological impact of MS post-intervention, using the Multiple Sclerosis Impact Scale (psychological sub-component). There was no evidence of an effect in favour of either group with a mean difference of $5.52(95 \% \mathrm{Cl}-3.90$ to 14.95 , $12=83 \%$ ). One study (Lennon 2013) examined the effect of exercise versus control on MS self-efficacy, post-intervention using the Multiple Sclerosis Self-Efficacy (MSSE) scale. There was evidence of an effect in favour of the control group with a mean difference of -7.58 $(95 \% \mathrm{Cl}-12.57$ to -2.59$)$. One study (Carling 2017$)$ examined the effect of exercise versus control on falls self-efficacy post-intervention, using the Falls Efficacy Scale-International (FES-I). There was no evidence of an effect in favour of the intervention with a mean difference of -0.57 ( $95 \% \mathrm{Cl}-26.35$ to 25.21 ). One study (Prosperini 2013) examined the effect of exercise versus control on the physical and psychological impact of MS post-intervention, using the Multiple Sclerosis Impact Scale (physical and psychological sub-components). There was no evidence of an effect in favour of the intervention with a mean difference of $9.00(95 \% \mathrm{Cl}-5.73$ to 23.73$)$.

\section{Cognition}

One study (Hoang 2016) examined the effect of exercise versus control on cognition post-intervention using the Timed Up and Go-Cognitive (TUG-Cog) measure. There was no evidence of an effect in favour of the exercise with a mean difference of $0.70(95 \% \mathrm{Cl}-2.21$ to 3.61). One study (Hoang 2016) examined the effect of exercise versus control on cognition post-intervention using the Symbols Digit Modality Test (SDMT) measure. There was no evidence of an effect in favour of the exercise with a mean difference of -1.00 (95\% $\mathrm{Cl}-6.96$ to 4.96). One study (Hoang 2016) examined the effect of exercise versus control on cognition post-intervention using the Trail Making Test (TMT) measure. There was no evidence of an effect in favour of the exercise with a mean difference of $-7.10(95 \% \mathrm{Cl}-$ 25.72 to 11.52 ). One study (Hoang 2016) examined the effect of exercise versus control on cognition post-intervention using the Stroop stepping test measure. There was evidence of an effect in favour of exercise with a mean difference of 16.40 (95\% Cl 5.34 to 27.46).

\section{Mobility}

\section{Self-reported mobility}

Three studies (Lennon 2013; Sosnoff 2014; Carling 2017) examined the effect of exercise versus control on self-reported mobility post-intervention using the Multiple Sclerosis Walking Scale-12 (MSWS-12). There was evidence of an effect in favouring exercise with a mean difference of 16.30 ( $95 \% \mathrm{Cl} 9.34$ to 23.26 , $12=0 \%)$. At 3month and 6-month follow-up points only one study (Lennon 2013) examined this outcome demonstrating no evidence of an effect in favour of either group with a mean difference of $2.89(95 \% \mathrm{Cl}-5.09$ to 10.87 ) at 3-month follow-up and a mean difference of 0.70 (95\% $\mathrm{Cl}-7.71$ to 9.11 ).

\section{Long walking measures of mobility}

Four studies examined the effect of exercise versus control on long walking tests of mobility post-intervention using the Six Minute Walk Test (6MWT) (Coote 2013; Sosnoff 2014; Hoang 2016) and the Two Minute Walk Test (2MWT) Carling 2017). There was no evidence of an effect in favour of either group with a standardised mean difference of $0.18\left(95 \% \mathrm{Cl}-0.24\right.$ to $\left.0.60, \mathrm{I}^{2}=49 \%\right)$.

\section{Short walking measures of mobility}

Five studies (Lennon 2013; Prosperini 2013; Sosnoff 2014; Hoang 2016; Carling 2017) examined the effect of exercise versus control on short walking tests of mobility post-intervention (25Ft walk and $10 \mathrm{~m}$ walk) There was evidence of an effect in favour of exercise with a standardised mean difference of 0.28 ( $95 \% \mathrm{Cl} 0.07$ to $0.50,12=0 \%$ ). At 3-month and 6-month follow-up points only one study (Lennon 2013) examined this outcome demonstrating no evidence of an effect in favour of either group with a mean difference of - 0.10 (95\% $\mathrm{Cl}-0.22$ to $0.02,95 \% \mathrm{Cl}-0.01$ to 0.21 ). Three studies (Sosnoff 2014; Hoang 2016; Carling 2017) examined the effect of exercise versus control on short walking tests of mobility using the TUG measure. There was no evidence of an effect in favour of either group with a mean difference of $2.26(95 \% \mathrm{Cl}-3.24$ to $7.75, \mathrm{l} 2=81 \%)$.

\section{Functional outcome}

One study (Lennon 2013) examined the effect of exercise versus control on basic activities of daily living post-intervention using the Barthel Activities of Daily Living scale. There was no effect in favour of exercise with a mean difference of $0.63(95 \% \mathrm{Cl} 0.07$ to 1.19).

\section{Fatigue}

Two studies examined the effect of exercise versus control on fatigue post-intervention using the Modified Fatigue Impact Scale (MFIS) (Coote 2013) and the Fatigue scale for Motor and Cognitive functions (Carling 2017). There was no effect in favour of the intervention (standardised mean difference $0.24,95 \% \mathrm{Cl}-0.14$ to 0.61 , $12=16 \%)$.

\section{Cost effectiveness}

None of the studies reported data on cost-effectiveness.

\section{- Education versus control}

\section{Physiological falls risk}

One study examined the effect of education versus control on physiological falls risk post-intervention using the PPA (Sosnoff 2015). There was no effect in favour of the intervention with a mean difference of $0.40(95 \% \mathrm{Cl}-1.37$ to 0.57$)$. 
- Exercise and education versus control

\section{Physiological falls risk}

One study examined the effect of exercise plus education versus control on physiological falls risk post-intervention using the PPA (Sosnoff 2015). There was no effect in favour of the intervention with a mean difference of $0.50(95 \% \mathrm{Cl}-0.79$ to 1.79$)$.

\section{- Yoga versus control}

\section{Balance function}

One study examined the effect of yoga exercise versus control on balance function post-intervention using the BBS (Coote 2013). There was no e effect in favour of the intervention with a MD of 6.10 , $95 \% \mathrm{Cl}-1.67$ to $13.87, \mathrm{p}=0.12$.

\section{Psychological measures}

One study examined the effect of yoga exercise versus control on the psychological impact of MS post-intervention using the MSISpsychological sub-component (Coote 2013). There was no effect in favour of the intervention with a mean difference of $2.05(95 \% \mathrm{Cl}$ 1.89 to 5.99 ).

\section{Fatigue}

One study examined the effect of yoga exercise versus control on fatigue post-intervention using the MFIS (Coote 2013). There was no effect in favour of the intervention with a mean difference of 10.10 ( $95 \% \mathrm{Cl}-2.16$ to 22.36 ).

\section{- Individual exercise versus contro}

\section{Balance function}

One study examined the effect of individual exercise versus control on balance function post-intervention using the BBS (Coote 2013). There was an effect in favour of the individual exercise group with a mean difference of 12.40 ( $95 \% \mathrm{Cl} 6.33$ to 18.47).

\section{Psychological measures}

One study examined the effect of individual exercise versus control on the psychological impact of MS post-intervention using the MSIS-psychological sub-component (Coote 2013). There was no effect in favour of the intervention with a mean difference of 0.44 $(95 \% \mathrm{Cl}-3.06$ to 3.94$)$.

\section{Fatigue}

One study examined the effect of individual exercise versus control on fatigue post-intervention using the MFIS (Coote 2013). There was no effect in favour of the intervention with a mean difference of 3.10 (95\% $\mathrm{Cl}-5.57$ to 11.77 ).

\section{Comparison 2: Falls intervention versus another falls intervention}

\section{- Functional electrical stimulation versus exercise}

\section{Psychological measures}

One study examined the effect of FES versus exercise on the psychological impact of MS post-intervention using the MSIS-29 (Taylor 2014). There was no effect in favour of either group with a mean difference of $-13.90(95 \% \mathrm{Cl}-30.29$ to 2.49$)$.

\section{Mobility}

One study examined the effect of FES versus exercise on mobility post-intervention using $10 \mathrm{~m}$ walking speed (Taylor 2014). There was no effect in favour of either group with a mean difference of $0.22(95 \% \mathrm{Cl}-0.57$ to 1.02$)$.

\section{- Exercise versus education}

\section{Physiological falls risk}

One study examined the effect of exercise versus education on the physiological falls risk post-intervention using the PFA (Sosnoff 2015). There was no effect in favour of the intervention with a mean difference of $0.60(95 \% \mathrm{Cl}-0.41$ to 1.61$)$.

\section{Balance function}

One study examined the effect of exercise versus education on computerised balance assessment post-intervention (Stephens 2001). There was no effect in favour of the intervention with a mean difference of $0.37(95 \% \mathrm{Cl}-0.19$ to 0.92$)$. One study examined the effect of exercise versus education on balance confidence post-intervention using the $A B C$ scale (Stephens 2001). There was no effect in favour of the intervention with a mean difference of - 5.73 (95\% $\mathrm{Cl}-25.37$ to 13.91$)$.

\section{Psychological measures}

One study examined the effect of exercise versus education on selfefficacy post-intervention using the MSSE (Stephens 2001). There was no effect in favour of the intervention with a mean difference of $12.80(95 \% \mathrm{Cl}-23.70$ to 49.30$)$.

\section{- Exercise plus education versus exercise \\ Physiological falls risk}

One study examined the effect of exercise plus education versus exercise on the physiological falls risk post-intervention using the PFA (Sosnoff 2015). There was non effect in favour of either group with a mean difference of $-0.90(95 \% \mathrm{Cl}-2.22$ to 0.42$)$.

\section{-Exercise plus education versus education}

\section{Physiological falls risk}

One study examined the effect of exercise plus education versus exercise on the physiological falls risk post-intervention using the PFA (Sosnoff 2015). There was no effect in favour of either group with a mean difference of -0.90 ( $95 \% \mathrm{Cl}-2.22$ to 0.42$)$.

\section{- Sensory integration balance training versus conventional rehabilitation}

\section{Quality of life}

One study examined the effect of Sensory Integration Balance Training (SIBT) versus conventional rehabilitation on quality of life post-intervention using the MS Quality of Life-54 scale (mental component) (Gandolfi 2015). There was no effect in favour of either group with a mean difference of $2.23(95 \% \mathrm{Cl}-4.62$ to 9.08). No evidence of an effect was evident at one-month follow-up with a mean difference of - $0.06(95 \% \mathrm{Cl}-6.99$ to 6.87$)$. One study examined the effect of SIBT versus conventional rehabilitation on quality of life post-intervention using the MS Quality of Life- 54 scale (physical component) (Gandolfi 2015). There was no effect in favour of either 
group with a mean difference of $5.92(95 \% \mathrm{Cl} 1.51$ to 10.33). The effect was in favour of the SIBT group at one-month follow-up (mean difference $5.02,95 \% \mathrm{Cl} 0.2$ to 9.82 ).

\section{Balance function}

One study examined the effect SIBT versus conventional rehabilitation on balance function using the BBS (Gandolfi 2015). There was an effect in favour of SIBT with a mean difference of $4.98(95 \% \mathrm{CI}$ 2.88 to 7.08 ). This effect was also evident at one-month follow-up with a mean difference of $4.59(95 \% \mathrm{Cl} 2.56$ to 6.62$)$. One study examined the effect of sensory integration balance training versus conventional rehabilitation on balance confidence post-intervention using the ABC scale (Gandolfi 2015). There was an effect in favour of SIBT with a mean difference of $8.97(95 \% \mathrm{Cl} 0.94$ to 17.00$)$. This effect was maintained at one-month follow-up (mean difference $8.43,95 \% \mathrm{Cl} 0.92$ to 15.94$)$.

\section{Fatigue}

One study examined the effect of sensory integration balance training versus conventional rehabilitation on fatigue post-intervention using the Fatigue Severity Scale (FSS) (Gandolfi 2015). There was no effect in favour of either group with a mean difference of $0.73(95 \%$ $\mathrm{Cl}-0.01$ to 1.45). There was no evidence of an effect in favour of the SIBT at one-month follow-up with a mean difference of 1.25 (95\% $\mathrm{Cl} 0.55$ to 1.95$)$.

\section{- Motor and sensory balance rehabilitation versus motor balance rehabilitation}

\section{Balance function}

One study examined the effect of motor and sensory balance rehabilitation versus motor balance rehabilitation on balance function (BBS) (Cattaneo 2007). There was no effect in favour of either group with a mean difference of $1.65(95 \% \mathrm{Cl}-2.06$ to 5.36). One study examined the effect of motor and sensory balance rehabilitation versus motor balance rehabilitation on balance confidence post-intervention using the $A B C$ scale (Cattaneo 2007).There was no effect in favour either group with a mean difference of - 10.78 (95\% Cl - 23.27 to 1.71$)$.

\section{- Motor and sensory balance rehabilitation versus conventional rehabilitation}

\section{Balance function}

Two studies examined the effect of motor and sensory balance rehabilitation versus conventional rehabilitation on balance function post-intervention using the BBS (Cattaneo 2007; Cattaneo 2016). There was no effect in favour of either group with a mean difference of $4.01(95 \% \mathrm{Cl}-3.90$ to $11.92, \mathrm{l} 2=89 \%)$. Two studies examined the effect of motor and sensory balance rehabilitation versus conventional rehabilitation on balance confidence post-intervention using the ABC scale (Cattaneo 2007; Cattaneo 2016). There was no effect in favour of either group with a mean difference of - $3.82(95 \% \mathrm{Cl}$ 8.63 to $0.98,12=0 \%)$.

\section{Mobility}

Two studies examined the effect of of motor and sensory balance rehabilitation versus conventional rehabilitation on mobility (DGI) (Cattaneo 2007, Cattaneo 2016). There was no effect in favour of either group with a mean difference of $2.01(95 \% \mathrm{Cl}-3.48$ to 7.49 , $\left.1^{2}=86 \%\right)$. One study examined the effect of motor and sensory balance rehabilitation versus conventional rehabilitation on mobility (TUG) (Cattaneo 2016). There was no effect in favour of either group with a mean difference of $0.10(95 \% \mathrm{Cl}-1.70$ to 1.90$)$.

\section{- Motor balance rehabilitation vs conventional non balance} rehabilitation

\section{Balance function}

One study examined the effect of motor balance rehabilitation versus conventional non balance rehabilitation on balance function (BBS) post-intervention (Cattaneo 2007). There was an effect in favour of the motor balance rehabilitation group with a mean difference of 6.75 ( $95 \% \mathrm{Cl} 1.09$ to 12.41 ). One study examined the effect of motor balance rehabilitation versus conventional non balance rehabilitation on balance confidence (ABC) (Cattaneo 2007). There was no effect in favour of either group with a mean difference of $6.81(95 \% \mathrm{Cl}-6.54$ to 20.16$)$.

\section{Mobility}

One study examined the effect of motor and sensory balance rehabilitation versus conventional non balance rehabilitation on mobility (DGI) (Cattaneo 2007). There was no effect in favour of either group with a mean difference of $1.83(95 \% \mathrm{Cl}-2.83$ to 6.49$)$.

\section{- Group exercise versus Yoga}

\section{Balance function}

One study examined the effect of group exercise versus yoga on balance function (BBS) (Coote 2013). There was an effect in favour of the exercise group with a mean difference of $6.60(95 \% \mathrm{Cl} 0.49$ to 12.71).

\section{Psychological measures}

One study examined the effect of group exercise versus yoga on the psychological impact of MS post-intervention using the MSIS-29 scale (Coote 2013). There was no effect in favour of either group with a mean difference of $-0.84(95 \% \mathrm{Cl}-3.62$ to 1.94$)$.

\section{Fatigue}

One study examined the effect of group exercise versus yoga on fatigue post-intervention using the MFIS (Coote 2013). There was no effect in favour of either group with a mean difference of - $3.10(95 \%$ $\mathrm{Cl}-13.37$ to 7.17$)$.

\section{- Group exercise versus individual exercise}

\section{Balance function}

One study examined the effect of group exercise versus individual exercise on balance function (BBS) post-intervention (Coote 2013). There was no effect in favour of either group with a mean difference of $0.30(95 \% \mathrm{Cl}-3.41$ to 4.01$)$.

\section{Psychological measures}

One study examined the effect of group exercise versus individual exercise on the psychological impact of MS post-intervention using the MSIS-29 scale (Coote 2013). There was no e effect in favour of either group with a mean difference of $0.77(95 \% \mathrm{Cl}-1.34$ to 2.88$)$.

Fatigue 
One study examined the effect of group exercise versus individual exercise on fatigue post-intervention using the MFIS (Coote 2013). There was no effect in favour of either group with a mean difference of $3.90(95 \% \mathrm{Cl}-1.59$ to 9.39$)$.

\section{- Individual exercise versus yoga}

\section{Balance function}

One study examined the effect of individual exercise versus yoga on balance function (BBS) (Coote 2013). There was no e effect in favour of either group with a mean difference of $6.30(95 \% \mathrm{Cl}-0.02$ to 12.62 ).

\section{Psychological measures}

One study examined the effect of individual exercise versus yoga on the psychological impact of MS post-intervention using the MSIS-29 scale (Coote 2013). There was no effect in favour of either group with a mean difference of $-1.61(95 \% \mathrm{Cl}-4.63$ to 1.41$)$.

\section{DISCUSSION}

\section{Summary of main results}

Despite the fact that the development and evaluation of interventions to reduce falls for people with MS has received increased scientific interest in the last decade, the evidence base presented in this review demonstrates many important unanswered questions and methodological short-comings.

We included 13 RCTs or cross-over RCTs in this review. These studies included either exercise interventions (of various delivery mechanism), functional electrical stimulation interventions, education interventions or interventions comprising multiple intervention components, e.g. exercise plus education. The included trials were of mixed quality, with many of them not adhering to the CONSORT guidelines (Moher 2012) and demonstrating mixed risk of bias throughout (see "Assessment of risk of bias in included studies").

\section{Comparison 1: Falls prevention interventions versus control}

Previous Cochrane reviews of falls interventions for older adults grouped trials by exercise modality into six categories using the ProFaNE taxonomy (Gillespie 2012). However for the first comparison, comparing falls prevention interventions to controls, in the current review we treated exercise as a single intervention and did not report results based on different sub-groupings of exercise modality. The rationale for pooling different types of exercise interventions and comparing to controls, relates to the scarcity of studies within this comparison.

Pooled comparisons post-intervention (immediately post-intervention in the included studies) between exercise and controls for any of the primary falls outcomes, demonstrated no evidence of an effect in favour of exercise compared to controls (Summary of findings for the main comparison). Relating to the pooled rate of falls outcome, which is recommended as the gold standard measurement of falls in MS trials (Coote 2014), there was a non-significant effect in favour of exercise compared to controls. However, due to the "very low" and "low" GRADE grading for the primary outcomes, there is uncertainty on the effect of exercises on prevention of falls compared to control.
For all of the other comparisons between falls interventions and controls, pooling of falls data across studies was not possible due to the heterogeneity of the interventions being tested. Results demonstrated that there was no evidence of an effect in favour of education, exercise plus education or yoga over control interventions for any of the falls outcomes. To our knowledge, this is the first review to aim to include falls prevention interventions, other than exercise-only interventions.

Mobility dysfunction has been demonstrated to be an independent risk factor for falls in MS (Gunn 2013). Our results demonstrated that there was pooled evidence from five studies demonstrating a positive effect of exercise compared with controls for self-reported mobility (Lennon 2013; Prosperini 2013; Sosnoff 2014; Hoang 2016; Carling 2017) and three studies for short objective walking tests (Lennon 2013; Sosnoff 2014; Carling 2017). Again, caution is needed in the interpretation of these results, given the wide nature of the confidence intervals presented.

There was no evidence from the included studies to demonstrate support of exercise interventions for the improvement of other secondary outcomes such as physiological falls risk, fatigue, long walking tests of mobility/walking endurance, and cognition.

\section{Comparison 2: Falls prevention interventions versus other in- tervention}

Due to the scarcity of data for pooling across all comparisons, there were data available from only two studies (Esnouf 2010; Taylor 2014), for two of our main outcomes only (number of falls per person and rate of falls), for the comparison between FES and exercise interventions. Summary results demonstrate no evidence in favour of FES or exercise for falls prevention among people with MS.

The substantial heterogeneity evident in the other types of interventions included in the studies in this comparison precluded pooling data for all other outcomes, and therefore we have presented results of individual studies per outcome (see the Effects of interventions section).

\section{Overall completeness and applicability of evidence}

\section{Participants}

As the majority of trials specifically excluded people who presented with severe disability due to MS, the results of this review may not be applicable to this group of people at risk. Participant characteristics did not vary greatly due to the recruitment methods used, and the inclusion and exclusion criteria applied. Participants in the majority of studies included people with mild to moderate severity of MS. Some trials recruited people being treated in hospital clinics, while the majority included people living in the community. None of the trials exclude people based on their falls history.

\section{Interventions}

Interventions to reduce falls are complex in nature and therefore more detail is required in published trials regarding what participants are experiencing in both the intervention and comparison groups. The description of the intervention and control groups in many of the studies could have been improved upon. Guidelines such as the Template for Intervention Description and Replication (TIDieR) (Hoffmann 2014) are essential for future trials including falls interventions. At protocol stage we planned to examine the ef- 
fectiveness of single, multiple- and multifactorial interventions to reduce falls rate. However, given the low number of studies available for inclusion, the scarcity of multiple-component interventions (only one study included a combined exercise and education intervention (Sosnoff 2015), and the complete lack of multi-factorial interventions, this was not possible in the current review. Given the established effectiveness of multi-factorial interventions to target known risk factors for falls in older adult populations (Gillespie 2012), there is strong rationale for the evaluation of such multi-factorial interventions in MS populations. The effectiveness of interventions targeting most risk factors for falls in MS has not been well researched or established. While the identification of risk factors for falling in MS has received increased scientific interest in the last decade, there is still much clarification needed regarding the most suitable factors to target in interventions. Gunn 2013 conducted a systematic review and meta-analysis of falls risk factors in MS and identified 20 risk factors. Due to the heterogeneity of included studies, pooled meta-analysis was feasible for only four individual risk factors: impairments of balance (Odds ratio: $1.07,95 \% \mathrm{Cl} 1.04$ to 1.10); use of a mobility aid (OR: $2.5,95 \% \mathrm{Cl} 2.21$ to 2.83 ); cognitive impairments (OR:1.28, $95 \% \mathrm{Cl} 1.2$ to 1.36 ) and; progressive versus relapse-remitting MS (OR:1.98, $95 \% \mathrm{Cl} 1.39$ to 2.80 ). This is in notable contrast to the older adult literature, wherein over 400 risk factors for falls have been identified Oliver 2004). Gaps include the examination of interventions addressing the management of urinary incontinence, medical interventions, and environmental modifications among people with MS.

\section{Outcomes}

We sought data for rate of falls and number of people falling. Few studies provided falls rate data. As the analyses demonstrate, some studies provided data for both falls and fallers, as recommended by the ProFaNE network (Lamb 2005; Lamb 2011) and the International MS FAlls Prevention Research Network (IMSFPRN) (Coote 2014; Sosnoff 2014b). Other studies provided data only for one or other fall outcome.

The selection of outcomes in the included trials also highlights some limitations. The fact that the outcome of interest, falling, was not always defined, is notable. Comparability of future research findings would be facilitated by adoption of the consensus definition of a fall as "an unexpected event in which the participants come to rest on the ground, floor, or lower level" developed for trials in clinical populations by the ProFaNE network (Lamb 2005; Lamb 2011) and recommended for use in MS trials by the the IMSFPRN (Coote 2014; Sosnoff 2014b). The included studies also illustrated the wider problems of variation in the methods of ascertaining, recording, analysing, and reporting falls. Studies should use consensus recommendations (IMSFPRN) for conducting fall prevention trials which include the daily recording of falls, with biweekly phone reminders, monthly returns and follow-up by the researchers blind to group allocation, with a falls data collection period of at least three months in duration (Coote 2014). In the current review, only one study included a measure of falls rate (Taylor 2014) and only eight studies used a prospective method to collect falls data (Esnouf 2010; Lennon 2013; Prosperini 2013; Taylor 2014; Gandolfi 2015; Sosnoff 2015; Hoang 2016; Carling 2017), and seven studies collected data for three months in duration (Esnouf 2010; Coote 2013; Lennon 2013; Prosperini 2013; Sosnoff 2014; Sosnoff 2015; Hoang 2016).
The current review aimed to examine the effectiveness of falls interventions on a large breadth of secondary outcomes, including balance function, function, mobility, fatigue, cognition, physiological falls risk. The results demonstrate that while balance and mobility outcomes were relatively well-addressed in the included studies, there are substantial gaps in terms of potentially important patient-oriented and cost-related outcomes which need to be considered in subsequent trials of falls interventions in MS. Of the 13 included studies only one study included measures of cognition (Hoang 2016) and only three studies included falls self-efficacy as an outcome (Carling 2017). Given that cognitive impairment is an established risk factor for falling in MS (Gunn 2013) and reduced self-efficacy related to falls has been identified as an independent risk factor for falling in MS (Matsuda 2012), future falls prevention trials need to consider these important outcomes. Of note, the costeffectiveness of included interventions was not examined by any of the included studies, demonstrating an important outcome for inclusion in future trials of falls prevention interventions in MS.

\section{Quality of the evidence}

This review containing 13 trials (839 participants) provides uncertain evidence regarding the effect in favour of exercise interventions compared to treatment as usual control for reducing falls rate, number of fallers and adverse events in people with MS. Results have highlighted some evidence in favour of exercise interventions compared with controls for balance function and mobility. However, there are some methodological flaws in the included studies to be considered when interpreting the results. The quality of the evidence base investigating the effectiveness of interventions to reduce falls for people with MS is mixed, with nine studies demonstrating high risk of bias for various methodological short-comings.

We identified a high risk of selection bias associated with allocation concealment in one study (Lennon 2013), detection bias associated with lack of blinding of outcome assessment in one study (Cattaneo 2007), attrition bias due to incomplete outcome data in two studies (Lennon 2013; Taylor 2014) and reporting bias due to selective reporting in seven studies ( Coote 2013; Lennon 2013; Sosnoff 2014; Gandolfi 2015; Sosnoff 2015; Cattaneo 2016; Hoang 2016). Many of the included studies were also judged to demonstrate an unclear RoB, mostly owing to inadequate reporting of methods used. This demonstrates the need for increased focus on issues related to bias when conducting future trials of falls preventions interventions in MS.

Using the GRADE criteria, we examined the overall quality of the evidence for this summary comparison. It is worth noting that the certainty of evidence across all of the main outcomes in this comparison is very low to low, indicating limited confidence in the estimate of the effects. In addition to the scarcity of available studies to meta-analyse, therefore the results need to be interpreted with caution. Using GRADE criteria, we considered the evidence to be of very low to low certainty for all of the main falls outcomes included in this review. Given the relatively small evidence base presented for many of the outcomes, further research is likely to have an important impact on our confidence in the estimate of effect and may change the estimate of these outcomes.

\section{Potential biases in the review process}

One of the review authors was a lead investigator in one of the included studies (Coote 2013). However, two authors independently 
extracted data and determined risk of bias in included studies, that of which was cross-checked by a third reviewer, limiting any potential bias.One our the review author, SC, is the author of one of the included studies and the RoB assessment for this study was completed independently by two other authors (SH and RG).

We attempted to minimise publication bias in the review by searching multiple databases and contacting authors of studies identified in trials registers that were ongoing or completed, but for which full reports had not been identified. We included one study not published as full reports (Lennon 2013) and obtained supplementary information from the authors of many of the included studies, in particular around the acquisition of additional falls outcomes. We also availed of translation services to aid screening of studies published in languages other than English.

\section{Agreements and disagreements with other studies or reviews}

This is the first systematic review and meta-analysis of interventions to examine the effectiveness of any intervention to reduce falls in people with MS. Gunn 2015 conducted a robust systematic review and meta-analysis of exercise interventions and therefore the current review differs by extending the search beyond exercise or physical therapy only interventions. Unlike the Gunn 2015 review, we have excluded studies that did not include a falls outcome. The current review used data available in published papers, in addition to accessing unpublished data (Lennon 2013) and thus provides a more exhaustive picture of the falls prevention intervention evidence base. Gunn 2015 did not report falls rate using rate ratios, which is the recommended primary outcome for falls in MS trials (Coote 2014). Our findings compare with the meta-analysis conducted by Gunn 2015, wherein the number of fallers data from two studies (Cattaneo 2007; Coote 2013) were pooled to demonstrate no evidence of effect in favour of exercise. We have accessed additional data from an unpublished study (Lennon 2013) and three more recent trials (Sosnoff 2014; Sosnoff 2015; Carling 2017) to add to this evidence base. Similarly, our meta-analysis demonstrates no evidence of an effect in favour of exercise over controls for number of fallers.

In relation to secondary outcomes, the current results demonstrated that there was evidence of a positive effect of exercise interventions compared to controls for the improvement of balance function. This finding is in line with the meta-analysis conducted by Gunn 2015. While we have added new data to the metaanalysis completed by Gunn et al (2015), the demonstrated effect size is moderate in nature and the statistical heterogeneity noted $(12=66 \%)$ is likely due to the differences in exercise types across studies. Of further note, the $\mathrm{Cl}$ 's presented in the current review are wide in nature, and therefore the pooled, significant SMD needs to be interpreted with caution. A systematic review and meta-analysis of cross-sectional, cohort and experimental trial studies (Gunn 2013) demonstrates that the impairment of balance function is an independent risk factor for falls among people with MS and therefore provides rationale for the targeting of improved balance function in falls prevention interventions.

The conclusions based on the data presented in the current review do not allow for recommendations in favour of falls interventions to reduce falls outcomes in people with MS. This is in agreement with the conclusion of Gunn 2015, wherein the authors reported a non-significant modest reduction in risk of falling ( $R R=0.75,95 \% \mathrm{Cl}$
0.12 to 4.80)- based on data from two exercise studies (Coote 2013; Cattaneo 2007). Similar to the pooled risk ratio reported by Gunn 2015, the current review reported a non-significant reduction in risk of falling among people with MS, based on five studies (Coote 2013; Lennon 2013; Sosnoff 2014; Sosnoff 2015; Carling 2017) of exercise interventions.

\section{AUTHORS' CONCLUSIONS}

\section{Implications for practice}

People with MS fall frequently and are often offered clinical interventions to reduce falls rate. However, their effectiveness has not been established. We used a comprehensive, transparent, and pragmatic system for rating the quality of the evidence (i.e. the GRADE approach) for falls rate, risk of falls and adverse events outcomes; and according to this approach, any estimate of effect based on very low to low quality evidence is uncertain, and further research may change the estimate. The current systematic review and meta-analysis has found that evidence in support of interventions for preventing falls in MS is sparse and does not currently demonstrate significantly positive results for falls outcomes. The evidence base demonstrates mixed risk of bias, with very low to low certainty of the evidence for the primary outcomes. There is some evidence to suggest that exercise-based falls interventions are effective in improving balance function and mobility outcomes among people with MS. The results did not demonstrate that the included interventions caused harm among people with MS, however, this is to be interpreted with caution as the majority of the studies did not report adverse events.

\section{Implications for research}

Of note, a significant gap in the current evidence base relates to the fact that none of the included studies included an economic evaluation, which has particular implications for future trials of falls interventions in MS, in terms of establishing the cost-effectiveness of interventions. This involves measuring health- related quality of life as an outcome, defining the perspective and timeframe for costs, collecting data on healthcare use, costing healthcare resources, calculating cost-effectiveness ratios (if the intervention is effective in reducing falls), and evaluating uncertainty.

Given the high risk of bias and methodological limitations demonstrated in nine of the included studies and the very low to low quality GRADE findings for selected clinically-important, falls-related outcomes, there are some methodological considerations for future trials in this area:

- Studies evaluating fall prevention should be adequately powered and use a contemporary standard definition of a fall (Lamb 2005).

- Falls should be measured prospectively, recorded daily and monitored monthly.

- Fall events should be reported by group as total number of falls, fallers, and people sustaining a fall-related injury; rate of falls (falls per person year); and number in each analysis.

- Design and reporting of trials should meet the contemporary standards of the CONSORT statement (Moher 2012) and the Tidier statement (Hoffmann 2014), respectively. 
A substantial gap identified by the current systematic review is the lack of multifactorial falls prevention interventions for people with MS. Given the effectiveness of multifactorial interventions for reducing falls rate in older adult populations (Gillespie 2012), there is strong theoretical rationale for the design, delivery and evaluation of such interventions that specifically target physiological falls risk factors among people with MS. Further robust RCTs of high methodological quality examining the effectiveness of multifactorial falls prevention interventions on falls outcomes are needed.

Another gap identified by this systematic review relates to the sparsity of evidence on falls prevention interventions among older people with MS. Falls and fall-related injuries are common and a serious problem in older people. People over 65 years of age have the high- est risk of falling. The rate of fall-related injuries also increases with age (Peel 2002). However, none of the included studies targeted an older MS population. There is a breadth of research examining the effectiveness of falls prevention interventions, classified according to the ProFANE taxonomy (Gillespie 2012), and future trials in MS need to be cognisant of the increased risk of falls with age.

\section{ACK N O WLEDGEMENTS}

Ms. Isabella Delunois- Medical librarian at University Hospital Limerick, Ireland who contributed to the search strategy.

Mr. Lonan Hughes, School of Allied Health, University of Limerick who contributed to data extraction from included studies. 


\section{RE F E R E N C E S}

\section{References to studies included in this review}

Carling 2017 \{published data only\}

* Carling A, Forsberg A, Gunnarsson M, Nilsagård Y. CoDuSe group exercise programme improves balance and reduces falls in people with multiple sclerosis: a multi-centre, randomised,controlled pilot study. Multiple Sclerosis Journal 2017;23:1394-404

\section{Cattaneo 2007 \{published data only\}}

* Cattaneo D, Jonsdottir J, Zocchi M, Regola A. Effects of balance exercises on people with multiples sclerosis: a pilot study. Clinical Rehabilitation 2007;21:771-81.

\section{Cattaneo 2016 \{published data only\}}

* Cattaneo D, Rasova K, Gervasoni E, Dobrovodská G, Montesano A, Jonsdottir J. Falls prevention and balance rehabilitation in multiple sclerosis: a bi-centre randomised controlled trial, disability and rehabilitation. Disability and Rehabilitation 2016;40:522-6.

NCT02390830. Falls Prevention and Balance Rehabilitation in Multiple Sclerosis. https://clinicaltrials.gov/ct2/show/ NCT02390830 18/03/2015.

\section{Coote 2013 \{published data only\}}

* Coote S, Hogan N, Franklin S. Falls in people with multiple sclerosis who use a walking aid: prevalence, factors, and effect of strength and balance interventions. Archives of physical medicine and rehabilitation 2013;94:616-21.

\section{Esnouf 2010 \{published data only\}}

* Esnouf JE, Taylor PN, Mann GE, Barrett CL. Impact on activities of daily living using a functional electrical stimulation device to improve dropped foot in people with multiple sclerosis, measured by the Canadian Occupational Performance Measure. Multiple Sclerosis 2010;16:1141-7.

\section{Gandolfi 2015 \{published data only\}}

* Gandolfi M, Munari D, Geroin C, Gajofatto A, Donata Benedetti M, Midiri A, et al. Sensory integration balance training inpatients with multiple sclerosis: a randomised, controlled trial. Multiple Sclerosis Journal 2015;21:1453-62.

\section{Hoang 2016 \{published data only\}}

ACTRN12612001139864. Balance exercise for multiple sclerosis [Exercise to improve balance and reduce fall risk in people with multiple sclerosis - a pilot randomized controlled trial]. https://www.anzctr.org.au/Trial/Registration/TrialReview.aspx? id=363148 26/10/2012.

* Hoang P, Schoene D, Gandevia S, Smith S, Lord SR. Effects of a home-based step training programme on balance, stepping, cognition and functional performance in people with multiple sclerosis - a randomised controlled trial. Multiple Sclerosis Journal 2016;22:94-103.
Lennon 2013 \{published data only\}

* Lennon S. Group exercise therapy for balance and mobility in people with multiple sclerosis: a randomised controlled trial. Personal communication with author.

Prosperini 2013 \{published data only\}

* Prosperini L, Fortuna D, Giannì C, Leonardi L, Marchetti MR, Pozzilli $C$. Home-based balance training using the wiibalance board: a randomized, crossover pilot study in multiple sclerosis. Neurorehabilitation and neural repair 2013;27:516-25.

Sosnoff 2014 \{published data only\} NCT01837017. Project FARMS: fall risk reduction in multiple sclerosis. https://clinicaltrials.gov/ct2/show/NCT01837017 22/04/2013.

* Sosnoff J, Finlayson M, McAuley E, Morrison S, Motl RW. Homebased exercise program and fall-risk reduction in older adults with multiple sclerosis: phase 1 randomised controlled trial. Clinical Rehabilitation 2014;28:254-63.

Sosnoff 2015 \{published data only\}

NCT01956227. Fall risk reduction in multiple sclerosis: exercise versus behavior (FARMS-2). https://clinicaltrials.gov/ct2/show/ NCT01956227 08/10/2013.

* Sosnoff JJ, Moon Y, Wajda DA, Finlayson ML, McAuley E, Peterson EW, et al. Fall risk and incidence reduction in high risk individuals with multiple sclerosis: a pilot randomised control trial. Clinical Rehabilitation 2015;29:952-60.

Stephens 2001 \{published data only\}

* Stephens J, DuShuttle D, Hatcher C, Schumnes J, Slaninka C. Use of awareness through movement improves balance and balance confidence in people with multiple sclerosis: a randomised controlled study. Journal of neurological physical therapy 2001;25:39-49.

Taylor 2014 \{published data only\}

* Taylor P, Barrett C, Mann G, Wareham W, Swain I. A feasibility study to investigate the effect of functional electrical stimulation and physiotherapy exercise on the quality of gait of people with multiple sclerosis. Neuromodulation 2014;17:75-84.

\section{References to studies excluded from this review}

ACTRN12612000218897 \{published and unpublished data\}

* ACTRN12612000218897. Investigating fatigue, balance, falls and mobility in people with multiple sclerosis. https:// www.anzctr.org.au/Trial/Registration/TrialReview.aspx? ACTRN=12612000218897 21/02/2012.

\section{Brichetto 2015 \{published data only\}}

Brichetto G, Piccardo E, Pedullà L, Battaglia MA, Tacchino A. Tailored balance exercises on people with multiple sclerosis: a pilot randomized, controlled study. Multiple sclerosis 2015;21(8):1055-63. 
Cadorin 2015 \{published and unpublished data\}

Cadorin C, Stabile MR, Rossi S, Boscolo E, Vendramin A, Campagnolo $D$, et al. A comparison between two technological tools for balance training in patients with progressive multiple sclerosis: a pilot study. Multiple sclerosis journal 2015;21:503.

\section{Cakt 2010 \{published data only\}}

Cakt BD, Nacir B, Genç H, Saraçoğlu M, Karagöz A, Erdem HR, et al. Cycling progressive resistance training for people with multiple sclerosis: a randomized controlled study. American journal of physical medicine and rehabilitation 2010;89:446-57.

Eftekharsadat 2015 \{published data only\}

Eftekharsadat B, Babaei-Ghazani A, Mohammadzadeh M, Talebi M, Eslamian F, Azari E. Effect of virtual reality-based balance training in multiple sclerosis. Neurological research 2015;37:539-44.

\section{Forsberg 2016 \{published and unpublished data\}}

Forsberg A, von Koch L, Nilsagård Y. Effects on balance and walking with the CoDuSe balance exercise program in people with multiple sclerosis: a multicenter randomized controlled trial. Multiple sclerosis international 2016;2016:7076265.

Francavilla 2015 \{published and unpublished data\} Francavilla G, Sgarito C, Brichetto G, Battaglia MA, Lopes de Carvalho MA. Randomized controlled trial about effectiveness of personalized treatment of balance disorders in multiple sclerosis: integration of visual, proprioceptive and vestibular components. American academy of physical medicine and rehabilitation 2015;7:s83.

Goodman 2008 \{published data only (unpublished sought but not used)\}

Goodman AD, Brown TR, Cohen JA, Krupp LB, Schapiro R, Schwid SR, et al. Dose comparison trial of sustained-release fampridine in multiple sclerosis. Neurology 2008;71:1134-41.

\section{Kalgarfard 2013 \{published data only\}}

Kargarfard M, Mehrabi M, Hamidi-Tehrani J, Rouzbahani R. Changes in speed, endurance and balance in women with multiple sclerosis after 4 and 8 weeks of aquatic exercise training. Journal of Isfahan medical school 2013;31:1628-39.

\section{Kalron 2016 \{published data only\}}

Kalron A, Fonkatz I, Frid L, Baransi H, Achiron A. The effect of balance training on postural control in people with multiple sclerosis using the CAREN virtual reality system: a pilot randomized controlled trial. Journal of neuroengineering and rehabilitation 2016;13:13.

\section{Kramer 2014 \{published data only\}}

Kramer A, Dettmers C, Gruber M. Exergaming with additional postural demands improves balance and gait in patients with multiple sclerosis as much as conventional balance training and leads to high adherence to home-based balance training. Archives of physical medicine and rehabilitation 2104;95:1803-9.

\section{Marzal Alfaro 2016 \{published data only\}}

Marzal Alfaro BM, Martin-Barbero M, Ribed A, Revuelta JL, TovarPozo M, De Lorenzo-Pinto A, et al. Adherence, quality of life and patient satisfaction with dalfampridine in clinical practice. European journal of hospital pharmacy 2016;23:A141.

McAuley 2007 \{published data only\}

McAuley E, Motl RW, Morris KS, Hu L, Doerksen SE, Elavsky S, et al. Enhancing physical activity adherence and well-being in multiple sclerosis: a randomised controlled trial. Multiple sclerosis 2007;13:652-9.

\section{Monjezi 2017 \{published data only\}}

Monjezi S, Negahban H, Tajali S, Yadollahpour N, Majdinasab N. Effects of dual-task balance training on postural performance in patients with multiple sclerosis: a double-blind, randomized controlled pilot trial. Clinical rehabilitation 2017;31:234-41.

NCT01829776 \{published and unpublished data\}

NCT01829776. Pilot study of free from falls program in multiple sclerosis (FFF). https://clinicaltrials.gov/ct2/show/NCT01829776 $11 / 04 / 2013$.

\section{Nedeljkoviü 2014 \{published data only\}}

Nedeljković U, Raspopović ED, Ilić N, Dačković J, Dujmović I. Endurance and resistance training in rehabilitation of patients with multiple sclerosis. Vojnosanit pregled 2014;71:963-8.

\section{Nilsagard 2014 \{published and unpublished data\}}

Nilsagard YE, von Koch LK, Nilsson M, Forsberg AS. Balance exercise program reduced falls in people with multiple sclerosis: a single-group, pretest-posttest trial. Archives of physical medicine and rehabilitation 2014; Vol. 95, issue 12:2428-34.

\section{O'Hara 2002 \{published data only\}}

O'Hara L, Cadbury H, De Souza L, Ide L. Evaluation of the effectiveness of professionally guided self-care for people with multiple sclerosis living in the community: a randomized controlled trial. Clinical rehabilitation 2002;16:119-28.

\section{Prosperini 2010 \{published data only\}}

Prosperini L, Leonardi L, De Carli P, ML Mannocchi, C Pozzilli. Visuo-proprioceptive training reduces risk of falls in patients with multiple sclerosis. Multiple sclerosis 2010;16:491-9.

\section{Prosperini 2014 \{published data only\}}

Prosperini L, Giannì C, Fortuna D, Marchetti MR, Pozzilli C. Oral Dalfampridine improves standing balance detected at static posturography in multiples sclerosis. Multiple sclerosis international 2014;2014:802307.

\section{Sandroff 2014 \{published data only\}}

Sandroff BM, Klaren RE, Pilutti LA, Dlugonski D, Benedict RHB, Motl RW. Randomized controlled trial of physical activity, cognition, and walking in multiple sclerosis. Journal of neurology 2014;261:363-72.

\section{Sebastiao 2017 \{published data only\}}

Sebastiãoa E, McAuley E, Shigematsu R, Motl RW. Feasibility study design and methods for a home-based, squarestepping exercise program among older adults with multiple sclerosis: The SSE-MS project. Contemporary clinical trials communications 2017;7:200-7. 
Segev-Jacubovski 2011 \{published data only\}

Segev-Jacubovski O, Herman T, Yogev-Seligmann G, Mirelman A, Giladi N, Hausdorff JM. The interplay between gait, falls and cognition: can cognitive therapy reduce fall risk? Expert review of neurotherapeutics 2011;11:1057-75.

Tarakci 2013 \{published data only\}

Tarakci E, Yeldan I, Huseyinsinoglu BE, Zenginler Y, Eraksoy M. Group exercise training for balance, functional status, spasticity, fatigue and quality of life in multiple sclerosis: a randomized controlled trial. Clinical rehabilitation 2013;27(9):813-22.

Ward 2004 \{published data only\}

Ward CD, Turpin G, Dewey ME, Fleming S, Hurwitz B, Ratib S, et al. Education for people with progressive neurological conditions can have negative effects: evidence from a randomized controlled trial. Clinical rehabilitation 2004; 18:717-25.

\section{Zenginler 2016 \{published data only\}}

Zenginler Y, Tarakci E, Kurtuncu M, Razak Ozdincler A. The impact of Nintendo Wii fit games on the balance and functionality of multiple sclerosis patients: a randomized controlled study. ECTRIMS online library. Kürtüncü M 2016;145682:EP1587.

\section{References to studies awaiting assessment}

Cattaneo 2018 \{published data only\}

Cattaneo D, Rasova K, Gervasoni E, Dobrovodska G, Montesano A, Jonsdottir J. Falls prevention and balance rehabilitation in multiple sclerosis: a bi-centre randomised controlled trial. Disability and rehabilitation 2018;40:522-6.

\section{Kannan 2017 \{published data only\}}

Kannan M, Hugos C, Hildebrand A, Wick K, Cameron M. Evaluation of a web-based fall prevention program among people with multiple sclerosis. Multiple sclerosis journal 2017;23:678.

\section{Martini 2018 \{published data only\}}

Hildebrand A, Martini D, Fling B, Cameron M. Ambulation assistive device training prevents falls, increases device satisfaction and may decrease sitting and increase walking in MS: a randomized-controlled pilot study. Neurology 2017;88(16 Supplement):S24.004.

* Martini DN, Zeeboer E, Hildebrand A, Fling BW, Hugos CL, Cameron MH. ADSTEP: preliminary investigation of a multicomponent walking aid program in people with multiple sclerosis. Archives of physical medicine and rehabilitation 2018;99:2050-8.

\section{References to ongoing studies}

ACTRN12616000415404 \{published and unpublished data\} ACTRN12616000415404. Do interventions targeting proprioceptive feedback and exercise improve functional gait and reduce falls and falls risk in people with MS?. https://
www.anzctr.org.au/Trial/Registration/TrialReview.aspx? id=370297 31/03/2016

ACTRN12616001053415 \{unpublished data only\}

ACTRN12616001053415. An interactive step training system to reduce falls in people with multiple sclerosis: a randomised controlled trial. https://www.anzctr.org.au/Trial/Registration/ TrialReview.aspx?id=370671 05/08/2016.

Hatton 2016 \{unpublished data only\}

Hatton AL, Dixon J, Rome K, Brauer SG, Williams K, Kerr G. The effects of prolonged wear of textured shoe insoles on gait, foot sensation and proprioception in people with multiple sclerosis: study protocol for a randomised controlled trial. Trials 2016;17:10.1186/s13063-016-1337-x.

ISRCTN13587999 (Gunn 2017) \{published and unpublished data\} ISRCTN13587999. Balance right in multiple sclerosis. https:// doi.org/10.1186/ISRCTN13587999 29/09/2016.

NCT02314585 \{published and unpublished data\}

NCT02314585. Fall risk reduction in multiple sclerosis (FIRMS). https://clinicaltrials.gov/ct2/show/NCT02314585 11/12/2014.

NCT02583386 \{published and unpublished data\}

NCT02583386. Comprehensive fall prevention and detection in multiple sclerosis (FFF). https://clinicaltrials.gov/ct2/show/ NCT02583386 22/10/2015.

NCT02694666 \{published data only\}

NCT02694666. Vibration training for preventing falls in healthy population and multiple sclerosis. https://clinicaltrials.gov/ct2/ show/NCT02694666 29/02/2016.

\section{NCT02885233 \{published and unpublished data\}}

NCT02885233. Evaluation of a web-based fall prevention program on people with multiple sclerosis. https:// clinicaltrials.gov/ct2/show/NCT02885233 31/08/2016.

\section{Additional references}

\section{Bazelier 2011}

Bazelier MT, van Staa T, Uitdehaag BM, Cooper C, Leufkens HG, Vestergaard $P$, et al. The risk of fracture in patients with multiple sclerosis: the UK general practice research database. Journal of bone and mineral research 2011;26:2271-9.

\section{Berg 1989}

Berg K, Wood-Dauphinee S, Williams JI, Gayton D. Measuring balance in the elderly: preliminary development of an instrument. Physiotherapy Canada 1989;41:304-11.

\section{Browne 2014}

Browne P, Chandraratna D, Angood C, Tremlett H, Baker C, Taylor BV, et al. Atlas of multiple sclerosis 2013: a growing global problem with widespread inequity. Neurology 2014;83:1022-4.

\section{Cameron 2012}

Cameron ID, Gillespie LD, Robertson MC, Murray GR, Hill KD, Cumming RG, et al. Interventions for preventing falls in 
older people in care facilities and hospitals. Cochrane Database of Systematic Reviews 2012, Issue 12. [DOI: 10.1002/14651858.CD005465]

\section{Carling 2017a}

Carling A, Forsberg A, Gunnarsson M, Nilsagard Y. [Request for additional results [personal communication]]. Email to $A$ Carling 20-03-2018.

\section{Cattaneo 2016a}

Cattaneo D, Rasova K, Gervasoni E, Dobrovodska G, Montesano A, Jonsdottir J. [Request for additional results [personal communication]]. Email D Cattaneo 22-06-2018.

\section{Coote 2013a}

Coote S, Hogan N, Franklin S. [Request for additional results [personal communication]]. Email to S Coote 06-03-2018.

\section{Coote 2013b}

Coote SC, Hogan N, Franklin S. Falls in people with multiple sclerosis who use a walking aid: prevalence, factors and effect of balance and strength interventions. Archives of physical medicine and rehabilitation 2013;94:616-21.

\section{Coote 2014}

Coote S, Sosnoff JJ, Gunn H. Fall incidence as the primary outcome in multiple sclerosis falls-prevention trials: recommendation from the international MS falls prevention research network. International journal of multiple sclerosis care 2014;16:178-84.

\section{Esnouf 2010a}

Esnouf JE, Taylor PN, Mann GE, Barrett CL. [Request for additional results [personal communication]]. Email to $P$ Taylor 22-06-2018.

\section{Finlayson 2010}

Finlayson M, Peterson E. Falls, aging and disability. Physical medicine and rehabilitation clinics of North America 2010;21:357-73.

\section{Fischer 1999}

Fischer JS, LaRocca NG, Miller DM, Ritvo PG, Andrews H, Paty D. Recent developments in the assessment of quality of life in multiple sclerosis (MS). Multiple sclerosis 1999;5:251-9.

\section{Franchignoni 2010}

Franchignoni FF, Horak M, Godi A, Nardone A, Giordano A. Using psychometric techniques to improve the balance evaluation systems test: the mini-BESTest. Journal of rehabilitation medicine 2010;42:323-31.

\section{Fry 2006}

Fry DK, Pfalzer LA. Reliability of four functional tests and rating of perceived exertion in persons with multiple sclerosis. Physiotherapy Canada. Physiotherapie Canada 2006;58:212-20.

\section{Gillespie 2003}

Gillespie LD, Gillespie WJ, Robertson MC, Lamb SE, Cumming RG, Rowe BH. Interventions for preventing falls in elderly people. Cochrane Database of Systematic Reviews 2003, Issue 4. [DOI: 10.1002/14651858.CD000340]

\section{Gillespie 2012}

Gillespie LD, Robertson MC, Gillespie WJ, Sherrington C, Gates S, Clemson LM, et al. Interventions for preventing falls in older people living in the community. Cochrane Database of Systematic Reviews 2012, Issue 9. [DOI: 10.1002/14651858.CD007146]

\section{Gunn 2013}

Gunn HJ, Newell P, Haas B, Marsden JF, Freeman JA. Identification of risk factors for falls in multiple sclerosis: a systematic review and meta-analysis. Physical therapy 2013;93:504-13.

\section{Gunn 2015}

Gunn H, Markevics S, Haas B, Marsden J, Freeman J. Systematic review: the effectiveness of interventions to reduce falls and improve balance in adults with multiple sclerosis.. Archive of physical and medical rehabilitation 2015;96:1898-912.

\section{Higgins 2011}

Higgins JPT, Green S. Cochrane Handbook for Systematic Reviews of Interventions Version 5.1.0 [updated March 2011]. The Cochrane Collaboration, 2011. Available from www.cochrane-handbook.org.

\section{Hoang 2016a}

Hoang P, Schoene D, Gandevia S, Smith S, Lord SR. [Request for additional results [personal communication]]. Email to $\mathrm{P}$ Hoang 12-07-2018.

\section{Hobart 2001}

Hobart J, Lamping D, Fitzpatrick R, Riazi A, Thompson A. The Multiple Sclerosis Impact Scale (MSIS-29): a new patient-based outcome measure. Brain 2001;124:962-73.

\section{Hobart 2003}

Hobart JC, Riazi A, Lamping DL, Fitzpatrick R, Thompson AJ. Measuring the impact of MS on walking ability: the 12-Item MS Walking Scale (MSWS-12). Neurology 2003;60:31-6.

\section{Hoffmann 2014}

Hoffmann TC, Glasziou PP, Boutron I, Milne R, Perera R, Moher D, et al. Better reporting of interventions: template for intervention description and replication (TIDieR) checklist and guide. BMJ 2014;348:g1687.

\section{Hohol 1995}

Hohol MJ, Orav EJ, Weiner HL. Disease steps in multiple sclerosis: a simple approach to evaluate disease progression. Neurology 1995;45:251-5.

\section{ICD-8 1965}

World Health Organization. Report of the international conference for the eighth revision of the international classification of diseases. Unpublished document WHO/ ICD9/74.4; available on request from Strengthening of Epidemiological and Statistical Services, World Health Organization. Geneva: World Health Organization, 1965. 


\section{Keith 1987}

Keith RA, Granger CV, Hamilton BB, Sherwin FS. The functional independence measure: a new tool for rehabilitation. Advances in clinical rehabilitation 1987;1:6-18.

\section{Kurtzke 1983}

Kurtzke JF. Rating neurologic impairment in multiple sclerosis: an expanded disability status scale (EDSS). Neurology 1983;11:1444-52.

\section{Lamb 2005}

Lamb SE, Jørstad-Stein EC, Hauer K, Becker C. Prevention of Falls Network Europe and Outcomes Consensus Group. Development of a common outcome data set for fall injury prevention trials: the Prevention of Falls Network Europe consensus. Journal of the American geriatrics society 2005;53:618-22.

\section{Lamb 2011}

Lamb SE, Becker C, Gillespie LD, Smith JL, Finnegan S, Potter R, et al. Reporting of complex interventions in clinical trials: development of a taxonomy to classify and describe fallprevention interventions. Trials 2011;12:125.

\section{Lefebvre 2011}

Lefebvre C, Manheimer E, Glanville J. Chapter 6: Searching for studies. In: Higgins JPT, Green S (editors). Cochrane Handbook for Systematic Reviews of Interventions Version 5.1.0 (updated March 2011). The Cochrane Collaboration, 2011. Available from www.cochrane-handbook.org.

\section{Lennon 2013a}

Lennon S. [Request for additional results [personal communication]]. Email to S Lennon 03-02-2018.

\section{Lord 2003}

Lord SR, Menz HB, Tiedemann A. A physiological profile approach to falls risk assessment and prevention. Physical therapy 2003;83:237-52.

\section{Lublin 1996}

Lublin FD, Reingold SC. Defining the clinical course of multiple sclerosis: results of an international survey. National Multiple Sclerosis Society (USA) Advisory Committee on Clinical Trials of New Agents in Multiple Sclerosis. Neurology 1996;46:907-11.

\section{Lublin 2014}

Lublin FD, Reingold SC, Cohen JA, Cutter GR, Sørensen PS, Thompson AJ, et al. Defining the clinical course of multiple sclerosis: the 2013 revisions. Neurology 2014;83:278-86.

\section{Matsuda 2011}

Matsuda PN, Shumway-Cook A, Bamer AM, Johnson SL, Amtmann $\mathrm{D}, \mathrm{Kraft} \mathrm{GH}$. Falls in multiple sclerosis. $P M \& R$ : the journal of injury, function, and rehabilitation 2011;3(7):624-32.

\section{Matsuda 2012}

Matsuda PN, Shumway-Cook A, Ciol MA, Bombardier CH, Kartin DA. Understanding falls in multiple sclerosis: association of mobility status, concerns about falling, and accumulated impairments. Physical therapy 2012;92:407-15.

\section{McColl 2001}

McColl MA, Davies D, Carlson P, Johnston J, Minnes P. The community integration measure: development and preliminary validation. Archives of physical medicine and rehabilitation 2001;82:429-34.

\section{McDonald 2001}

McDonald WI, Compston A, Edan G, Goodkin D, Hartung HP, Lublin FD, et al. Recommended diagnostic criteria for multiple sclerosis: guidelines from the international panel on the diagnosis of multiple sclerosis. Annals of neurology 2001;50:121-7.

\section{Moher 2012}

Moher D, Hopewell S, Schulz KF, Montori V, Gøtzsche PC, Devereaux PJ, et al. CONSORT 2010 explanation and elaboration: updated guidelines for reporting parallel group randomised trials. International journal of surgery 2012;10:28-55.

\section{NGC 2014}

National Guideline Clearinghouse (NGC). Guideline summary: management of multiple sclerosis in primary and secondary care. National Clinical Guideline Centre (UK).

\section{Nilsagard 2015}

Nilsagård Y, Gunn H, Freeman J, Hoang P, Lord S, Mazumder R, et al. Falls in people with MS, an individual data meta-analysis from studies from Australia, Sweden, United Kingdom and the United States. Multiple sclerosis (Houndmills, Basingstoke, England) 2015;21:92-100.

\section{Oliver 2004}

Oliver D, Daly F, Martin FC, McMurdo ME. Risk factors and risk assessment tools for falls in hospital in-patients: a systematic review. Age and ageing 2004;33:122-30.

\section{Polman 2005}

Polman CH, Reingold SC, Edan G, Filippi M, Hartung HP, Kappos L, et al. Diagnostic criteria for multiple sclerosis: 2005 revisions to the "McDonald Criteria". Annals of neurology 2005;58:840-6.

\section{Polman 2011}

Polman CH, Reingold SC, Banwell B, Clanet M, Cohen JA, Filippi M, et al. Diagnostic criteria for multiple sclerosis: 2010 revisions to the McDonald criteria. Annals of neurology 2011;69:292-302.

\section{Poser 1983}

Poser CM, Paty DW, Scheinberg L, McDonald WI, Davis FA, Ebers GC, et al. New diagnostic criteria for multiple sclerosis: guidelines for research protocols. Annals of neurology 1983;13:227-31.

\section{Prosperini 2013a}

Prosperini L, Fortuna D, Gianni C, Leonardi L, Marchetti MR, Pozzilli C. [Request for additional results [personal communication]]. Email to L Prosperini 22-06-2018. 


\section{Review Manager 2014 [Computer program]}

Copenhagen: Nordic Cochrane Centre, The Cochrane Collaboration. Review Manager (RevMan). Version 5.3. Copenhagen: Nordic Cochrane Centre, The Cochrane Collaboration, 2014.

\section{Schumacher 1965}

Schumacher GA, Beebe G, Kibler RF, Kurland LT, Kurtzke JF, McDowell F, et al. Problems of experimental trials of therapy in multiple sclerosis: report by the panel on the evaluation of experimental trials in multiple sclerosis. Annals of the New York Academy of Sciences 1965;122:552-68.

\section{Smith 1982}

Smith A. Symbol Digits Modalities Test. Los Angeles: Western Psychological Services, 1982.

\section{Sosnoff 2014a}

Sosnoff JJ, Finlayson M, McAuley E, Morrison S, Motl RW. [Request for additional results [personal communication]]. Email to J Sosnoff 22-06-2018.

\section{Sosnoff 2014b}

Sosnoff JJ, Finlayson M. International MS falls prevention research network. International journal of MS care 2014;16:161-2.

\section{Sosnoff 2015a}

Sosnoff JJ, Moon Y, Wajda DA, Finlayson ML, McAuley E, Peterson EW, et al. [Request for additional results [personal communication]]. Email to JJ Sosnoff 22-06-2018.

\section{Stephens 2001a}

Stephens J, DuShuttle D, Hatcher C, Shmunes J, Slaninka C. [Request for additional results [personal communication]]. Email to J Stephens 07-03-2018.

\section{Taylor 2014a}

Taylor P, Barrett C, Mann G, Wareham W, Swain I. [Request for additional results [personal communication]]. Email to $P$ Taylor 12-07-2018.

\section{Verheyden 2013}

Verheyden GSAF, Weerdesteyn V, Pickering RM, Kunkel D, Lennon S, Geurts ACH, et al. Interventions for preventing falls in people after stroke. Cochrane Database of Systematic Reviews 2013, Issue 5. [DOI: 10.1002/14651858.CD008728]

\section{References to other published versions of this review Hayes 2017}

Hayes S, Kennedy C, Galvin R, Finlayson M, McGuigan C, Walsh CD, et al. Interventions for preventing falls in people with multiple sclerosis. Cochrane Database of Systematic Reviews 2017, Issue 1. [DOI: 10.1002/14651858.CD012475]

* Indicates the major publication for the study

\section{CHARACTERISTICS OF STUDIES}

Characteristics of included studies [ordered by study ID]

Carling 2017

Methods Multi-centre single-blinded randomised controlled pilot study, computerised random allocation with varied block sizes

Participants $\quad n=51$, Randomised: $(E=25, C=26)$, Anaylsed $(E=23, C=25)$

Groups differed at baseline for age, gender and MS subtype - E group older, higher proportion of females and no participants with relapsing remitting MS

\begin{tabular}{ll} 
Interventions & $\begin{array}{l}\text { Core stability exercise, dual tasking and sensory strategies individualised and progressed by physio- } \\
\text { therapists in groups of 2-5. } 14 \text { sessions over } 7 \text { weeks, } 60 \text { minute per session. }\end{array}$ \\
& $2-5$ individualised and progressive home exercises, twice a week \\
\hline Outcomes & $\begin{array}{l}\text { Number of falls per group, number of fallers, number of multiple fallers, Fatigue, trunk impairment, } \\
\text { timed sit-to-stand, postural sway, balance function, falls efficacy, walking mobility, timed mobility, } \\
\text { walking velocity }\end{array}$
\end{tabular}

\section{Risk of bias}


Carling 2017 (Continued)

Random sequence genera- Low risk An external statistician conducted a computerized random allocation setion (selection bias) quence with varied block sizes

Allocation concealment Low risk
(selection bias)

(selection bias)

Blinding of participants and personnel (perfor-

mance bias)

All outcomes
Concealed allocation was achieved using sealed envelopes, which were opened right after baseline measure by the physiotherapist in charge at each site

Not outlined in paper that participants or healthcare providers were blinded

\section{Blinding of outcome as- Low risk}

sessment (detection bias)

All outcomes

Incomplete outcome data Low risk

(attrition bias)

All outcomes

\begin{tabular}{lll}
\hline $\begin{array}{l}\text { Selective reporting (re- } \\
\text { porting bias) }\end{array}$ & Low risk & $\begin{array}{l}\text { Compared with planned outcome reporting outlined in the registered trial } \\
\text { (NCT 02209467) all outcomes are reported in the trial }\end{array}$ \\
\hline Other bias & Low risk & Sample size calculated a priori and required number of participants recruited. \\
\hline
\end{tabular}

\section{Cattaneo 2007}

Methods Randomised controlled trial, participants allocated to groups by matching order of admission to hospital with pre-study randomised list

$\begin{array}{ll}\text { Participants } & \mathrm{n}=50, \text { randomised \& analysed groups: } M \& S=23, M=12, C=15 \\ & \text { No statistically significant difference between groups for characteristics or baseline measures. For total } \\ \text { group, mean age } 46 \text { years }+/-10.2, M S \text { onset mean } 13.8 \text { years }+/-8.1 \& n=15 \text { used a walking aid. }\end{array}$

Interventions M\&S: Strategies that challenged the motor and sensory system to maintain equilibrium. Biofeedback incorporated. Progressive difficulty. 1 to 1 with experienced therapist. 10-12 sessions fo 45 minutes over 3 weeks.

M: As above with motor strategies only.

C: Conventional therapy not directly targeted at balance improvements. Dosage as above.

\begin{tabular}{ll}
\hline Outcomes & Number of fallers, balance function, mobility, balance confidence, \\
\hline Notes & M\&S: Motor \& Sensory Rehabilitation, M: Motor Rehabilitation, C: Control, BBS: Berg Balance Scale, DGI: \\
& Dynamic Gait Index
\end{tabular}

\section{Risk of bias}

\begin{tabular}{lll}
\hline Bias & Authors' judgement & Support for judgement \\
\hline $\begin{array}{ll}\text { Random sequence genera- } \\
\text { tion (selection bias) }\end{array}$ & Low risk & $\begin{array}{l}\text { Following initial assessment, the subjects were randomly assigned to three } \\
\text { subgroups using computer- } \\
\end{array}$ \\
& & generated random numbers. \\
\hline
\end{tabular}




\section{Cattaneo 2007 (Continued)}

Allocation concealment (selection bias)

Unclear risk Allocation concealment mechanism not outlined in the paper.

\begin{tabular}{|c|c|c|}
\hline $\begin{array}{l}\text { Blinding of participants } \\
\text { and personnel (perfor- } \\
\text { mance bias) } \\
\text { All outcomes }\end{array}$ & Unclear risk & $\begin{array}{l}\text { Not enough information is presented in the study to determine if participants } \\
\text { or personnel were blinded. }\end{array}$ \\
\hline $\begin{array}{l}\text { Blinding of outcome as- } \\
\text { sessment (detection bias) } \\
\text { All outcomes }\end{array}$ & High risk & $\begin{array}{l}\text { Whenever possible an independent rater not directly involved in the treatment } \\
\text { rated both the initial and the final assessment. The rater was not masked with } \\
\text { respect to the subject's group assignment. }\end{array}$ \\
\hline $\begin{array}{l}\text { Incomplete outcome data } \\
\text { (attrition bias) } \\
\text { All outcomes }\end{array}$ & Low risk & Attrition balanced across both groups \\
\hline $\begin{array}{l}\text { Selective reporting (re- } \\
\text { porting bias) }\end{array}$ & Unclear risk & $\begin{array}{l}\text { Results reported are in line with planned analysis, however, published proto- } \\
\text { col or trial registration is not available }\end{array}$ \\
\hline Other bias & Unclear risk & $\begin{array}{l}\text { No sample size calculated and inferential statistics computed. Study may be at } \\
\text { risk of a type II error }\end{array}$ \\
\hline
\end{tabular}

Methods Multi-centre, single-blinded randomised controlled trial, independent clinician within clinical centre al-
located participants with pre-study randomised list

\begin{tabular}{|c|c|}
\hline \multirow[t]{5}{*}{ Participants } & $n=119$ \\
\hline & Randomised: $\mathrm{I}=78, \mathrm{C}=41$ \\
\hline & Analysed Post: $\mathrm{I}=69, \mathrm{C}=36$ \\
\hline & Analysed Follow-Up: I=58, C=26 \\
\hline & $\begin{array}{l}\text { Baseline characteristics were similar between groups and centres. Less participants in I group had } \\
\text { more than } 2 \text { falls in two months prior to study. }\end{array}$ \\
\hline \multirow[t]{2}{*}{ Interventions } & $\begin{array}{l}\text { I: Balance treatment to improve control of posture, moving centre of mass and body segments during } \\
\text { static, dynamic and transitional tasks. } 1 \text { to } 1 \text { with experienced physical therapist for } 45 \text { minutes. } 20 \text { ses- } \\
\text { sions over } 7-10 \text { weeks. }\end{array}$ \\
\hline & $\begin{array}{l}\text { C: Treatments that reduce limitations of body function and activity levels, with max of } 10 \text { minutes for } \\
\text { balance. Dosage as above. }\end{array}$ \\
\hline Outcomes & $\begin{array}{l}\text { Number of fallers, number of multiple fallers, balance function, dynamic balance, mobility, balance } \\
\text { confidence }\end{array}$ \\
\hline Notes & $\begin{array}{l}\text { I: Intervention, C: Control, BBS: Berg Balance Scale, DGI: Dynamic Gait Index, TUG: Timed Up and Go, } \\
\text { ABC: Activities-specific Balance Confidence scale }\end{array}$ \\
\hline
\end{tabular}

\section{Risk of bias}

\begin{tabular}{lll} 
Bias & Authors' judgement & Support for judgement \\
\hline $\begin{array}{l}\text { Random sequence genera- } \\
\text { tion (selection bias) }\end{array}$ & Unclear risk & $\begin{array}{l}\text { randomisation list made before the beginning of the study- randomisation } \\
\text { procedure is not identified }\end{array}$ \\
\hline
\end{tabular}




\section{Cattaneo 2016 (Continued)}

Allocation concealment Unclear risk Method of concealment not described in enough detail (selection bias)

Blinding of participants

Unclear risk

Participants were not aware of group assignment. Not enough information is and personnel (perforpresented in the study to determine if personnel were blinded mance bias)

All outcomes

$\begin{array}{lll}\text { Blinding of outcome as- } & \text { Low risk } & \text { Blinded assessor took assessments } \\ \text { sessment (detection bias) }\end{array}$

ection bias)

All outcomes

Incomplete outcome data Low risk Reasons for missing data in groups provided
(attrition bias)

All outcomes

Selective reporting (re- High risk

porting bias)

Trial registration number NCT02390830. Additional outcomes reported in the paper that weren't included in the protocol including the TUG, DGI, ABC and BBS

Other bias Low risk Sample size calculated and required number of participants recruited

Coote 2013

Methods Multi-centre single-blinded block randomised controlled trial. Allocation of blocks by sealed envelope with a piece of paper for each group, emitted once selected.
Participants $\quad n=111$, randomised \& analysed groups: 1. Group physiotherapy $(\mathrm{GP})=48 ; 2.1$-to-1 physiotherapy = 35; Yoga $=13$,
$C=15$

Baseline characteristics of intervention groups not reported. Differences between fallers \& non-fallers were: significantly greater physical and psychological impact of MS and impact of fatigue for fallers

All interventions were for 1 hour per week for 10 weeks
GP: physiotherapist supervised circuit class of 6 strength \& balance exercises with progressions
1-to-1 physiotherapy: at discretion of physiotherapist (focus was exercise to improve balance and
strength)
Yoga instructor classes, focus on yoga postures, stretching, breathing, meditation and relaxation exer-
cises

\section{Outcomes}

1. The number of falls in the last 3 months, coded as 0 for no falls or 1 for one or more falls.

2. The proportion of fallers (people who reported 1 or more falls in the last 3 months),

Participants were asked retrospectively about the number of falls in the 3 months before the baseline assessment. They were reassessed at week 12 , during which they were asked about the number of falls in the 3 months before that assessment.

- At impairment level, lower limb sensation was evaluated using a simple verbal numerical rating scale, with 0 indicating no feeling at all and 10 indicating normal sensation. Three areas of the lower limb were tested bilaterally; thus a total of 60 indicated normal sensation.

- Proprioception was assessed by placing participants' big toe in an "up" or "down" position and asking participants to identify where their toe was. It was scored as either normal or abnormal. 
- At activities level, balance was assessed using the Berg Balance Scale (BBS), a 14-item clinical scale that evaluates balance in sitting and standing and rates performance from 0 (cannot perform) to 4 (normal performance).

- Walking endurance was measured using the 6-minute walk test (6MWT).

- At participation level, the Multiple Sclerosis Impact Scale-29 version 230 (MSIS-29v2) physical and psychological components were used.

- The impact of fatigue was measured using the Modified Fatigue Impact Scale (MFIS)

Notes

\section{Risk of bias}

\begin{tabular}{|c|c|c|}
\hline Bias & Authors' judgement & Support for judgement \\
\hline $\begin{array}{l}\text { Random sequence genera- } \\
\text { tion (selection bias) }\end{array}$ & Unclear risk & $\begin{array}{l}\text { Insufficient information presented in the paper to permit a judgement of low } \\
\text { or high risk of bias }\end{array}$ \\
\hline $\begin{array}{l}\text { Allocation concealment } \\
\text { (selection bias) }\end{array}$ & Unclear risk & $\begin{array}{l}\text { Insufficient information presented in the paper to permit a judgement of low } \\
\text { or high risk of bias }\end{array}$ \\
\hline $\begin{array}{l}\text { Blinding of participants } \\
\text { and personnel (perfor- } \\
\text { mance bias) } \\
\text { All outcomes }\end{array}$ & Unclear risk & $\begin{array}{l}\text { Insufficient information presented in the paper to permit a judgement of low } \\
\text { or high risk of bias }\end{array}$ \\
\hline $\begin{array}{l}\text { Blinding of outcome as- } \\
\text { sessment (detection bias) } \\
\text { All outcomes }\end{array}$ & Unclear risk & $\begin{array}{l}\text { Insufficient information presented in the paper to permit a judgement of low } \\
\text { or high risk of bias }\end{array}$ \\
\hline $\begin{array}{l}\text { Incomplete outcome data } \\
\text { (attrition bias) } \\
\text { All outcomes }\end{array}$ & Unclear risk & $\begin{array}{l}\text { Insufficient information presented in the paper to permit a judgement of low } \\
\text { or high risk of bias }\end{array}$ \\
\hline $\begin{array}{l}\text { Selective reporting (re- } \\
\text { porting bias) }\end{array}$ & High risk & Some outcome data not reported, e.g. PCI and HHD \\
\hline Other bias & Unclear risk & $\begin{array}{l}\text { No sample size calculation reported in the paper. Study may be exposed to a } \\
\text { type II error }\end{array}$ \\
\hline
\end{tabular}

Esnouf 2010

Methods Randomized controlled study, allocation by computer-generated randomisation

Participants $n=64$

Randomised: (ODFS=32, $\mathrm{E}=32)$

Anaylsed (ODFS=26, $\mathrm{E}=27)$

No statistical difference between groups for performance or satisfaction on COPM.

ODFS $=53$ years (mean), 62\% female

E: 57 years (mean), 66\% female

Similar proportion of participants in each group on Kurtze scale 
Esnouf 2010 (Continued)

Interventions

ODFS: Wear ODFS daily for mobility for 18 weeks

E: Physiotherapist prescribed exercises, individualised, to improve gait and strength (core, hip). 1-2 per day at home for 30 minutes, for 18 weeks

\begin{tabular}{ll}
\hline Outcomes & Number of falls per person, adverse events, occupational performance \\
\hline Notes & ODFS: Oddstock drop foot stimulator, E: Exercise, COPM: Canadian Occupational Performance Measure
\end{tabular}

\section{Risk of bias}

\begin{tabular}{|c|c|c|}
\hline Bias & Authors' judgement & Support for judgement \\
\hline $\begin{array}{l}\text { Random sequence genera- } \\
\text { tion (selection bias) }\end{array}$ & Low risk & $\begin{array}{l}\text { Following recruitment, the research volunteers were randomly assigned by } \\
\text { computer-generated randomisation to ODFS and exercise groups }\end{array}$ \\
\hline $\begin{array}{l}\text { Allocation concealment } \\
\text { (selection bias) }\end{array}$ & Unclear risk & $\begin{array}{l}\text { Insufficient information available to permit a judgement of 'low risk' or 'high } \\
\text { risk }\end{array}$ \\
\hline $\begin{array}{l}\text { Blinding of participants } \\
\text { and personnel (perfor- } \\
\text { mance bias) } \\
\text { All outcomes }\end{array}$ & Unclear risk & $\begin{array}{l}\text { Insufficient information available to permit a judgement of 'low risk' or 'high } \\
\text { risk' }\end{array}$ \\
\hline $\begin{array}{l}\text { Blinding of outcome as- } \\
\text { sessment (detection bias) } \\
\text { All outcomes }\end{array}$ & Low risk & $\begin{array}{l}\text { The occupational therapist was not involved in any aspect of the study inter- } \\
\text { vention and was blinded to group allocation. }\end{array}$ \\
\hline $\begin{array}{l}\text { Incomplete outcome data } \\
\text { (attrition bias) } \\
\text { All outcomes }\end{array}$ & Low risk & $\begin{array}{l}\text { Missing outcome data balanced in numbers across intervention groups, with } \\
\text { similar reasons for missing data across groups }\end{array}$ \\
\hline $\begin{array}{l}\text { Selective reporting (re- } \\
\text { porting bias) }\end{array}$ & Unclear risk & $\begin{array}{l}\text { No published trial protocol or registered trial is cited in the paper, therefore } \\
\text { unclear }\end{array}$ \\
\hline Other bias & Unclear risk & $\begin{array}{l}\text { No sample size calculated and inferential statistics computed. The study may } \\
\text { be exposed to a type II error }\end{array}$ \\
\hline
\end{tabular}

Gandolfi 2015

\begin{tabular}{ll}
\hline Methods & $\begin{array}{l}\text { Single-blinded block randomised controlled trial, allocation by an } 8 \text { block list using computer-generat- } \\
\text { ed random numbers tables }\end{array}$ \\
\hline Participants & $\mathrm{n}=80$, randomised \& analysed: $\mathrm{E}=39, \mathrm{C}=41$ \\
& $\begin{array}{l}\text { No statistically significant differences between groups at baseline. C was slightly older, longer disease } \\
\text { duration, higher EDSS \& BBS scores. }\end{array}$ \\
\hline Interventions & $\begin{array}{l}50 \text { minutes a day, } 3 \text { days/week, for } 5 \text { weeks } \\
\text { E: Physiotherapist supervised, sensory integration balance training, individualised \& progressive } \\
\text { C: Physiotherapist supervised, mobilization, stretching and strengthening in accordance with MS reha- } \\
\text { bilitation guidelines }\end{array}$
\end{tabular}


Gandolfi 2015 (Continued)

Outcomes Number of falls per person, balance function, balance confidence, quality of life, fatigue, sensory organisation balance test

Notes

E: Exercise, C: Control, EDSS: Expanded Disability Status Scale, BBS: Berg Balance Scale, FSS: Fatigue Severity Scale, SOT: Sensory Organisation Balance Test, ABC: Activities Balance Confidence Scale, MSQOL-54 PHC: Multiple Sclerosis Quality of Life-54 Physical Health Component

\section{Risk of bias}

\begin{tabular}{lll}
\hline Bias & Authors' judgement & Support for judgement \\
\hline $\begin{array}{l}\text { Random sequence genera- } \\
\text { tion (selection bias) }\end{array}$ & Low risk & Computer generated random number tables were used \\
\hline $\begin{array}{l}\text { Allocation concealment } \\
\text { (selection bias) }\end{array}$ & Low risk & "According to the assignment in the block by a second blinded physician" \\
\hline $\begin{array}{l}\text { Blinding of participants } \\
\text { and personnel (perfor- } \\
\text { mance bias) } \\
\text { All outcomes }\end{array}$ & Unclear risk & $\begin{array}{l}\text { Insufficient information available to permit a judgement of 'low risk' or 'high } \\
\text { risk' }\end{array}$ \\
\hline
\end{tabular}

Blinding of outcome as- Low risk The examiner was blinded to group assignment

sessment (detection bias)

All outcomes

\begin{tabular}{lll}
\hline $\begin{array}{l}\text { Incomplete outcome data } \\
\text { (attrition bias) } \\
\text { All outcomes }\end{array}$ & Low risk & $\begin{array}{l}\text { Missing outcome data balanced in numbers across intervention groups, with } \\
\text { similar reasons for missing data across groups }\end{array}$ \\
\hline $\begin{array}{l}\text { Selective reporting (re- } \\
\text { porting bias) }\end{array}$ & High risk & $\begin{array}{l}\text { Trial registration number NCT01040117. No outcomes from GAITRite, platform } \\
\text { stabilometry or postural evaluation reported }\end{array}$ \\
\hline Other bias & Low risk & Sample size calculated and recruitment of required sample \\
\hline
\end{tabular}

\section{Hoang 2016}

\begin{tabular}{ll}
\hline Methods & $\begin{array}{l}\text { Single-blinded block randomised controlled trial. Allocation by computer-generated random number } \\
\text { schedule }\end{array}$ \\
\hline Participants & $\mathrm{n}=50$ \\
& Randomised: $\mathrm{E}=28, \mathrm{C}=22$ \\
& Analysed: $\mathrm{E}=23, \mathrm{C}=21$ \\
& $\begin{array}{l}\text { No differences at baseline between groups on primary (CSRT \& SST) \& secondary (CSRT decision \& } \\
\text { movement time, postural sway, TUG, 10MWT, 6MWT, TMT, SDMT, 9-HPT, MSFC \& number of falls) mea- } \\
\text { sures }\end{array}$ \\
\hline Interventions & $\begin{array}{l}\text { multiple directions to cues } \\
\text { C: } \text { no intervention, continued their normal physical activity }\end{array}$ \\
\hline
\end{tabular}

Outcomes Number of falls per group, mobility, dual task mobility, cognition, MS function, stepping reaction time


Hoang 2016 (Continued)

Notes

E: Exercise, C: Control, CSRT: Choice Stepping Reaction Time, SST: Stroop Stepping Test, TUG: Timed Up and Go, 10MWT: 10 meter walk test, 6MWT: 6 minute walk test, TMT: trail making test, SDMT" symbol digit modalities test, 9-HPT: 9 hole peg test, MSFC: multiple sclerosis functional composite

\section{Risk of bias}

\begin{tabular}{|c|c|c|}
\hline Bias & Authors' judgement & Support for judgement \\
\hline $\begin{array}{l}\text { Random sequence genera- } \\
\text { tion (selection bias) }\end{array}$ & Low risk & "Computer generated random number schedule" \\
\hline $\begin{array}{l}\text { Allocation concealment } \\
\text { (selection bias) }\end{array}$ & Unclear risk & $\begin{array}{l}\text { Insufficient information available to permit a judgement of 'low risk' or 'high } \\
\text { risk' }\end{array}$ \\
\hline $\begin{array}{l}\text { Blinding of participants } \\
\text { and personnel (perfor- } \\
\text { mance bias) } \\
\text { All outcomes }\end{array}$ & Unclear risk & $\begin{array}{l}\text { Insufficient information available to permit a judgement of 'low risk' or 'high } \\
\text { risk' }\end{array}$ \\
\hline $\begin{array}{l}\text { Blinding of outcome as- } \\
\text { sessment (detection bias) } \\
\text { All outcomes }\end{array}$ & Low risk & $\begin{array}{l}\text { "Reassessments were conducted by a physiotherapist who was blind to group } \\
\text { allocation"... }\end{array}$ \\
\hline $\begin{array}{l}\text { Incomplete outcome data } \\
\text { (attrition bias) } \\
\text { All outcomes }\end{array}$ & Low risk & $\begin{array}{l}\text { Balanced across groups and reasons for missing data unlikely to be related to } \\
\text { outcome }\end{array}$ \\
\hline $\begin{array}{l}\text { Selective reporting (re- } \\
\text { porting bias) }\end{array}$ & High risk & $\begin{array}{l}\text { Trial registration number ACTRN12612001139864.Additional outcomes pre- } \\
\text { sented in the paper to those presented in the protocol including MSFC, TUG, } \\
\text { TMT and SDMT }\end{array}$ \\
\hline Other bias & Low risk & Sample size calculated and required number of participants recruited \\
\hline
\end{tabular}

Lennon 2013

Methods Single-blinded stratified randomised controlled trial. Allocation by computer generated randomisation code \& stratification using RMI score

Participants $n=177$, randomised \& analysed: $\mathrm{E}=89, \mathrm{C}: 88$

No significant differences between groups at baseline for characteristics or outcome measures.

Interventions E: Physiotherapy supervised group exercise (warm-up/stretch, functional mobility \& cool-down), individualised \& progressed. 2 hours twice a week for 6 weeks

C: Weekly 10 minute call with structured questions about balance and mobility, for 6 weeks

Outcomes

Number of falls per group, number of fallers, number of multiple fallers, mobility, activities of daily living, balance function, MS impact (physical and psychological), MS self-efficacy, walking velocity

Notes RMI: Rivermead Index, E: Exercise, C: Control, BBS: Berg Balance Scale, MSIS-Phy: Multiple Sclerosis Impact Scale Physical, MSIS-Psy: Multiple Sclerosis Impact Scale Psychological, MSWS: Multiple Sclerosis Walking Scale, MSSES: Multiple Sclerosis Self-Efficacy Scale, 10MWT: 10 meter walk test

\section{Risk of bias}


Lennon 2013 (Continued)

\begin{tabular}{lll} 
Bias & Authors' judgement & Support for judgement \\
\hline $\begin{array}{l}\text { Random sequence genera- } \\
\text { tion (selection bias) }\end{array}$ & Low risk & $\begin{array}{l}\text { "Computer generated randomisation code stratified according to .their scores } \\
\text { on the primary outcome" }\end{array}$ \\
\hline
\end{tabular}

\begin{tabular}{|c|c|c|}
\hline $\begin{array}{l}\text { Allocation concealment } \\
\text { (selection bias) }\end{array}$ & Unclear risk & No details on allocation concealment \\
\hline $\begin{array}{l}\text { Blinding of participants } \\
\text { and personnel (perfor- } \\
\text { mance bias) } \\
\text { All outcomes }\end{array}$ & Unclear risk & $\begin{array}{l}\text { Insufficient information available to permit a judgement of 'low risk' or 'high } \\
\text { risk' }\end{array}$ \\
\hline $\begin{array}{l}\text { Blinding of outcome as- } \\
\text { sessment (detection bias) } \\
\text { All outcomes }\end{array}$ & Low risk & "Member of the research team who was blinded to the intervention" \\
\hline $\begin{array}{l}\text { Incomplete outcome data } \\
\text { (attrition bias) } \\
\text { All outcomes }\end{array}$ & High risk & $\begin{array}{l}\text { "A total of } 177 \text { participants were randomised into the trial. } 89 \text { participants } \\
\text { were randomised into the exercise group and } 88 \text { to the control group. Within } \\
\text { the exercise group } 5 \text { failed to complete post intervention outcomes measure- } \\
\text { ments and } 8 \text { were lost to } 3 \text { a } 6 \text { month follow-up. Seven participants were lost } \\
\text { to all outcome assessment within the control group." No data on reasons for } \\
\text { missing data given }\end{array}$ \\
\hline $\begin{array}{l}\text { Selective reporting (re- } \\
\text { porting bias) }\end{array}$ & High risk & $\begin{array}{l}\text { Trial registration ISRCTN78227711- all primary and secondary outcomes re- } \\
\text { ported but additional outcomes reported in the study include the } 10 \mathrm{~m} \text { walking } \\
\text { speed and number of fallers }\end{array}$ \\
\hline Other bias & Unclear risk & $\begin{array}{l}\text { No sample size calculated and inferential statistics calculated. Study may be } \\
\text { exposed to a type II error }\end{array}$ \\
\hline
\end{tabular}

Prosperini 2013

\begin{tabular}{ll}
\hline Methods & Single-blinded randomised cross-over trial. Allocation by computer-generated random numbers in a \\
& $1: 1$ ratio.
\end{tabular}

\begin{tabular}{ll}
\hline Participants & $\mathrm{n}=36$ \\
& Randomised: $\mathrm{GA}=18, \mathrm{~GB}=18$ \\
& $\begin{array}{l}\text { Analysed: } \mathrm{GA}=17, \mathrm{~GB}=17 \\
\text { No significant difference between groups at baseline for demographic \& clinical characteristics }\end{array}$ \\
\hline Interventions & $\begin{array}{l}30 \text { minutes/day, } 5 \text { days/week for } 12 \text { weeks use of Wii Fit Plus balance games of progressive difficulty, at } \\
\text { home }\end{array}$ \\
\hline Outcomes & $\begin{array}{l}\text { Number of falls per group, static balance function, dynamic balance function, mobility, MS impact } \\
\text { (physical and psychological) }\end{array}$ \\
\hline Notes & $\begin{array}{l}\text { GA: Group A, GB: Group B, COP Path Centre of Pressure Path, FSST: Four Step Square Test, 25-FWT: 25 } \\
\text { Foot Walk Test, MSIS-29: Multiple Sclerosis Impact Scale-29, WBBS: Wii Balance Board System }\end{array}$ \\
\hline
\end{tabular}

\section{Risk of bias}


Prosperini 2013 (Continued)

Random sequence genera- Low risk tion (selection bias)
"Patients who met all eligibility criteria underwent study assessments and were randomly assigned in a 1:1 ratio to 2 counterbalanced arms by computer-generated random numbers. Randomization procedure was performed by an operator (LL) not involved in study measurements"

\begin{tabular}{|c|c|c|}
\hline $\begin{array}{l}\text { Allocation concealment } \\
\text { (selection bias) }\end{array}$ & Unclear risk & $\begin{array}{l}\text { Insufficient information available to permit a judgement of 'low risk' or 'high } \\
\text { risk'. This is usually the case if the method of concealment is not described or } \\
\text { not described in sufficient detail to allow a definite judgement }\end{array}$ \\
\hline
\end{tabular}

\begin{tabular}{|c|c|c|}
\hline $\begin{array}{l}\text { Blinding of participants } \\
\text { and personnel (perfor- } \\
\text { mance bias) } \\
\text { All outcomes }\end{array}$ & Unclear risk & $\begin{array}{l}\text { Insufficient information available to permit a judgement of 'low risk' or 'high } \\
\text { risk' }\end{array}$ \\
\hline $\begin{array}{l}\text { Blinding of outcome as- } \\
\text { sessment (detection bias) } \\
\text { All outcomes }\end{array}$ & Low risk & $\begin{array}{l}\text { The following outcome measures were collected at each scheduled visit (T0, } \\
\text { T1, and T2) by } 2 \text { neurologists (LP and CG) unaware of the training order alloca- } \\
\text { tion }\end{array}$ \\
\hline $\begin{array}{l}\text { Incomplete outcome data } \\
\text { (attrition bias) } \\
\text { All outcomes }\end{array}$ & Low risk & $\begin{array}{l}\text { Missing outcome data balanced in numbers across intervention groups, with } \\
\text { similar reasons for missing data across groups. }\end{array}$ \\
\hline $\begin{array}{l}\text { Selective reporting (re- } \\
\text { porting bias) }\end{array}$ & Unclear risk & $\begin{array}{l}\text { Registered trial protocol is not cited in paper so it is not possible to check } \\
\text { against planned a-priori analyses }\end{array}$ \\
\hline Other bias & Unclear risk & $\begin{array}{l}\text { No sample size calculated and inferential statistics calculated. Study may be } \\
\text { exposed to a type II error }\end{array}$ \\
\hline
\end{tabular}

Sosnoff 2014

Methods Single-blinded randomised controlled pilot trial. Allocation by computer-generated random numbers,
1:1 ratio

\begin{tabular}{ll}
\hline Participants & $\mathrm{n}=27$ \\
& Randomised: $\mathrm{E}=13, \mathrm{C}=14$ \\
& $\begin{array}{l}\text { Analysed: } \mathrm{E}=10, \mathrm{C}=12 \\
\text { No differences in characteristics between groups at baseline }\end{array}$ \\
\hline Interventions & $\begin{array}{l}\mathrm{E}: \text { Progressive home exercise programme to improve balance, walking, lower limb and trunk strength } \\
\text { and spasticity. } 45-60 \text { minutes, } 3 \text { times/week for } 3 \text { months }\end{array}$ \\
& C: No intervention or contact, on wait-list \\
\hline Outcomes & $\begin{array}{l}\text { Number of fallers, adverse events, physiological falls risk, mobility, walking endurance, balance func- } \\
\text { tion, balance confidence }\end{array}$ \\
\hline Notes & $\begin{array}{l}\text { E: Exercise, C: Control, PPA: Physiological Profile Assessment, T25F: Timed 25 Foot Walk, ABC: Activi- } \\
\text { ties-Specific Balance Confidence }\end{array}$
\end{tabular}

\section{Risk of bias}


Sosnoff 2014 (Continued)

Random sequence genera- Low risk tion (selection bias)
"After baseline assessment, participants were randomised into two groups (exercise and control)

using a simple randomisation method with a 1:1 allocation ratio (independent of baseline assessment)

by computer-generated random numbers

Allocation concealment Low risk "Group allocation for each participant was concealed in opaque envelopes"
(selection bias)

(selection bias)

Insufficient information available to permit a judgement of 'low risk' or 'high risk'

and personnel (perfor-

Unclear risk

mance bias)

All outcomes

\begin{tabular}{lll}
\hline $\begin{array}{l}\text { Blinding of outcome as- } \\
\text { sessment (detection bias) } \\
\text { All outcomes }\end{array}$ & Low risk & "The outcome assessors were blinded to group allocation" \\
\hline $\begin{array}{l}\text { Incomplete outcome data } \\
\text { (attrition bias) }\end{array}$ & Low risk & $\begin{array}{l}\text { Data from five participants who were randomised were not analysed die to } \\
\text { withdrawal for various reasons. Acceptable reasons for incomplete date are } \\
\text { outlined and balanced across groups and do not suggest bias }\end{array}$ \\
\hline
\end{tabular}

Selective reporting (re- High risk porting bias)

The self-reported falls at baseline and incidence of falls throughout the intervention were not reported- this was outlined as planned outcomes in the methods section of the paper. All other planned outcomes (outlined in methods section of paper) were reported. However, the registered trial (NCT01837017) outlined a planned outcome reporting of spasticity at 3months using the Modified Ashworth Scale- this outcome is not reported in the trial paper

$\begin{array}{ll}\text { Other bias } \quad \text { Unclear risk } & \begin{array}{l}\text { No sample size calculated and inferential statistics calculated. Study may be } \\ \text { exposed to a type ll error }\end{array}\end{array}$

Sosnoff 2015

Methods $\quad$ Single-blinded randomised controlled trial. Allocation by computer generated numbers with a 1:1:1:1
ratio.

Participants $\mathrm{n}=37$
Randomized: $\mathrm{Ex}+\mathrm{Ed}=8, \mathrm{Ex}=11, \mathrm{Ed}=9, \mathrm{C}=9$
Analysed: $\mathrm{Ex}+\mathrm{Ed}=8, \mathrm{Ex}=10, \mathrm{Ed}=8, \mathrm{C}=8$

No statistically significant difference between groups at baseline

MS duration (in years) was greater in the $\mathrm{C}(19+/-9.3) \& \mathrm{Ex}+\mathrm{Ed}(20+/-7.4)$ groups, compared to the Ex
$(15+/-5.6) \& \mathrm{Ed}(14.6+/-10.9)$ groups

Interventions $\quad$ Ex: Standard set of progressive exercises for balance, lower limb \& trunk strength \& stretching, per-
formed at home, 3 times/week for 12 weeks, with 4 clinic visits for guidance

Ed: Group education led by trained interventionist involving self-management \& self-efficacy enhancement techniques. 1 hour, 4 times over 12 weeks

Ex + Ed: Combination of Ex \& Ed groups 
Sosnoff 2015 (Continued)

C: No intervention, wait-list control

\begin{tabular}{ll}
\hline Outcomes & Number of fallers, adverse events, fall prevention strategy, physiological profile assessment \\
\hline Notes & $\begin{array}{l}\text { Ex: Exercise, Ed: Education, Ex + Ed: Exercise and Education, C: Control, PPA: Physiological Profile As- } \\
\text { sessment }\end{array}$
\end{tabular}

\section{Risk of bias}

\begin{tabular}{|c|c|c|}
\hline Bias & Authors' judgement & Support for judgement \\
\hline $\begin{array}{l}\text { Random sequence genera- } \\
\text { tion (selection bias) }\end{array}$ & Low risk & $\begin{array}{l}\text { "After baseline assessment, participants were randomised into groups (exer- } \\
\text { cise, education, exercise plus education, and control) using a simple randomi- } \\
\text { sation method with a 1:1:1:1 allocation ratio (independent of baseline assess- } \\
\text { ment) by computer generated random numbers" }\end{array}$ \\
\hline $\begin{array}{l}\text { Allocation concealment } \\
\text { (selection bias) }\end{array}$ & Low risk & "Group allocation for each participant was concealed in opaque envelopes" \\
\hline $\begin{array}{l}\text { Blinding of participants } \\
\text { and personnel (perfor- } \\
\text { mance bias) } \\
\text { All outcomes }\end{array}$ & Unclear risk & $\begin{array}{l}\text { Insufficient information available to permit a judgement of 'low risk' or 'high } \\
\text { risk' }\end{array}$ \\
\hline $\begin{array}{l}\text { Blinding of outcome as- } \\
\text { sessment (detection bias) } \\
\text { All outcomes }\end{array}$ & Low risk & "The outcome assessors were blinded to group allocation" \\
\hline $\begin{array}{l}\text { Incomplete outcome data } \\
\text { (attrition bias) } \\
\text { All outcomes }\end{array}$ & Low risk & $\begin{array}{l}\text { "Three participants withdrew and were not included in analysis. The reasons } \\
\text { are reported clearly, are acceptable and do not suggest bias" }\end{array}$ \\
\hline $\begin{array}{l}\text { Selective reporting (re- } \\
\text { porting bias) }\end{array}$ & High risk & $\begin{array}{l}\text { Stusy is lacking detail on the falls incidence data in the trial groups, with on- } \\
\text { ly the p-value reported. In addition, some planned outcomes, outlined in the } \\
\text { trial registration (NCT01956227), are not reported in the trial paper, including } \\
\text { timed } 25 \mathrm{ft} \text { walk at } 3 \text { months, 6MWT at } 3 \text { months, TUG at } 3 \text { months, BBS at } 3 \\
\text { months, ABC at } 3 \text { months }\end{array}$ \\
\hline Other bias & Unclear risk & $\begin{array}{l}\text { No sample size calculated and inferential statistics calculated. Study may be } \\
\text { exposed to a type II error }\end{array}$ \\
\hline
\end{tabular}

Stephens 2001

\begin{tabular}{ll}
\hline Methods & Randomised controlled trial \\
\hline Participants & $\mathrm{n}=12$, ATM $=6$, EDU $=6$ \\
& No statistically significant difference between groups for characteristics or outcomes at baseline \\
\hline Interventions & $\begin{array}{l}\text { ATM: Class led by Guild Certified Feldenkrais practitioners \& based on the principles of this approach } \\
\text { to developing functional movement awareness progressively through practice of tasks. } 8 \text { classes of } 2-4 \\
\text { hours totaling } 20 \text { hours over } 10 \text { weeks }\end{array}$ \\
& $\begin{array}{l}\text { EDU: Group education on topics of acupuncture, exercise, social support and dealing with MS. } 4 \text { classes } \\
\text { of } 90 \text { minutes over } 10 \text { weeks }\end{array}$ \\
\hline
\end{tabular}


Stephens 2001 (Continued)

Outcomes NUmber of falls per person, sway velocity, balance confidence, MS self-efficacy

Notes ATM: Awareness Through Movement, EDU: Education, ,CTSIB: modified Clinical Test of Sensory Interac-
tion in Balance, ABC: Activities-Specific Balance Confidence Scale

\section{Risk of bias}

\begin{tabular}{|c|c|c|}
\hline Bias & Authors' judgement & Support for judgement \\
\hline $\begin{array}{l}\text { Random sequence genera- } \\
\text { tion (selection bias) }\end{array}$ & Unclear risk & $\begin{array}{l}\text { "Subjects were randomly assigned to the ATM group of the control group". } \\
\text { Therefore, there is insufficient information about the sequence generation } \\
\text { process available to permit a judgement of 'low risk' or 'high risk' }\end{array}$ \\
\hline $\begin{array}{l}\text { Allocation concealment } \\
\text { (selection bias) }\end{array}$ & Unclear risk & $\begin{array}{l}\text { Insufficient information about the allocation concealment process available to } \\
\text { permit a judgement of 'low risk' or 'high risk' }\end{array}$ \\
\hline $\begin{array}{l}\text { Blinding of participants } \\
\text { and personnel (perfor- } \\
\text { mance bias) } \\
\text { All outcomes }\end{array}$ & Unclear risk & $\begin{array}{l}\text { While some participants knew each other prior to the study, an attempt was } \\
\text { made to prevent communication between groups by scheduling classes at dif- } \\
\text { ferent times". Blinding of key study participants and personnel attempted, but } \\
\text { likely that the blinding could have been broken. Therefore Insufficient infor- } \\
\text { mation available to permit a judgement of 'low risk' or 'high risk' }\end{array}$ \\
\hline
\end{tabular}

Blinding of outcome as- Unclear risk The study did not address this outcome

sessment (detection bias)

All outcomes

\begin{tabular}{lll}
\hline $\begin{array}{l}\text { Incomplete outcome data } \\
\text { (attrition bias) } \\
\text { All outcomes }\end{array}$ & Unclear risk & The study did not address this outcome \\
\hline $\begin{array}{l}\text { Selective reporting (re- } \\
\text { porting bias) }\end{array}$ & Unclear risk & $\begin{array}{l}\text { No registered trial cited in the paper- cannot compare with a-priori plans for } \\
\text { analyses }\end{array}$ \\
\hline Other bias & Unclear risk & $\begin{array}{l}\text { The output of the sample size is unclear in terms of how it relates to study par- } \\
\text { ticipant numbers }\end{array}$ \\
\hline
\end{tabular}

Taylor 2014

\begin{tabular}{ll}
\hline Methods & Single-blinded randomised crossover trial. \\
\hline Participants & $\mathrm{n}=25$ \\
& Randomized: $\mathrm{FES}=11, \mathrm{C}=14$ \\
& Analysed: $\mathrm{FES}=9, \mathrm{C}=11$ \\
& No statistically significant difference between groups for baseline characteristics, although there was a \\
& higher proportion of walking aid users in C \\
\hline Interventions & FES: The ODFS for perineal stimulation worn for 6 weeks, gluteal stimulation added from week 6. At \\
& week 12 core stability exercises weekly in clinic to week 18. Exercises continued at home till week 24 \\
C: No intervention, wait list control
\end{tabular}

Outcomes

Gait analysis, $10 \mathrm{~m}$ walk speed, MS impact (physical and psychological), falls rate 
Taylor 2014 (Continued)

Notes

FES: Functional Electrical Stimulation, C: Control, ODFS: Oddstock Drop Foot Stimulator, ROGA: Rivermead Observational Gait Analysis

\section{Risk of bias}

\begin{tabular}{|c|c|c|}
\hline Bias & Authors' judgement & Support for judgement \\
\hline $\begin{array}{l}\text { Random sequence genera- } \\
\text { tion (selection bias) }\end{array}$ & Low risk & $\begin{array}{l}\text { Randomization was performed using computer generated random numbers } \\
\text { and group allocations were held by an independent medical statistician }\end{array}$ \\
\hline $\begin{array}{l}\text { Allocation concealment } \\
\text { (selection bias) }\end{array}$ & Unclear risk & $\begin{array}{l}\text { Insufficient information available to permit a judgement of 'low risk' or 'high } \\
\text { risk' }\end{array}$ \\
\hline $\begin{array}{l}\text { Blinding of participants } \\
\text { and personnel (perfor- } \\
\text { mance bias) } \\
\text { All outcomes }\end{array}$ & Unclear risk & $\begin{array}{l}\text { Insufficient information available to permit a judgement of 'low risk' or 'high } \\
\text { risk' }\end{array}$ \\
\hline $\begin{array}{l}\text { Blinding of outcome as- } \\
\text { sessment (detection bias) } \\
\text { All outcomes }\end{array}$ & Unclear risk & $\begin{array}{l}\text { Blinding of outcome assessors is not outlined in the paper. To this end, Insuffi- } \\
\text { cient information available to permit a judgement of 'low risk' or 'high risk' ex- } \\
\text { cept for the ROGA }\end{array}$ \\
\hline $\begin{array}{l}\text { Incomplete outcome data } \\
\text { (attrition bias) } \\
\text { All outcomes }\end{array}$ & High risk & $\begin{array}{l}\text { Only volunteers who completed the protocol were included in the analysis." } \\
\text { There is discrepancy in the flow of participants throughout the trial- text on } \\
\text { pg } 77 \text { outlines that } 28 \text { people were recruited, however, figure } 3 \text { demonstrates } \\
\text { that } 27 \text { participants were enrolled. Of the } 25 \text { randomised participants, } 5 \text { partic- } \\
\text { ipants withdrew for different reasons }\end{array}$ \\
\hline $\begin{array}{l}\text { Selective reporting (re- } \\
\text { porting bias) }\end{array}$ & Unclear risk & $\begin{array}{l}\text { No registered protocol was referenced in the paper so it is difficult to assess re- } \\
\text { porting bias }\end{array}$ \\
\hline Other bias & Unclear risk & $\begin{array}{l}\text { Potential risk of bias introduced as the intervention delivery mechanism (the } \\
\text { Odstock Drop Foot Stimulator) is produced by a company owned by some of } \\
\text { the authors- however, this potential conflict of interest is outlined by the au- } \\
\text { thors. No sample size calculated and inferential statistics calculated. Study } \\
\text { may be exposed to a type II error }\end{array}$ \\
\hline
\end{tabular}

Characteristics of excluded studies [ordered by study ID]

\begin{tabular}{ll}
\hline Study & Reason for exclusion \\
\hline ACTRN12612000218897 & Case series. Uncontrolled longitudinal study \\
\hline Brichetto 2015 & Falls not measured \\
\hline Cadorin 2015 & Case series. Uncontrolled longitudinal study \\
\hline Cakt 2010 & Falls not measured \\
\hline Eftekharsadat 2015 & Falls not measured \\
\hline Forsberg 2016 & Falls not measured \\
\hline Francavilla 2015 & Abstract only published. Authors contacted twice for unpublished data without reply \\
\hline
\end{tabular}




\begin{tabular}{|c|c|}
\hline Study & Reason for exclusion \\
\hline Goodman 2008 & Not falls prevention intervention \\
\hline Kalgarfard 2013 & Falls not measured \\
\hline Kalron 2016 & Falls not measured \\
\hline Kramer 2014 & Controlled before-and-after study \\
\hline Marzal Alfaro 2016 & Case series. Uncontrolled longitudinal study \\
\hline McAuley 2007 & Falls not measured \\
\hline Monjezi 2017 & Falls not measured \\
\hline NCT01829776 & Case series. Uncontrolled longitudinal study \\
\hline Nedeljkoviü 2014 & Review \\
\hline Nilsagard 2014 & Single-group. Pre-intervention post-intervention study \\
\hline O'Hara 2002 & Falls not measured \\
\hline Prosperini 2010 & Controlled before-and-after study \\
\hline Prosperini 2014 & Case series. Uncontrolled longitudinal study \\
\hline Sandroff 2014 & Falls not measured \\
\hline Sebastiao 2017 & Study protocol \\
\hline Segev-Jacubovski 2011 & Review \\
\hline Tarakci 2013 & Falls not measured \\
\hline Ward 2004 & $\begin{array}{l}\text { The study included } 53 \text { participants with Parkinson's disease and } 45 \text { participants with MS. } \\
\text { Separate data for participants with MS were not reported in the published article and not avail- } \\
\text { able from authors }\end{array}$ \\
\hline Zenginler 2016 & Abstract only published. Data unavailable from authors \\
\hline
\end{tabular}

Characteristics of studies awaiting assessment [ordered by study ID]

Cattaneo 2018

\begin{tabular}{ll}
\hline Methods & A bi-centre randomised rater-blinded controlled trial \\
\hline Participants & People with MS \\
\hline Interventions & $\begin{array}{l}\text { Participants in the intervention group received treatment aimed at improving balance and mobili- } \\
\text { ty. Participants in the control group received treatments to reduce limitations at activity and body } \\
\text { function level }\end{array}$
\end{tabular}

\section{Outcomes}

Primary measures were frequency of fallers ( $>1$ fall in two months) and responders ( $>3$ points improvement) at the Berg Balance Scale (BBS) 
Cattaneo 2018 (Continued)

Notes If suitable, we will include this study in the next iteration of this Cochrane review

Kannan 2017

\begin{tabular}{ll}
\hline Methods & Randomised controlled trial \\
\hline Participants & People with MS \\
\hline Interventions & $\begin{array}{l}\text { Participants in the intervention group will receive a "free from falls online" intervention, consisting } \\
\text { of } 8 \text { weekly } 30 \text {-minute webinars with supplementary printable material and an hour long exercise } \\
\text { video demonstrating exercises targeted for improving balance and posture }\end{array}$ \\
\hline Outcomes & $\begin{array}{l}\text { Outcomes are all assessed remotely and include fall frequency and self-reported measures physi- } \\
\text { cal function, fatigue, self-efficacy, psychosocial illness impact, social participation and satisfaction } \\
\text { and perception of global health }\end{array}$ \\
\hline Notes & $\begin{array}{l}\text { This is published only in abstract format and we await the full text and suitable data for the next it- } \\
\text { eration of this Cochrane review }\end{array}$ \\
\hline
\end{tabular}

Martini 2018

\begin{tabular}{ll}
\hline Methods & Randomised controlled trial \\
\hline Participants & People with MS using a walking aid at baseline who had fallen in the previous year \\
\hline Interventions & $\begin{array}{l}\text { Participants in the intervention group were randomised to the Assistive Device Selection, Training } \\
\text { and Education Program (ADSTEP) intervention ( } 6 \text { weekly, } 40-\text { minute, } 1 \text {-on- } 1 \text { sessions with a physi- } \\
\text { cal therapist) and participants in the control group were randomised to usual medical care with the } \\
\text { option of ADSTEP after the study }\end{array}$
\end{tabular}

Outcomes

The following were assessed at baseline, intervention completion, and 3 months later: falls, timed up and go, timed 25-foot walk, 2-minute walk, four square step test, international physical activity questionnaire, Quebec user evaluation of satisfaction with assistive technologies, Multiple Sclerosis walking scale-12, activities-specific balance confidence scale, and Multiple Sclerosis impact scale-29

Notes

If suitable, we will include this study in the next iteration of this Cochrane review

\section{Characteristics of ongoing studies [ordered by study ID]}

\section{ACTRN12616000415404}

Trial name or title

Methods

\begin{tabular}{ll}
\hline Participants & Participants with MS \\
\hline Interventions & $\begin{array}{l}\text { Experimental treatment: four exercises at home on a whole body vibration (WBV) board, at least } 3 \\
\text { times a week for } 10 \text { weeks. Each exercise session should take } 30 \text { minutes }\end{array}$
\end{tabular}

Interventions for preventing falls in people with multiple sclerosis (Review)

Copyright @ 2019 The Cochrane Collaboration. Published by John Wiley \& Sons, Ltd.

Do interventions targeting proprioceptive feedback and exercise improve functional gait and reduce falls and falls risk in people with MS?

Randomised controlled trial 
ACTRN12616000415404 (Continued)

Control treatment: the treatment will be the same as in the WBV group, except that participants will perform the same four exercises on a hard stable surface at least 3 times a week for 10 weeks

\section{Outcomes}

Primary: falls risk will be assessed using the Physiological Profile Assessment (PPA) fall risk index score. This is a series of tests composed of weighted values from five sensorimotor and balance domains: quadriceps muscle strength, hand reaction time, proprioception, postural sway, and visual contrast sensitivity. Falls risk will be measured at baseline and at 10 weeks after the commencement of the intervention.

\begin{tabular}{ll}
\hline Starting date & 18/04/2016 \\
\hline Contact information & Dr David Kennedy. University of Sydney, East St Lidcombe. NSW. 2141 Australia \\
& phone: +61 293519589 \\
& email: david.kennedy@sydney.edu.au \\
\hline
\end{tabular}

Notes

\section{ACTRN12616001053415}

Trial name or title
An interactive step training system to reduce falls in people with multiple sclerosis: a randomised controlled trial

\begin{tabular}{ll}
\hline Methods & Randomised controlled trial \\
\hline Participants & $\begin{array}{l}\text { Confirmed diagnosis of Multiple Sclerosis with Expanded Disability Status Scale score between } 2 \\
\text { and } 6\end{array}$
\end{tabular}

Interventions

Balance and step training delivered through a novel home-based step-training system (smart +/step). The system involves a computerised training mat measuring approximately one square metre with eight step panels and connected to a visual display (television or computer screen) that displays training instructions and game-based stepping exercises. The control group: participants not engaging in the minimum weekly training dose for 2 consecutive weeks will be contacted by telephone to discuss any issues and to encourage adherence during the 6-month intervention period

Outcomes

The proportion of fallers in each group: Falls will be monitored with monthly falls diaries for the 12 months after baseline assessment; The rate of fallers in each group: Falls will be monitored with monthly falls diaries for the 12 months after baseline assessment;Static and dynamic balance will be measured using the swaymeter device from the Physiological Profile Assessment;Clinical measures of lower leg strength will be measured using a dynamometer;Clinical measures of gait (velocity and distance) will be assessed with the 10-metre and 6-minute walk tests;Clinical measures of stepping will be measured using the Choice Stepping Reaction Time (CSRT) tests;MS disease severity will be measured using the Multiple Sclerosis Functional Composite (MSFC); Questionnaire measure of concern about falling using the Iconographical Falls Efficacy Scale;Questionnaire measure of physical activity levels using the Incidental Planned Exercise Questionnaire;Cognition measured using the Trails A and Trails B tests; Questionnaire measure of quality of life using the European Quality of Life - 5 Dimensions and World Health Organisation Disability Assessment Schedule 2.0; Questionnaire measure of mood using the Patient Health Questionnaire-9; Questionnaire measure of fatigue using the Modified Fatigue Impact Scale;Cost-effectiveness of the intervention measured by data linkage to fall-related medical health records;Movement detection threshold about the ankle joint measured using a motorised foot plate designed for this study;Maximal isometric voluntary force of the calf muscles measured with surface electrodes <br>;Measures of sleep disruption using a take-home sleep testing device. Home testing will be performed using either a standard Type 2 (e.g. Nox A1 Polysomnography system) or Type 3 (e.g. ResMed ApneaLink plus) device.;Questionnaire measures of sleepiness and sleep quality using the Epworth Sleepiness Scale, Functional outcomes of sleep questionnaire, Karolinska sleepiness scale, and Pittsburgh sleepi- 
ACTRN12616001053415 (Continued)

ness scale;Screening questionnaires for the presence of sleep apnoea measured using the STOP BANG, Berlin sleep questionnaire, and OSA50; Joint position sense about the ankle joint measured using a motorised foot plate designed for this study; Reaction time to small movements about the ankle joint using a motorised foot plate designed for this study;Voluntary activation of the calf muscles using twitch interpolation and measured with surface electrodes; Twitch force of the calf muscles elicited by electrical stimulation and measured with surface electrodes;Fatigue of the calf muscles with a sustained isometric contraction measured with electrical muscle stimulation and surface electrodes; Daily life walking patterns measured with a wearable physical activity monitor over a seven day period ; Sit to stand transitions measured with a wearable physical activity monitor over a seven day period;Number of near falls, slips or trips measured with a wearable physical activity monitor over a seven day period;Total energy expenditure from activities of daily living measured with a wearable physical activity monitor over a seven day period;Sedentary time measured with a wearable physical activity monitor over a seven day period;Daily life sleeping patterns measured with a wearable physical activity monitor over a seven day period;Dual task cost assessed with a dual task and 10-metre walk

\begin{tabular}{ll}
\hline Starting date & $23 / 08 / 2016$ \\
\hline Contact information & s.lord@neura.edu.au \\
\hline Notes & Ongoing study- recruiting \\
\hline
\end{tabular}

\section{Hatton 2016}

\section{Trial name or title}

Methods

Do textured insoles alter gait, foot sensation \& proprioception in people with Multiple Sclerosis?

Quasi-randomised controlled trial

176 community-dwelling pwMS, across Brisbane, Australia. Adults with a diagnosis of MS (disease steps 1-4), who

are ambulant over 100 meters, and meet specific inclusion criteria, will be recruited

\begin{tabular}{ll}
\hline Interventions & Participants will be randomised to a smooth control insole $(\mathrm{N}=88)$ or textured insole $(\mathrm{N}=88)$ group \\
\hline Outcomes & $\begin{array}{l}\text { The primary outcome measure will be mediolateral base of support when walking over even and } \\
\text { uneven surfaces. } \\
\text { Secondary outcome measures include: spatio temporal gait parameters, gait kinematics, foot sen- } \\
\text { sation (light touch-pressure, vibration, 2-point discrimination) and proprioception (ankle joint po- } \\
\text { sition sense) }\end{array}$ \\
\hline
\end{tabular}

$$
\text { Starting date }
$$

Contact information a.hatton1@uq.edu.au

Notes Study protocol published- Ongoing study- data collection stage

\section{ISRCTN13587999 (Gunn 2017)}

$\begin{array}{ll}\text { Trial name or title } & \text { Balance right in Multiple Sclerosis (BRiMS): a guided self-management programme to reduce falls } \\ & \text { and improve quality of life, balance and mobility in people with secondary progressive multiple } \\ \text { sclerosis: a protocol for a feasibility randomised controlled trial }\end{array}$


ISRCTN13587999 (Gunn 2017) (Continued) Participants $\begin{aligned} & \text { Sixty ambulant people with secondary progressive MS who self-report two or more falls in the pre- } \\ & \text { vious 6-months }\end{aligned}$

Interventions BRiMS programme plus usual care or to usual care alone

Outcomes Feasibility outcomes, including trial recruitment, retention and completionAssessment of the proposed outcome measures for the anticipated definitive trial (including measures of walking, quality of life, falls, balance and activity level). Measures of adherence to the BRiMS programme and data to inform the economic evaluation in a future trial. Process evaluation (assessment of treatment fidelity)

\begin{tabular}{ll} 
Starting date & 09/01/2017 \\
\hline Contact information & margie.berrow@plymouth.ac.uk \\
\hline Notes & Ongoing study
\end{tabular}

\section{NCT02314585}

\begin{tabular}{ll}
\hline Trial name or title & Fall risk reduction in multiple sclerosis: exercise intervention vs. attention control modification \\
\hline Methods & Randomised controlled trial \\
\hline Participants & $\begin{array}{l}\text { People with an established definite diagnosis of MS. Ability to walk } 25 \text { feet with or without aid. Re- } \\
\text { lapse free in the last } 30 \text { days. Being= } 50 \text { years of age. Having fallen at least once in the past year }\end{array}$ \\
\hline Interventions & Exercise versus education \\
\hline Outcomes & Primary: change in fall risk; secondary: identification of fall risk factors \\
\hline Starting date & December 2014 \\
\hline Contact information & jwajda@illinois.edu;jwajda@illinois.edu \\
\hline Notes & Ongoing study, data collection
\end{tabular}

\section{NCT02583386}

\begin{tabular}{ll}
\hline Trial name or title & Comprehensive fall prevention and detection in multiple sclerosis \\
\hline Methods & Randomised controlled trial \\
\hline Participants & $\begin{array}{l}\text { The investigators will recruit } 94 \text { people with multiple sclerosis, who report having fallen at least } \\
\text { twice in the previous } 2 \text { months. }\end{array}$ \\
\hline Interventions & $\begin{array}{l}\text { Participants will be randomised to be placed in either a group that receives classroom training dur- } \\
\text { ing the study, or into a wait-listed control group that will be offered the classroom training after } \\
\text { their participation in the study is completed. } \\
\text { In addition, } 30 \text { participants will be randomised to wear electronic fall detectors on their bodies for } \\
\text { the duration of the study. These detectors will record when and where falls occur, and this data will } \\
\text { be compared with the participants' self-reported falls as recorded on the falls calendars }\end{array}$
\end{tabular}


NCT02583386 (Continued)

Outcomes

All participants will receive mobility and quality of life assessments at baseline, 9 weeks, 5 months, and 8 months. All participants will be asked to record any falls they have on falls calendars

\begin{tabular}{ll}
\hline Starting date & April 2016 \\
\hline Contact information & cameromi@ohsu.edu \\
\hline Notes & Ongoing study, data collection
\end{tabular}

\section{NCT02694666}

\begin{tabular}{ll}
\hline Trial name or title & Vibration training for preventing falls in healthy population and multiple sclerosis \\
\hline Methods & Randomised parallel controlled trial \\
\hline Participants & Healthy population and people with multiple sclerosis \\
\hline Interventions & $\begin{array}{l}\text { Vibration training group: the vibration group will receive 8-week controlled whole-body vibration } \\
\text { training as the intervention on the Galileo Med L device } \\
\text { Placebo comparator: placebo training group } \\
\text { The placebo group will receive 8-week placebo training on the Galileo Med L device }\end{array}$ \\
\hline Outcomes & Primary: real life falls. Time frame: up to 12 months \\
\hline Starting date & April 2015 \\
\hline Contact information & Georgia State University. Pl: Feng Yang \\
\hline Notes & Estimated study completion date: December 2020 \\
\hline
\end{tabular}

\section{NCT02885233}

\section{Trial name or title}

Methods

Participants

Interventions

Outcomes
Evaluation of a web-based fall prevention program on people with multiple sclerosis

$$
\text { Randomised controlled trial }
$$

MS of any type with no relapse in the previous month. Self-reported history of 2 or more falls in the previous 2 months. Ability to walk at least 100 meters with intermittent or unilateral constant assistance (Expanded Disability Severity Scale step <6.0)

\section{Experimental group (behavioral): free from falls online; control group: wait-list}

Primary outcome: difference in mean change in total falls between intervention and control arms; difference in mean change in total falls between intervention and control arms. Secondary outcomes: difference in patient reported outcomes including physical function, fatigue, self efficacy, psychosocial illness impact, social participation and satisfaction, and perception of global health between intervention and control arms

\begin{tabular}{ll}
\hline Starting date & August 2016 \\
\hline Contact information & cameromi@ohsu.edu \\
\hline
\end{tabular}


NCT02885233 (Continued)

Notes Ongoing study- data collection

DATA AND ANALYSES

Comparison 1. Exercise versus control

\begin{tabular}{lllll}
\hline Outcome or subgroup title & $\begin{array}{l}\text { No. of } \\
\text { studies }\end{array}$ & $\begin{array}{l}\text { No. of } \\
\text { partici- } \\
\text { pants }\end{array}$ & Statistical method & Effect size \\
\hline 1 Falls rate & 5 & 399 & Rate Ratio (Random, 95\% Cl) & $0.68[0.43,1.06]$ \\
\hline 2 Number of fallers & 5 & 355 & Risk Ratio (M-H, Random, 95\% Cl) & $0.85[0.51,1.43]$ \\
\hline 3 Adverse events & 3 & 97 & Risk Ratio (M-H, Fixed, 95\% Cl) & $1.25[0.26,6.03]$ \\
\hline
\end{tabular}

Analysis 1.1. Comparison 1 Exercise versus control, Outcome 1 Falls rate.

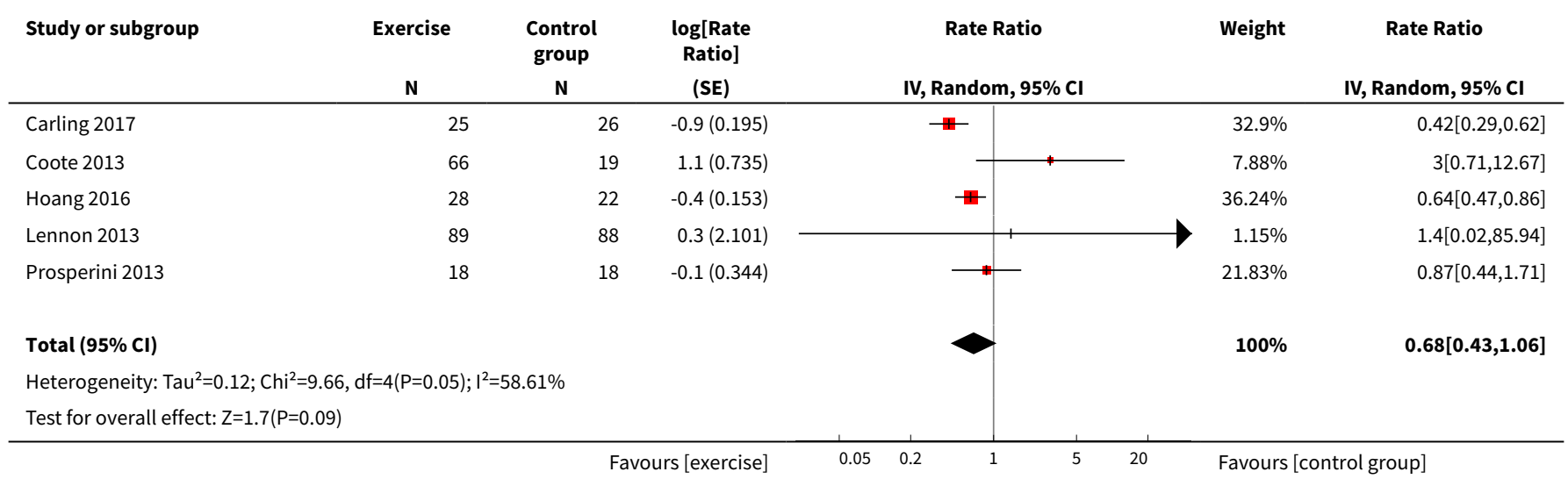

Analysis 1.2. Comparison 1 Exercise versus control, Outcome 2 Number of fallers.

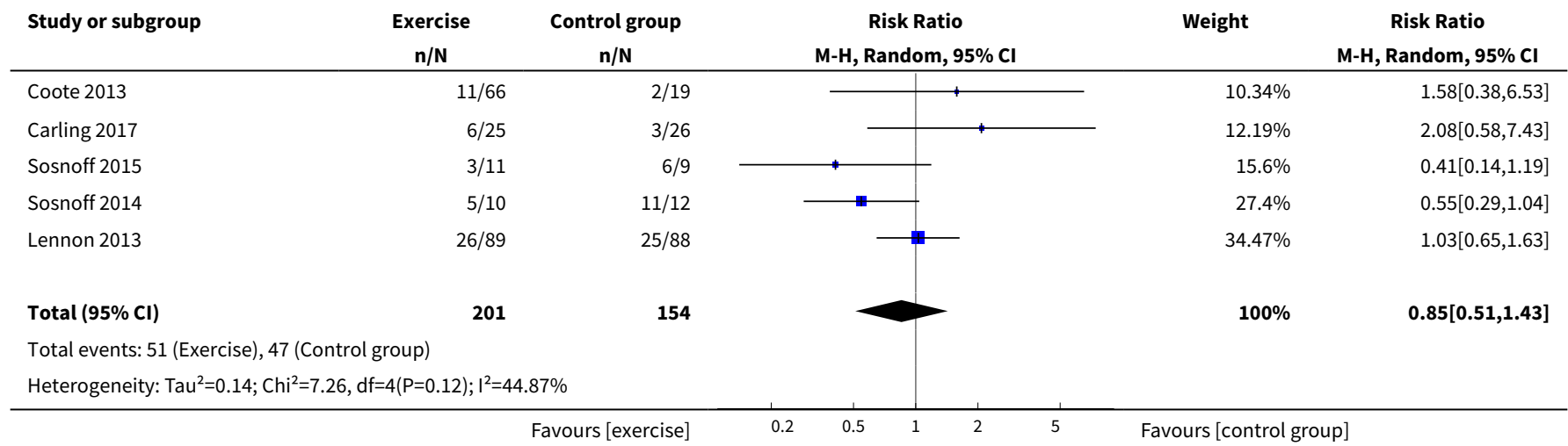




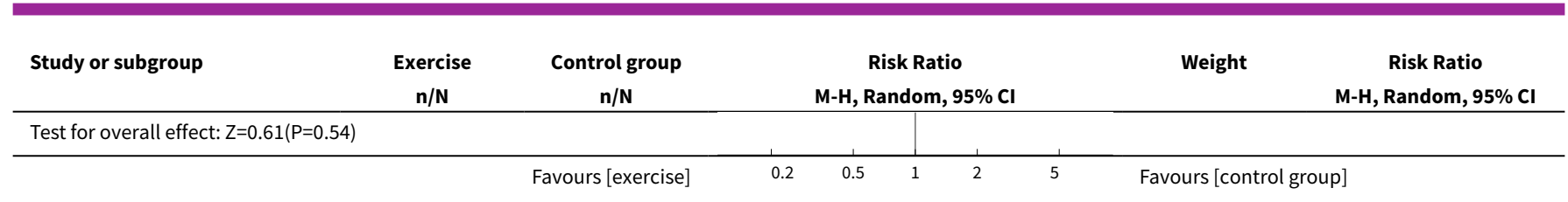

Analysis 1.3. Comparison 1 Exercise versus control, Outcome 3 Adverse events.

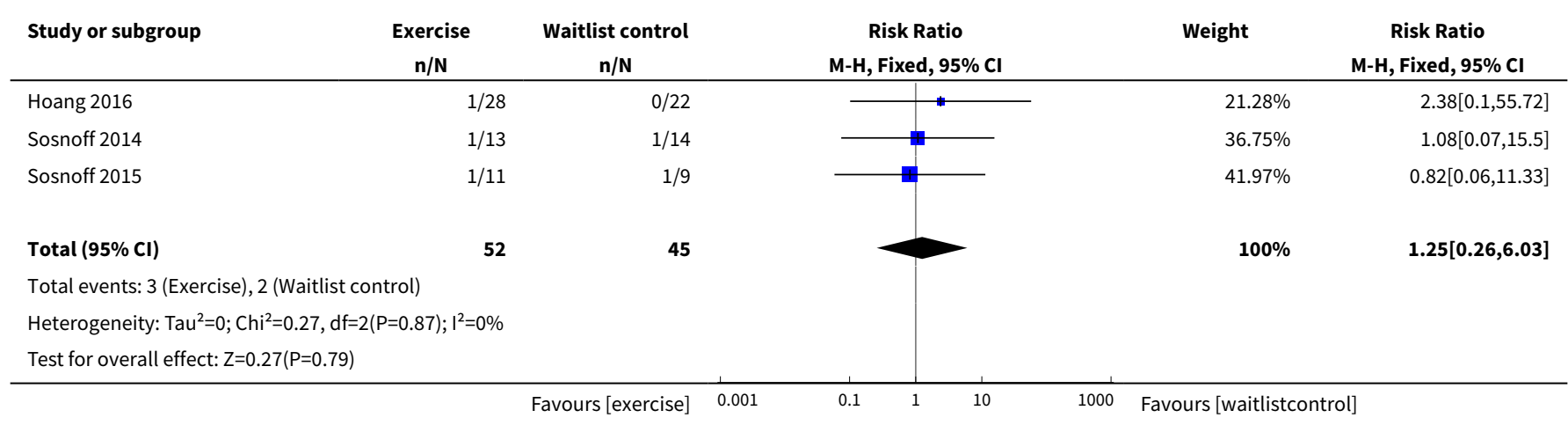

\section{Comparison 2. Education versus control}

\begin{tabular}{lllll}
\hline Outcome or subgroup title & $\begin{array}{l}\text { No. of } \\
\text { studies }\end{array}$ & $\begin{array}{l}\text { No. of } \\
\text { partici- } \\
\text { pants }\end{array}$ & Statistical method & Effect size \\
\hline 1 Number of fallers & 1 & & Risk Ratio (M-H, Fixed, 95\% Cl) & Totals not selected \\
\hline 2 Adverse events & 1 & Risk Ratio (M-H, Fixed, $95 \% \mathrm{Cl})$ & Totals not selected \\
\hline
\end{tabular}

Analysis 2.1. Comparison 2 Education versus control, Outcome 1 Number of fallers.

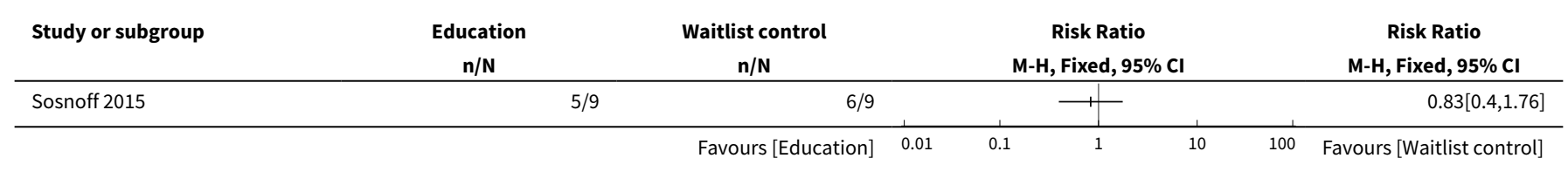

Analysis 2.2. Comparison 2 Education versus control, Outcome 2 Adverse events.

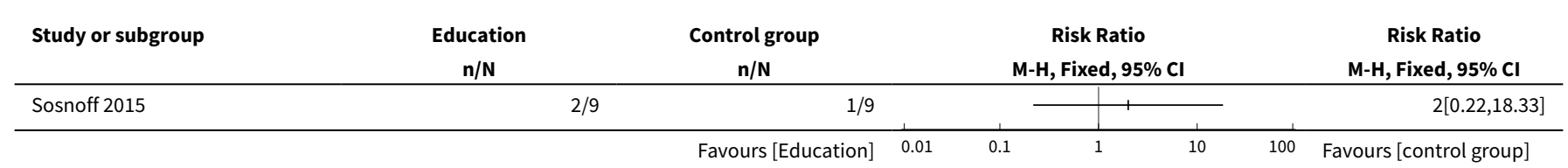


Comparison 3. Exercise plus education versus control

\begin{tabular}{lllll}
\hline Outcome or subgroup title & $\begin{array}{l}\text { No. of } \\
\text { studies }\end{array}$ & $\begin{array}{l}\text { No. of } \\
\text { partici- } \\
\text { pants }\end{array}$ & Statistical method & Effect size \\
\hline 1 Number of fallers & 1 & Risk Ratio (M-H, Fixed, 95\% Cl) & Totals not selected \\
\hline 2 Adverse events & 1 & Risk Ratio (M-H, Fixed, 95\% Cl) & Totals not selected \\
\hline
\end{tabular}

Analysis 3.1. Comparison 3 Exercise plus education versus control, Outcome 1 Number of fallers.

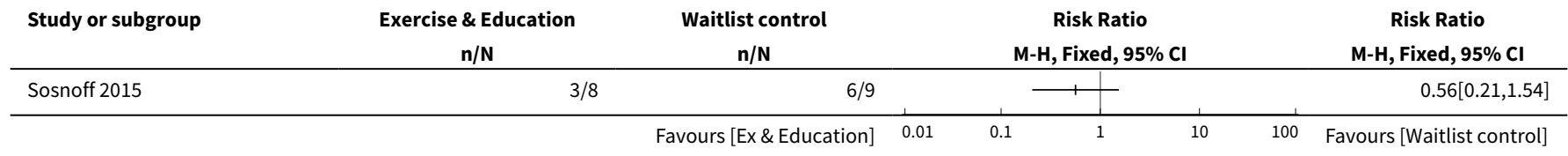

Analysis 3.2. Comparison 3 Exercise plus education versus control, Outcome 2 Adverse events.

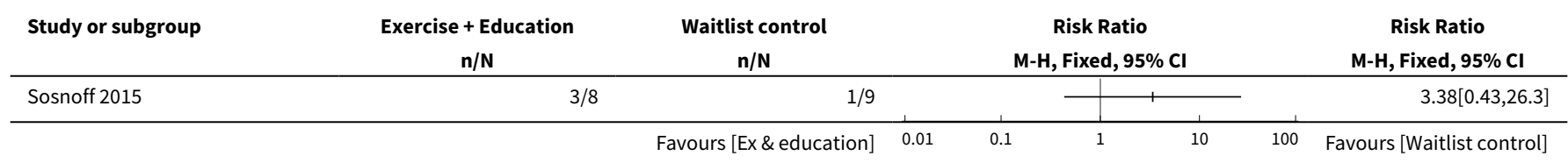

Comparison 4. Individual exercise versus control

\begin{tabular}{lllll}
\hline Outcome or subgroup title & $\begin{array}{l}\text { No. of } \\
\text { studies }\end{array}$ & $\begin{array}{l}\text { No. of } \\
\text { partici- } \\
\text { pants }\end{array}$ & Statistical method & Effect size \\
\hline 1 Falls rate & 1 & & Rate Ratio (Fixed, 95\% Cl) & Totals not selected \\
\hline 2 Number of fallers & 1 & Risk Ratio (M-H, Fixed, 95\% Cl) & Totals not selected \\
\hline
\end{tabular}

Analysis 4.1. Comparison 4 Individual exercise versus control, Outcome 1 Falls rate.

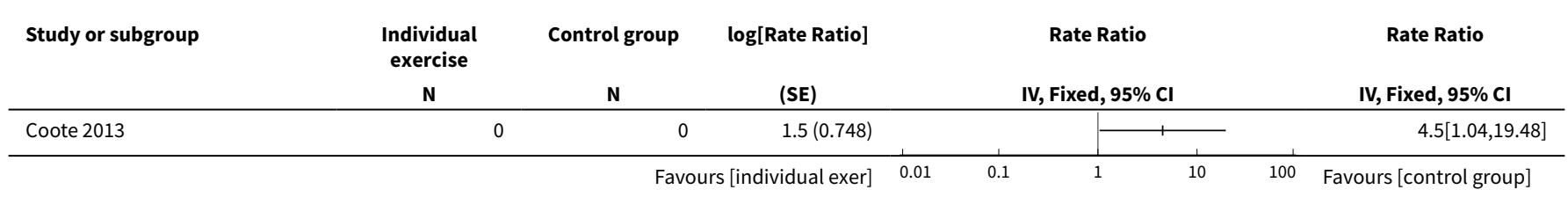


Analysis 4.2. Comparison 4 Individual exercise versus control, Outcome 2 Number of fallers.

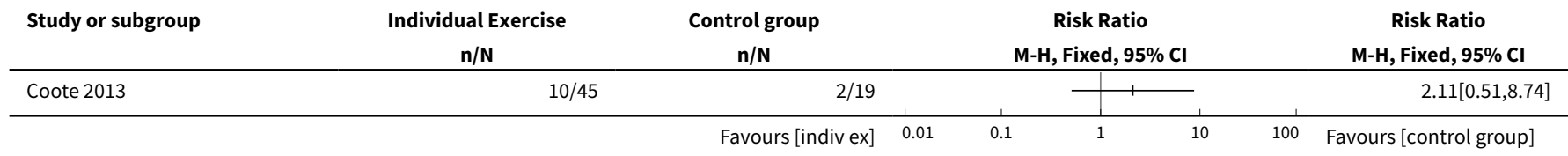

Comparison 5. Yoga versus control

\begin{tabular}{lllll}
\hline Outcome or subgroup title & $\begin{array}{l}\text { No. of } \\
\text { studies }\end{array}$ & $\begin{array}{l}\text { No. of partici- } \\
\text { pants }\end{array}$ & Statistical method & Effect size \\
\hline 1 Falls rate & 1 & Rate Ratio (Fixed, 95\% Cl) & Totals not selected \\
\hline
\end{tabular}

Analysis 5.1. Comparison 5 Yoga versus control, Outcome 1 Falls rate.

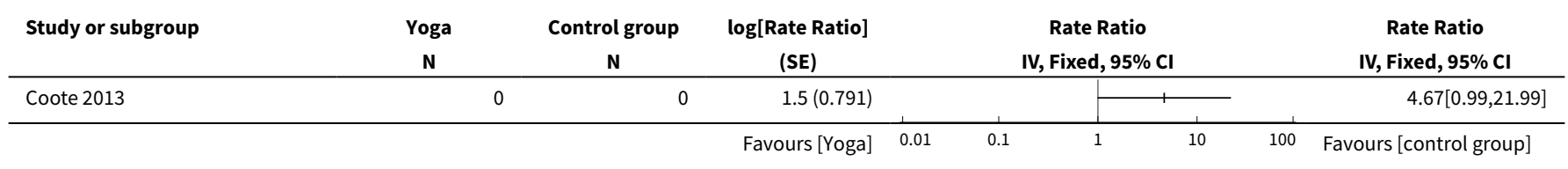

Comparison 6. Functional Electrical Stimulation versus Exercise

\begin{tabular}{lllll}
\hline Outcome or subgroup title & $\begin{array}{l}\text { No. of } \\
\text { studies }\end{array}$ & $\begin{array}{l}\text { No. of } \\
\text { partici- } \\
\text { pants }\end{array}$ & Statistical method & Effect size \\
\hline 1 Falls rate & 2 & & Rate Ratio (Random, 95\% Cl) & $0.91[0.78,1.06]$ \\
\hline 2 Adverse events & 1 & Risk Ratio (M-H, Fixed, 95\% Cl) & Totals not selected \\
\hline
\end{tabular}

Analysis 6.1. Comparison 6 Functional Electrical Stimulation versus Exercise, Outcome 1 Falls rate.

\begin{tabular}{|c|c|c|c|c|c|c|}
\hline \multirow[t]{2}{*}{ Study or subgroup } & FES & Exercise & \multirow{2}{*}{$\begin{array}{c}\log [\text { Rate } \\
\text { Ratio] } \\
\text { (SE) }\end{array}$} & \multirow{2}{*}{$\begin{array}{c}\text { Rate Ratio } \\
\text { IV, Random, } 95 \% \text { CI }\end{array}$} & \multirow[t]{2}{*}{ Weight } & \multirow{2}{*}{$\begin{array}{l}\text { Rate Ratio } \\
\text { andom, } 95 \% \mathrm{Cl} \\
\end{array}$} \\
\hline & $\mathbf{N}$ & $\mathbf{N}$ & & & & \\
\hline Esnouf 2010 & 0 & 0 & $-0.2(0.037)$ & & $68.4 \%$ & $0.86[0.8,0.92]$ \\
\hline Taylor 2014 & 0 & 0 & $0(0.11)$ & + & $31.6 \%$ & $1.02[0.82,1.27]$ \\
\hline Total $(95 \% \mathrm{Cl})$ & & & & & $100 \%$ & $0.91[0.78,1.06]$ \\
\hline \multicolumn{7}{|c|}{ Test for overall effect: $Z=1.22(P=0.22)$} \\
\hline & & & avours [FES] & 0.7 & Favours & \\
\hline
\end{tabular}


Analysis 6.2. Comparison 6 Functional Electrical Stimulation versus Exercise, Outcome 2 Adverse events.

\begin{tabular}{|c|c|c|c|c|c|c|c|}
\hline Study or subgroup & $\begin{array}{l}\text { FES } \\
n / N\end{array}$ & $\begin{array}{c}\text { Exercise } \\
\mathrm{n} / \mathrm{N}\end{array}$ & & \multicolumn{2}{|c|}{$\begin{array}{c}\text { Risk Ratio } \\
\text { M-H, Fixed, 95\% Cl }\end{array}$} & & \multirow{2}{*}{$\begin{array}{c}\text { Risk Ratio } \\
\begin{array}{c}\text { M-H, Fixed, } \mathbf{9 5} \% \mathbf{~ C l} \\
2[0.39,10.16\end{array}\end{array}$} \\
\hline Esnouf 2010 & $4 / 32$ & $2 / 32$ & & & $\mid$ & & \\
\hline
\end{tabular}

\section{Comparison 7. Exercise versus education}

\begin{tabular}{lllll}
\hline Outcome or subgroup title & $\begin{array}{l}\text { No. of } \\
\text { studies }\end{array}$ & $\begin{array}{l}\text { No. of } \\
\text { partici- } \\
\text { pants }\end{array}$ & Statistical method & Effect size \\
\hline 1 Falls rate & 1 & & Rate Ratio (Fixed, $95 \% \mathrm{Cl})$ & Totals not selected \\
\hline 2 Number of fallers & 1 & Risk Ratio $(\mathrm{M}-\mathrm{H}$, Fixed, $95 \% \mathrm{Cl})$ & Totals not selected \\
\hline 3 Adverse events & 1 & Risk Ratio (M-H, Fixed, 95\% Cl) & Totals not selected \\
\hline
\end{tabular}

Analysis 7.1. Comparison 7 Exercise versus education, Outcome 1 Falls rate.

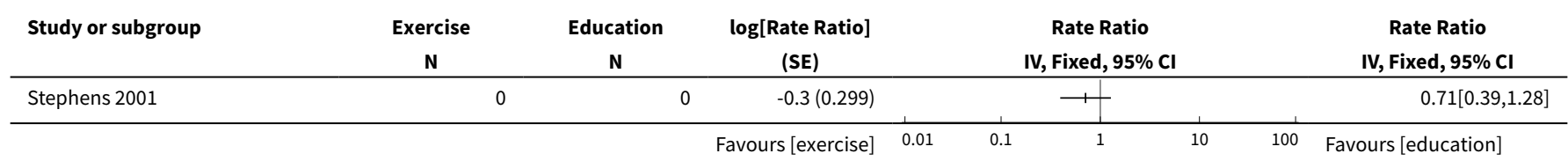

Analysis 7.2. Comparison 7 Exercise versus education, Outcome 2 Number of fallers.

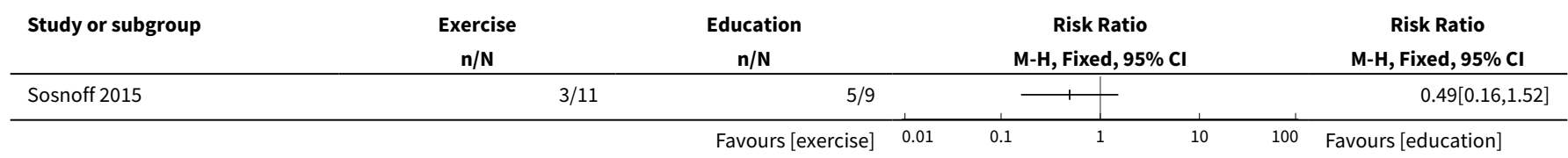

Analysis 7.3. Comparison 7 Exercise versus education, Outcome 3 Adverse events.

\begin{tabular}{|c|c|c|c|c|c|c|c|}
\hline Study or subgroup & $\begin{array}{c}\text { Exercise } \\
\mathrm{n} / \mathrm{N}\end{array}$ & $\begin{array}{c}\text { Education } \\
\mathrm{n} / \mathrm{N} \\
\end{array}$ & & & $\begin{array}{l}\text { k Ratio } \\
\text { xed, } 95 \% \mathrm{Cl}\end{array}$ & & $\begin{array}{c}\text { Risk Ratio } \\
\text { M-H, Fixed, } 95 \% \mathrm{Cl}\end{array}$ \\
\hline Sosnoff 2015 & $1 / 11$ & $2 / 9$ & & 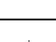 & \begin{tabular}{l|l} 
\\
\end{tabular} & & $0.41[0.04,3.82]$ \\
\hline
\end{tabular}


Comparison 8. Exercise versus Exercise plus Education (post-intervention)

\begin{tabular}{lllll}
\hline Outcome or subgroup title & $\begin{array}{l}\text { No. of } \\
\text { studies }\end{array}$ & $\begin{array}{l}\text { No. of } \\
\text { partici- } \\
\text { pants }\end{array}$ & Statistical method & Effect size \\
\hline 1 Number of fallers & 1 & Risk Ratio (M-H, Fixed, $95 \% \mathrm{Cl})$ & Totals not selected \\
\hline 2 Adverse events & 1 & Risk Ratio (M-H, Fixed, 95\% Cl) & Totals not selected \\
\hline
\end{tabular}

Analysis 8.1. Comparison 8 Exercise versus Exercise plus Education (post-intervention), Outcome 1 Number of fallers.

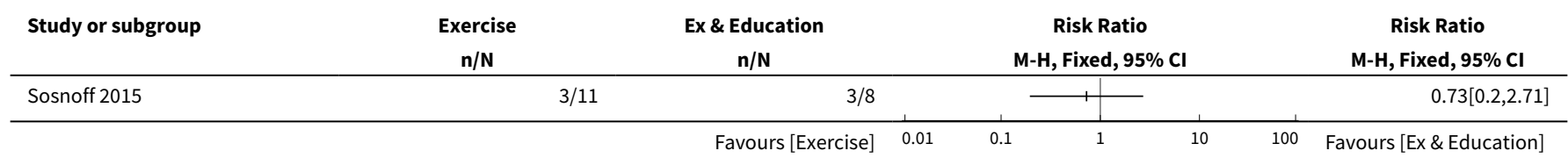

Analysis 8.2. Comparison 8 Exercise versus Exercise plus Education (post-intervention), Outcome 2 Adverse events.

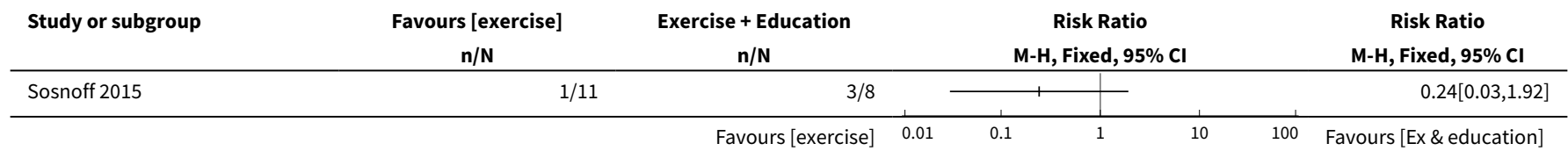

Comparison 9. Education versus Exercise plus Education (post-intervention)

\begin{tabular}{lllll}
\hline Outcome or subgroup title & $\begin{array}{l}\text { No. of } \\
\text { studies }\end{array}$ & $\begin{array}{l}\text { No. of } \\
\text { partici- } \\
\text { pants }\end{array}$ & Statistical method & Effect size \\
\hline 1 Number of fallers & 1 & & Risk Ratio (M-H, Fixed, 95\% Cl) & Totals not selected \\
\hline 2 Adverse events & 1 & Risk Ratio (M-H, Fixed, 95\% Cl) & Totals not selected \\
\hline
\end{tabular}

Analysis 9.1. Comparison 9 Education versus Exercise plus Education (post-intervention), Outcome 1 Number of fallers.

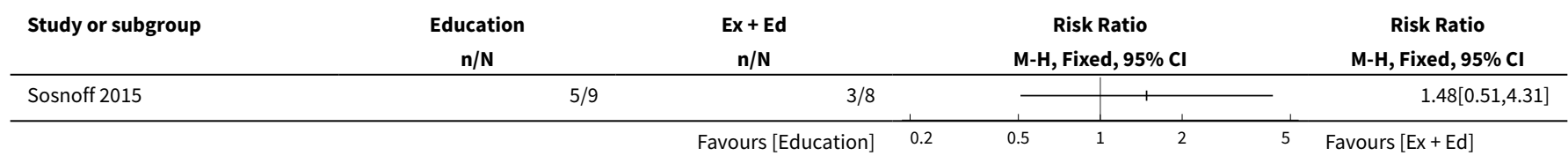


Analysis 9.2. Comparison 9 Education versus Exercise plus Education (post-intervention), Outcome 2 Adverse events.

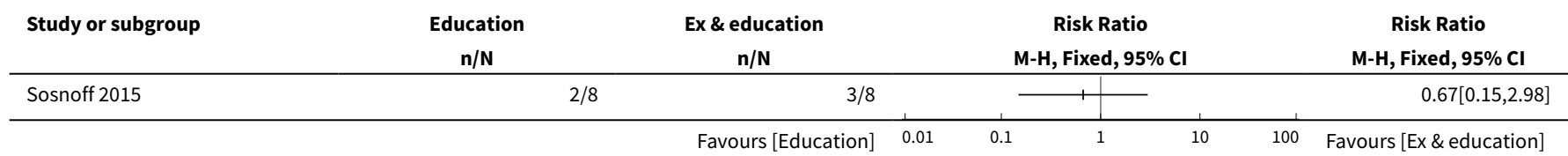

\section{Comparison 10. Sensory integration balance training versus conventional rehabilitation}

\begin{tabular}{lllll}
\hline Outcome or subgroup title & $\begin{array}{l}\text { No. of } \\
\text { studies }\end{array}$ & $\begin{array}{l}\text { No. of partici- } \\
\text { pants }\end{array}$ & Statistical method & Effect size \\
\hline 1 Falls rate & 1 & Rate Ratio (Fixed, 95\% Cl) & Totals not selected \\
\hline
\end{tabular}

Analysis 10.1. Comparison 10 Sensory integration balance training versus conventional rehabilitation, Outcome 1 Falls rate.

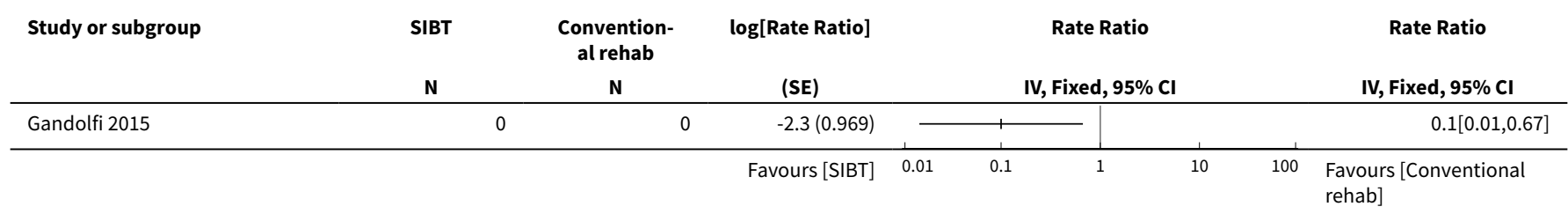

Comparison 11. Motor and sensory balance rehabilitation versus motor balance rehabilitation

\begin{tabular}{lllll}
\hline Outcome or subgroup title & $\begin{array}{l}\text { No. of } \\
\text { studies }\end{array}$ & $\begin{array}{l}\text { No. of } \\
\text { partici- } \\
\text { pants }\end{array}$ & Statistical method & Effect size \\
\hline 1 Falls rate & 1 & & Rate Ratio (Fixed, 95\% Cl) & Totals not selected \\
\hline 2 Number of fallers & 1 & Risk Ratio (M-H, Fixed, 95\% Cl) & Totals not selected \\
\hline
\end{tabular}

Analysis 11.1. Comparison 11 Motor and sensory balance rehabilitation versus motor balance rehabilitation, Outcome 1 Falls rate.

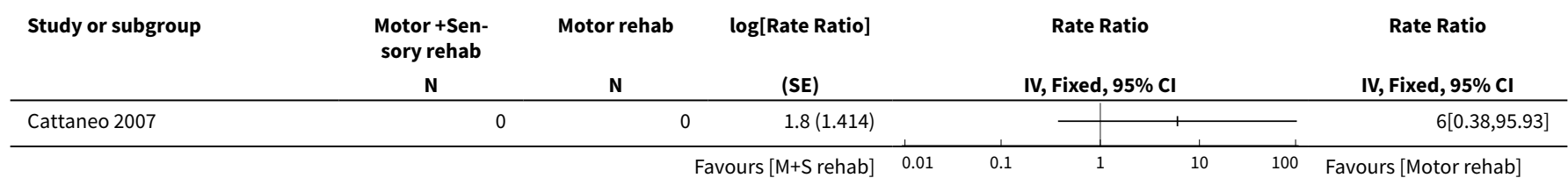


Analysis 11.2. Comparison 11 Motor and sensory balance rehabilitation versus motor balance rehabilitation, Outcome 2 Number of fallers.

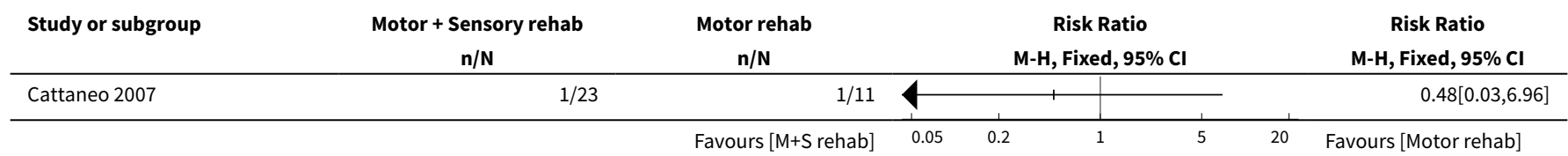

Comparison 12. Motor and sensory balance rehabilitation versus conventional rehabilitation

\begin{tabular}{lllll}
\hline Outcome or subgroup title & $\begin{array}{l}\text { No. of } \\
\text { studies }\end{array}$ & $\begin{array}{l}\text { No. of } \\
\text { partici- } \\
\text { pants }\end{array}$ & Statistical method & Effect size \\
\hline 1 Falls rate & 1 & Rate Ratio (Fixed, 95\% Cl) & Totals not selected \\
\hline 2 Number of fallers & 1 & Risk Ratio (M-H, Fixed, $95 \% \mathrm{Cl})$ & Totals not selected \\
\hline
\end{tabular}

Analysis 12.1. Comparison 12 Motor and sensory balance rehabilitation versus conventional rehabilitation, Outcome 1 Falls rate.

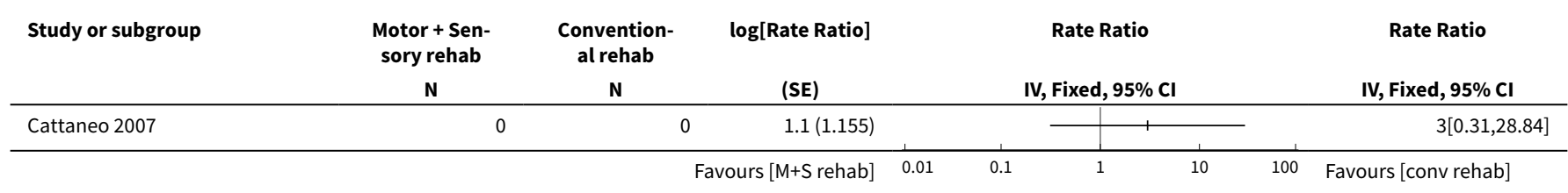

Analysis 12.2. Comparison 12 Motor and sensory balance rehabilitation versus conventional rehabilitation, Outcome 2 Number of fallers.

\begin{tabular}{|c|c|c|c|c|c|c|}
\hline \multirow{2}{*}{$\begin{array}{l}\text { Study or subgroup } \\
\text { Cattaneo } 2016\end{array}$} & $\begin{array}{c}\text { Motor + Sensory rehab } \\
\mathrm{n} / \mathrm{N} \\
\end{array}$ & $\begin{array}{c}\text { Conventional rehab } \\
\mathrm{n} / \mathrm{N}\end{array}$ & & \multicolumn{2}{|c|}{$\begin{array}{c}\text { Risk Ratio } \\
\text { M-H, Fixed, 95\% Cl }\end{array}$} & \multirow{2}{*}{$\begin{array}{c}\text { Risk Ratio } \\
\text { M-H, Fixed, 95\% Cl } \\
1.05[0.49,2.25]\end{array}$} \\
\hline & $16 / 78$ & $8 / 41$ & & & + & \\
\hline
\end{tabular}

\section{Comparison 13. Motor balance rehabilitation vs conventional non balance rehabilitation}

\begin{tabular}{llll}
\hline Outcome or subgroup title & $\begin{array}{l}\text { No. of } \\
\text { studies }\end{array}$ & $\begin{array}{l}\text { No. of } \\
\text { partici- } \\
\text { pants }\end{array}$ & Statistical method \\
\hline 1 Falls rate & 1 & Rate Ratio (Fixed, 95\% Cl) & Odds Ratio (M-H, Fixed, 95\% Cl) \\
\hline 2 Number of fallers & 1 & & Totals not selected \\
\hline
\end{tabular}


Analysis 13.1. Comparison 13 Motor balance rehabilitation vs conventional non balance rehabilitation, Outcome 1 Falls rate.

\begin{tabular}{|c|c|c|c|c|c|c|c|}
\hline Study or subgroup & $\begin{array}{c}\text { Experimental } \\
\mathrm{N} \\
\end{array}$ & $\begin{array}{c}\text { Control } \\
\mathrm{N}\end{array}$ & $\begin{array}{c}\log [\text { Rate Ratio }] \\
\text { (SE) }\end{array}$ & & $\begin{array}{c}\text { Rate Ratio } \\
\text { IV, Fixed, } 95 \% \text { CI }\end{array}$ & & $\begin{array}{c}\text { Rate Ratio } \\
\text { IV, Fixed, } 95 \% \text { CI }\end{array}$ \\
\hline Cattaneo 2007 & 0 & & $-0.7(1.155)$ & & \begin{tabular}{l|l}
1 & \\
\end{tabular} & & $0.5[0.05,4.81]$ \\
\hline
\end{tabular}

Analysis 13.2. Comparison 13 Motor balance rehabilitation vs conventional non balance rehabilitation, Outcome 2 Number of fallers.

\begin{tabular}{|c|c|c|c|c|c|c|c|}
\hline \multirow{2}{*}{$\begin{array}{l}\text { Study or subgroup } \\
\text { Cattaneo } 2007\end{array}$} & $\begin{array}{c}\text { Motor Balance rehab } \\
\qquad \mathrm{n} / \mathrm{N} \\
\end{array}$ & $\begin{array}{c}\text { Conventional rehab } \\
n / N\end{array}$ & \multicolumn{3}{|c|}{$\begin{array}{c}\text { Odds Ratio } \\
\text { M-H, Fixed, } 95 \% \mathrm{Cl}\end{array}$} & & \multirow{2}{*}{$\begin{array}{c}\begin{array}{c}\text { Odds Ratio } \\
\text { M-H, Fixed, } \mathbf{9 5} \% \mathbf{~ C l}\end{array} \\
1.2[0.07,21.72\end{array}$} \\
\hline & $1 / 11$ & $1 / 13$ & & $\longrightarrow$ & $1+$ & & \\
\hline
\end{tabular}

Comparison 14. Group exercise versus Yoga

\begin{tabular}{lllll}
\hline Outcome or subgroup title & $\begin{array}{l}\text { No. of } \\
\text { studies }\end{array}$ & $\begin{array}{l}\text { No. of } \\
\text { partici- } \\
\text { pants }\end{array}$ & Statistical method & Effect size \\
\hline 1 Falls rate & 1 & Rate Ratio (Fixed, 95\% Cl) & Totals not selected \\
\hline 2 Number of fallers & 1 & Risk Ratio (M-H, Fixed, 95\% Cl) & Totals not selected \\
\hline
\end{tabular}

Analysis 14.1. Comparison 14 Group exercise versus Yoga, Outcome 1 Falls rate.

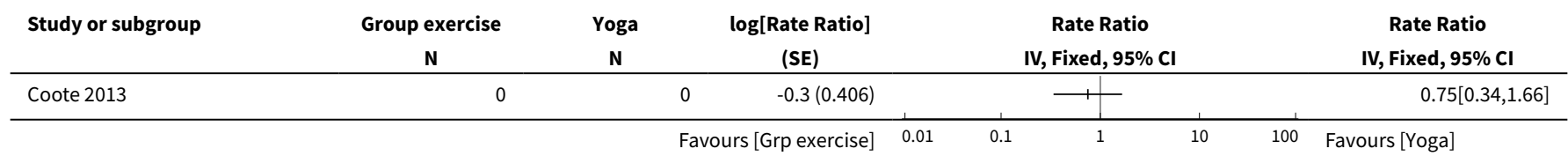

Analysis 14.2. Comparison 14 Group exercise versus Yoga, Outcome 2 Number of fallers.

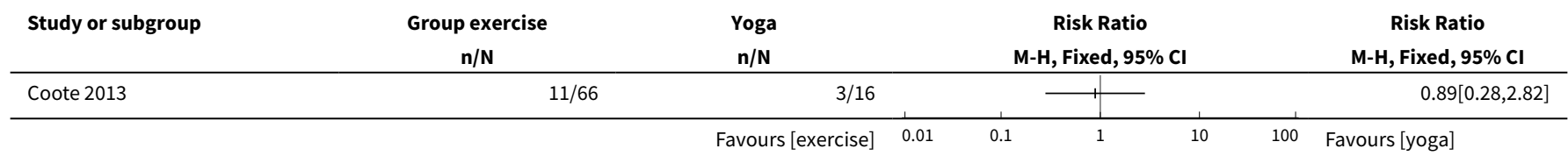


Comparison 15. Group exercise versus individual exercise

\begin{tabular}{lllll}
\hline Outcome or subgroup title & $\begin{array}{l}\text { No. of } \\
\text { studies }\end{array}$ & $\begin{array}{l}\text { No. of } \\
\text { partici- } \\
\text { pants }\end{array}$ & Statistical method & Effect size \\
\hline 1 Falls rate & 1 & Rate Ratio (Fixed, 95\% Cl) & Totals not selected \\
\hline 2 Number of fallers & 1 & Risk Ratio (M-H, Fixed, 95\% Cl) & Totals not selected \\
\hline
\end{tabular}

Analysis 15.1. Comparison 15 Group exercise versus individual exercise, Outcome 1 Falls rate.

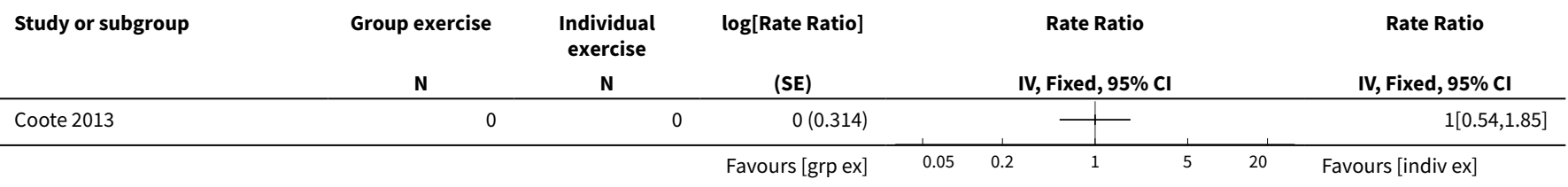

Analysis 15.2. Comparison 15 Group exercise versus individual exercise, Outcome 2 Number of fallers.

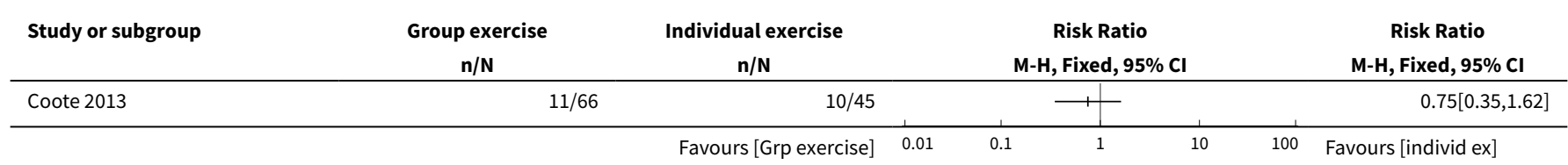

Comparison 16. Individual exercise versus yoga

\begin{tabular}{lllll}
\hline Outcome or subgroup title & $\begin{array}{l}\text { No. of } \\
\text { studies }\end{array}$ & $\begin{array}{l}\text { No. of } \\
\text { partici- } \\
\text { pants }\end{array}$ & Statistical method & Effect size \\
\hline 1 Falls rate & 1 & & Rate Ratio (Fixed, $95 \% \mathrm{Cl})$ & Totals not selected \\
\hline 2 Number of fallers & 1 & Risk Ratio (M-H, Fixed, 95\% Cl) & Totals not selected \\
\hline
\end{tabular}

Analysis 16.1. Comparison 16 Individual exercise versus yoga, Outcome 1 Falls rate.

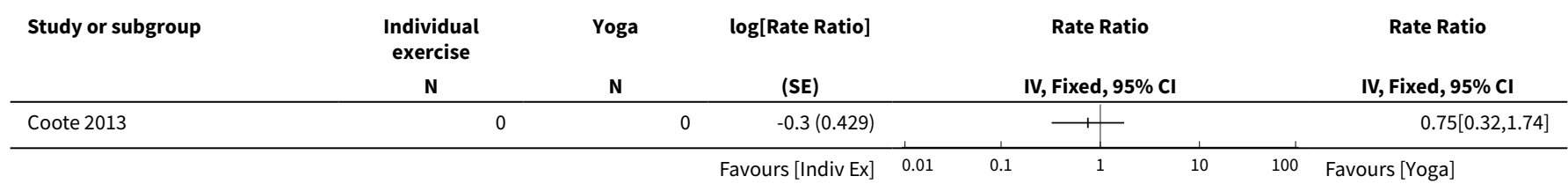


Analysis 16.2. Comparison 16 Individual exercise versus yoga, Outcome 2 Number of fallers.

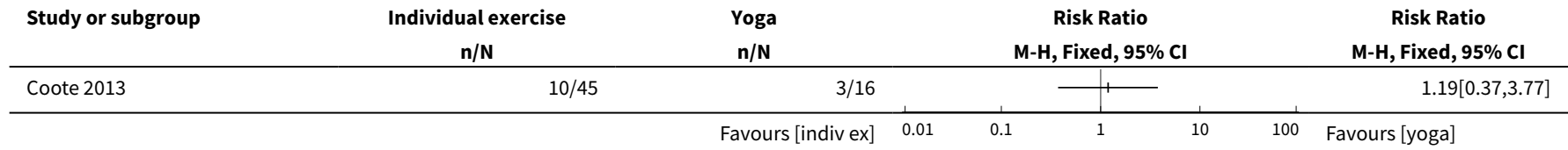

Comparison 17. Exercise versus control (3-month follow-up)

\begin{tabular}{lllll}
\hline Outcome or subgroup title & $\begin{array}{l}\text { No. of } \\
\text { studies }\end{array}$ & $\begin{array}{l}\text { No. of par- } \\
\text { ticipants }\end{array}$ & Statistical method & Effect size \\
\hline 1 Number of fallers & 1 & Risk Ratio (M-H, Random, 95\% Cl) & Totals not selected \\
\hline
\end{tabular}

Analysis 17.1. Comparison 17 Exercise versus control (3-month follow-up), Outcome 1 Number of fallers.

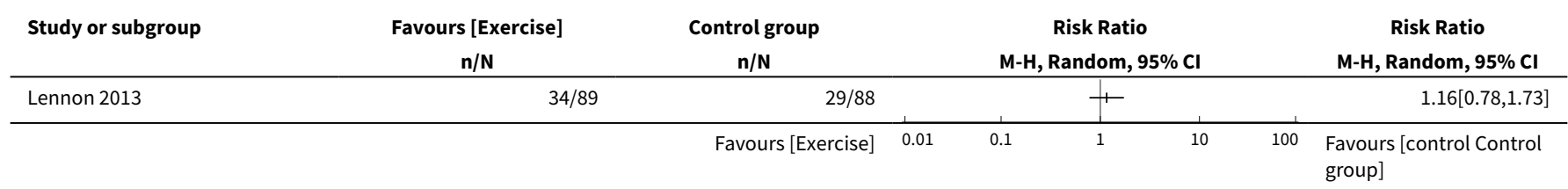

Comparison 18. Exercise versus control (6 month follow up)

\begin{tabular}{lllll}
\hline Outcome or subgroup title & $\begin{array}{l}\text { No. of } \\
\text { studies }\end{array}$ & $\begin{array}{l}\text { No. of par- } \\
\text { ticipants }\end{array}$ & Statistical method & Effect size \\
\hline 1 Number of fallers & 1 & & Risk Ratio $(\mathrm{M}-\mathrm{H}$, Random, 95\% Cl) & Totals not selected \\
\hline
\end{tabular}

Analysis 18.1. Comparison 18 Exercise versus control ( 6 month follow up), Outcome 1 Number of fallers.

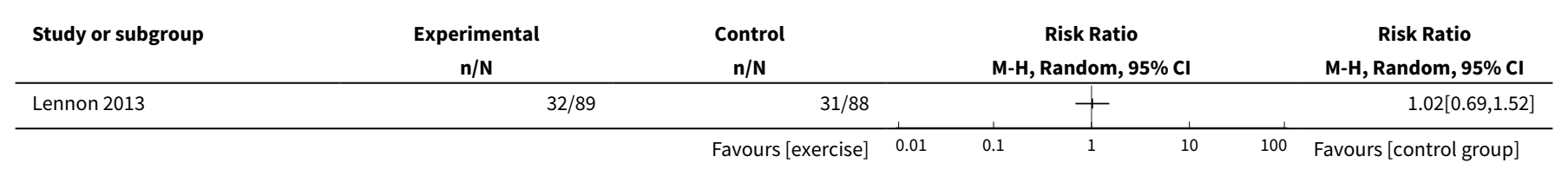

Comparison 19. Balance and mobility rehabilitation versus conventional rehabilitation ( 2 month follow-up)

\begin{tabular}{lllll}
\hline Outcome or subgroup title & $\begin{array}{l}\text { No. of } \\
\text { studies }\end{array}$ & $\begin{array}{l}\text { No. of par- } \\
\text { ticipants }\end{array}$ & Statistical method & Effect size \\
\hline 1 Number of fallers & 1 & Risk Ratio (M-H, Fixed, 95\% Cl) & Totals not selected \\
\hline
\end{tabular}


Analysis 19.1. Comparison 19 Balance and mobility rehabilitation versus conventional rehabilitation ( 2 month follow-up), Outcome 1 Number of fallers.

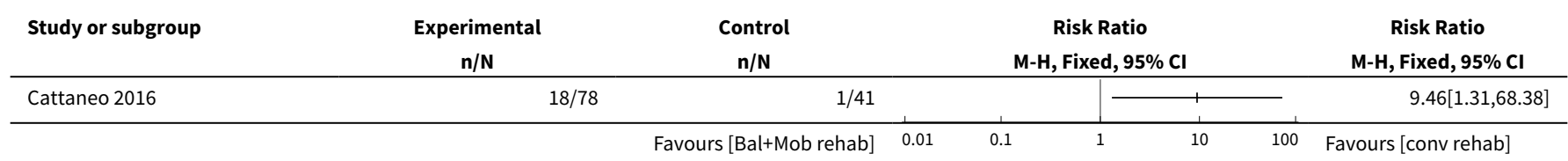

\section{AP PE N DICES}

\section{Appendix 1. Keywords for searching the MS Group Register}

((((("falls"[Title/Abstract]) OR "recurrent falls"[Title/Abstract]) OR "reduced falls"[Title/Abstract]) OR "falls prevention"[Title/Abstract])) AND ((("Tertiary Prevention"[Mesh]) OR "intervention"[Title/Abstract]) OR "prevention"[Title/Abstract]))

\section{Appendix 2. Appendix 2}

MEDLINE (PubMed) (1966 to 23 October 2017)

(((()((((("Multiple Sclerosis"[Mesh:noexp] OR "Multiple Sclerosis, Chronic Progressive"[Mesh]) OR "Multiple Sclerosis, Relapsing-Remitting"[Mesh]) OR "Demyelinating Diseases"[Mesh:noexp]) OR "Optic Neuritis"[Mesh]) OR "Demyelinating Autoimmune Diseases, CNS"[Mesh:noexp]) OR "Encephalomyelitis, Acute Disseminated"[Mesh]) OR "Myelitis, Transverse"[Mesh]) OR (()(()(()((()((("multiple sclerosis"[Title/Abstract]) OR "chronic progressive multiple sclerosis"[Title/Abstract]) OR "progressive relapsing multiple sclerosis"[Title/Abstract]) OR "secondary progressive multiple sclerosis"[Title/Abstract]) OR "primary progressive multiple sclerosis"[Title/Abstract]) OR "relapsing remitting multiple sclerosis"[Title/Abstract]) OR "remitting-relapsing multiple sclerosis"[Title/Abstract]) OR "acute relapsing multiple sclerosis"[Title/Abstract]) OR "neuromyelitis optica"[Title/Abstract]) OR "optic neuritis"[Title/Abstract]) OR "devic disease"[Title/Abstract]) OR "demyelinating disease"[Title/Abstract]) OR adem[Title/Abstract]) OR "demyelinating disorder"[Title/Abstract]) OR "clinically isolated syndrome"[Title/Abstract]) OR "transverse myelitis"[Title/Abstract]) OR "acute disseminated encephalomyelitis"[Title/Abstract] OR ("encephalomyelitis"[Title/Abstract])))))) AND (((((((("Accidental Falls"[Mesh]) OR "falls"[Title/Abstract]) OR "recurrent falls"[Title/Abstract]) OR "reduced falls"[Title/Abstract]) OR "falls prevention"[Title/Abstract]) OR "faller"[Title/Abstract])) AND (("Tertiary Prevention"[Mesh]) OR (Intervention[Title/Abstract] OR prevention[Title/Abstract])))

Embase (EMBASE.com) (1974 to 23 October 2017)

\#1 'multiple sclerosis'/exp

\#2 'demyelinating disease'/exp OR 'demyelinating disease'

\#3 'optic neuritis'/exp OR 'optic neuritis'

\#4 'acute disseminated encephalomyelitis'/exp

\#5 'myelooptic neuropathy'/exp

\#6 'myelitis'/exp

\#7 'multiple sclerosis' OR 'chronic progressive multiple sclerosis' OR 'progressive relapsing multiple sclerosis' OR 'secondary progressive multiple sclerosis' OR 'primary progressive multiple sclerosis' OR 'relapsing remitting multiple sclerosis':ti,ab

\#8 'remitting-relapsing multiple sclerosis' OR 'acute relapsing multiple sclerosis' OR 'optic neurities' OR 'neuromyelitis optica' OR encephalomyelitis OR 'clinically isolated syndrome':ti,ab

\#9 'transverse myelitis' OR 'devic disease' OR 'demyelinating disease' OR 'demyelinating disorder' OR 'acute disseminated encephalomyelitis' OR adem:ti,ab

\#10 \#1 OR \#2 OR \#3 OR \#4 OR \#5 OR \#6 OR \#7 OR \#8 OR \#9

\#11 'falls'/exp OR 'falls'

\#12 'accidental falls' OR 'falls' OR 'recurrent falls' OR 'reduced falls' OR faller:ti,ab 
\#13 falls NEAR/4 (prevention OR intervention)

\#14 \#11 OR \#12 OR \#13

\#15 \#10 AND \#14

\#16 \#10 AND \#14 AND [humans]/lim AND [embase]/lim

\#17 \#16 AND ('clinical article'/de OR 'clinical trial'/de OR 'controlled study'/de OR 'major clinical study'/de OR 'randomized controlled trial'/de)

\section{Cochrane Central Register of Controlled Trials (CENTRAL) (2017 Issue 10)}

\#1 MeSH descriptor Multiple Sclerosis, this term only

\#2 MeSH descriptor Multiple Sclerosis, Chronic Progressive, this term only

\#3 MeSH descriptor Multiple Sclerosis, Relapsing-Remitting, this term only

\#4 MeSH descriptor Myelitis, Transverse explode trees 3, 5 and 7

\#5 MeSH descriptor Optic Neuritis explode all trees

\#6 MeSH descriptor Encephalomyelitis, Acute Disseminated, this term only

\#7 MeSH descriptor Demyelinating Autoimmune Diseases, CNS, this term only

\#8 "multiple sclerosis":ti,ab,kw or "chronic progressive multiple sclerosis":ti,ab,kw or "progressive relapsing multiple sclerosis":ti,ab,kw

or "secondary progressive multiple sclerosis":ti,ab,kw or "primary progressive multiple sclerosis":ti,ab,kw

\#9 "relapsing remitting multiple sclerosis":ti,ab,kw or "remitting-relapsing multiple sclerosis":ti,ab,kw or "acute relapsing multiple sclerosis":ti,ab,kw or "neuromyelitis optica":ti,ab,kw or "optic neuritis":ti,ab,kw

\#10 "devic disease":ti,ab,kw or "demyelinating disease":ti,ab,kw or (adem):ti,ab,kw or "demyelinating disorder":ti,ab,kw or "clinically isolated syndrome":ti,ab,kw

\#11 "transverse myelitis":ti,ab,kw or "acute disseminated encephalomyelitis":ti,ab,kw or (encephalomyelitis):ti,ab,kw

\#12 (\#1 OR \#2 OR \#3 OR \#4 OR \#5 OR \#6 OR \#7 OR \#8 OR \#9 OR \#10 OR \#11)

\#13 MeSH descriptor: [Accidental Falls] explode all trees

\#14 "falls" or "recurrent falls" or "reduced falls" or "falls prevention" or "faller":ti,ab,kw

\#15 \#13 OR \#14

\#16 MeSH descriptor: [Tertiary Prevention] explode all trees

\#17 "Tertiary Prevention" or Intervention or prevention:ti,ab,kw

\#18 \#16 OR \#17

\#19 \#12 AND \#15 AND \#18

Cumulative Index to Nursing and Allied Health Literature (CINAHL) (EBSCOhost) (1981 23 October 2017)

"Multiple sclerosis" AND ("accidental falls" OR falls OR faller OR "falls prevention") AND ("tertiary prevention" OR prevention OR intervention)

Latin American and Caribbean Health Science Information Database (LILACS) (Bireme) (1982 23 October 2017)

"Multiple sclerosis" AND "accidental falls"

\section{CONTRIBUTIONS OFAUTHORS}

SH and RG drafted the paper. All authors participated in reviewing and editing the manuscript as necessary. All authors read and approved the final manuscript.

\section{DECLARATIONS OF INTEREST}

$\mathrm{SH}$ - none.

CK - none.

RG - none.

MF - none. 
CM - none.

CDW - none.

SC - SC is an author of one of the included studies in this Cochrane Review (Coote 2013).

\section{SOURCES OF SUPPORT}

\section{Internal sources}

- No sources of support supplied

\section{External sources}

- Health Research Board, Ireland.

Dr. Hayes has been awarded a two-year part-time Fellowship from the Irish Health Research Board to complete this Cochrane Review protocol and subsequent review.

\section{DIFFERENCES BETWEEN PROTOCOL AND REVIEW}

We replaced the "number of recurrent or frequent fallers" outcome with the "number of fallers" outcome (number of participants who fell at least once during the study), which was omitted from the protocol- as the latter outcome also captures recurrent fallers. We removed the "number of falls per person" outcome- as this is also reflected in the rate of falls (the number of falls per person year) outcome.

As outlined in the review protocol (Hayes 2017), falls prevention interventions were considered to be any programme in which the primary or secondary aim was to reduce the rate of falls. The current review provides a more specific description of the types of interventions that were considered for inclusion and therefore a minor change from the protocol. This review included all interventions tested in trials that measured one or more of the primary falls outcomes (rate of falls, risk of falling). Trials that did not include a measure of falls (one or more of our primary falls outcomes), were excluded, as the review authors decided that falls prevention was not an aim of the intervention. Trials that focused on intermediate outcomes such as improved balance or strength, and did not report rate of falls or risk of falling as an outcome, were excluded. 